\title{
Service Dogs for Veterans with PTSD: Taxonomy, Work Stress Reduction, and Matching
}

Lindsay Parenti

West Virginia University, Iparentibcba@gmail.com

Follow this and additional works at: https://researchrepository.wvu.edu/etd

Part of the Alternative and Complementary Medicine Commons, Disability Studies Commons, Other Animal Sciences Commons, Other Psychology Commons, Other Rehabilitation and Therapy Commons, and the Vocational Rehabilitation Counseling Commons

\section{Recommended Citation}

Parenti, Lindsay, "Service Dogs for Veterans with PTSD: Taxonomy, Work Stress Reduction, and Matching" (2019). Graduate Theses, Dissertations, and Problem Reports. 3853.

https://researchrepository.wvu.edu/etd/3853

This Dissertation is protected by copyright and/or related rights. It has been brought to you by the The Research Repository @ WVU with permission from the rights-holder(s). You are free to use this Dissertation in any way that is permitted by the copyright and related rights legislation that applies to your use. For other uses you must obtain permission from the rights-holder(s) directly, unless additional rights are indicated by a Creative Commons license in the record and/ or on the work itself. This Dissertation has been accepted for inclusion in WVU Graduate Theses, Dissertations, and Problem Reports collection by an authorized administrator of The Research Repository @ WVU.

For more information, please contact researchrepository@mail.wvu.edu. 
Service Dogs for Veterans with PTSD: Taxonomy, Work Stress Reduction, and Matching Lindsay Parenti

Dissertation

submitted to the

Davis College of Agriculture, Natural Resources and Design

at West Virginia University

in partial fulfillment of the requirements for the degree of

Doctor of Philosophy in

Animal Nutritional Sciences

Matthew Wilson, Ph.D., Chair

Kennon A. Lattal, Ph.D.

Megan Maxwell, Ph.D.

B. Jean Meade, Ph.D.

Oliver Wirth, Ph.D.

Department of Animal Sciences

Morgantown, West Virginia 2019

Keywords: veterans, PTSD, service dogs, assistance animals, stress, HRV

Copyright 2019 Lindsay Parenti 


\begin{abstract}
Service Dogs for Veterans with PTSD: Taxonomy, Work Stress Reduction, and Matching

Lindsay Parenti
\end{abstract}

Research suggests that many veterans with post-traumatic stress disorder (PTSD) struggle with reintegration (Sayer et al., 2010), but are unlikely to seek help or complete treatment (Schottenbauer et al., 2008). To make matters worse, available treatment options are often time consuming, challenging, and/or associated with negative side effects (Carafano \& Hutchinson, 2017). Using animals as a treatment modality for veterans with PTSD is an emerging topic of interest and has shown promise (Owen, et al., 2016; Richie et al., 2016). However, several factors have hindered the advancement of this field. Obstacles include a lack of standard terminology and classification system, a need for empirical research to support the effectiveness of animal assisted interventions, and consideration of individual differences in response to animal assisted interventions. This investigation aims to fill these voids by proposing a novel taxonomy to promote research and development, describing an innovative investigation into whether the presence of a dog impacts veterans' stress response to a task, and exploring whether the relationship between personality characteristics of service dogs and veterans impacts the success of the team. Results suggest that the demand for service dogs for veterans in the Unites States is growing and currently exceeds the supply. In addition, the inconsistent findings in the literature regarding therapeutic effects of assistance animals may be due to whether the team is compatible. This study found a potential correlation between veteran and service dog assertiveness and the benefits provided by the presence of the dog. Due to methodological concerns, results must be interpreted cautiously. More research in this area is needed, and future recommendations are provided. 


\section{Table of Contents}

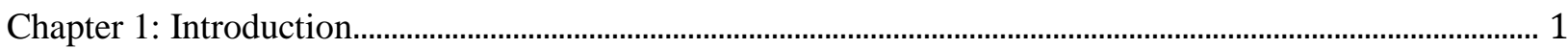

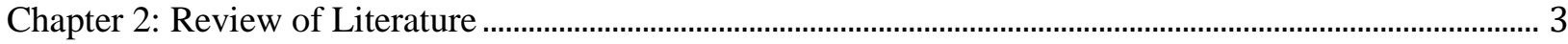

Veterans with PTSD and Reintegration................................................................................................................ 3

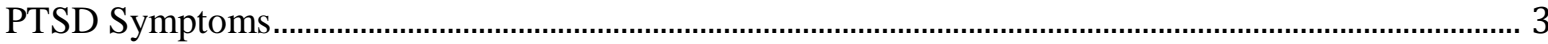

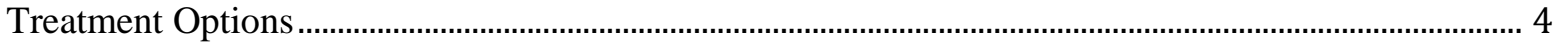

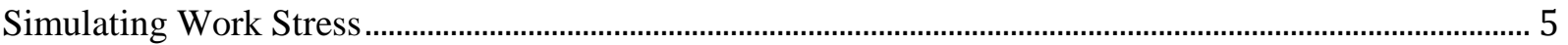

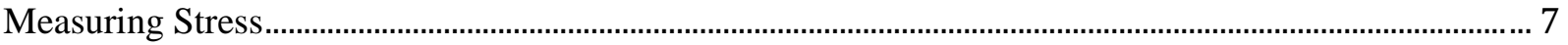

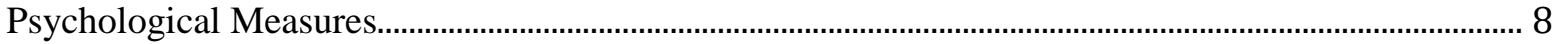

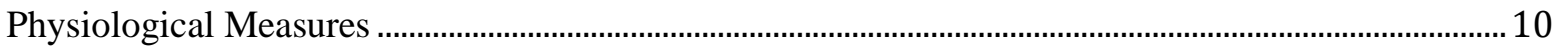

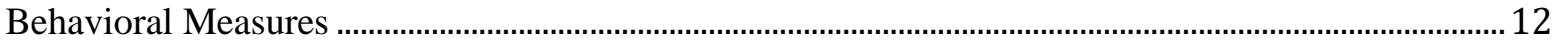

Animal Assisted Interventions/Activities ....................................................................................................... 13

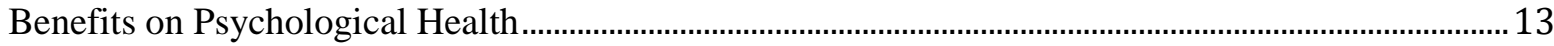

Benefits on Physiological Health............................................................................................................. 14

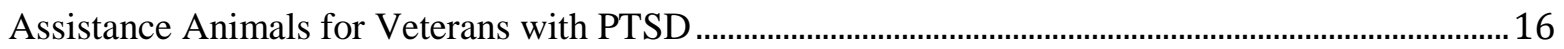

Problems with Animal Assisted Interventions .........................................................................................16

Matching Dog and Human............................................................................................................................ 18

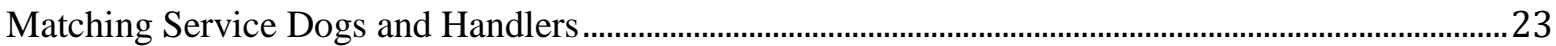

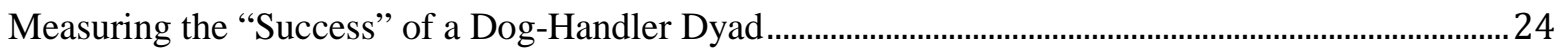

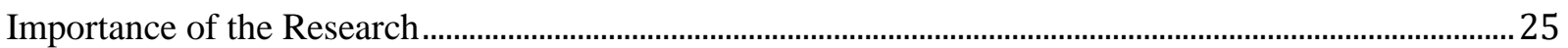

Chapter 3: A Revised Taxonomy of Assistance Animals.....................................................................................28

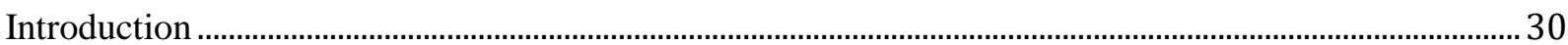

The Vocabulary of Assistance Animals in Society........................................................................................... 31

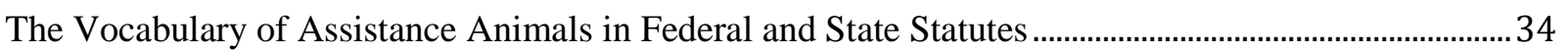

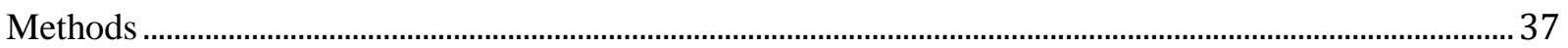

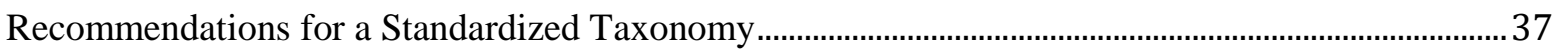

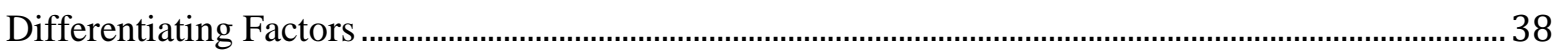

Results: Functional Categories of Assistance Animals ................................................................................. 40

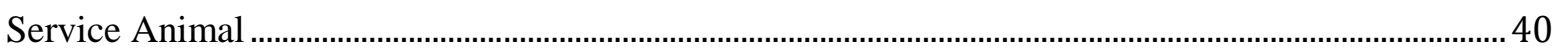

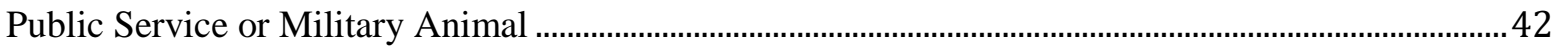

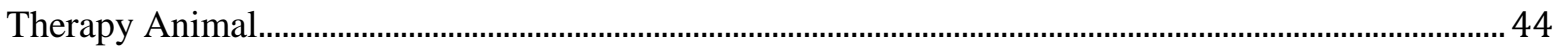




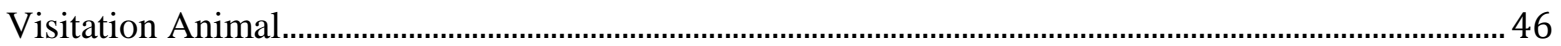

Sporting, Recreational, or Agricultural Animal .................................................................................................4

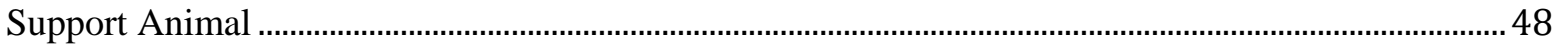

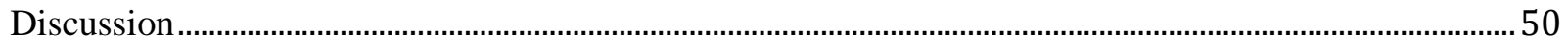

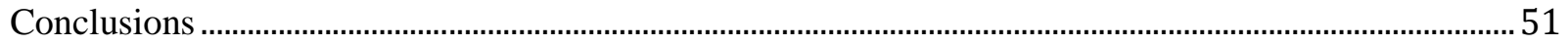

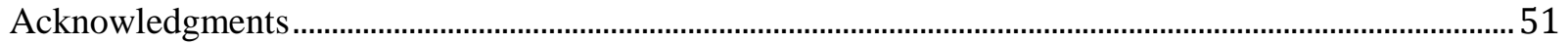

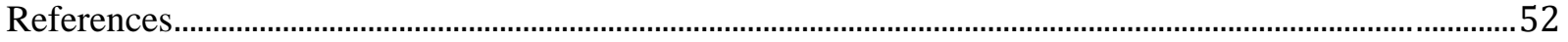

Chapter 4: The Effect of Dogs on Veteran Stress and the Impact of Veteran and Service Dog Personality

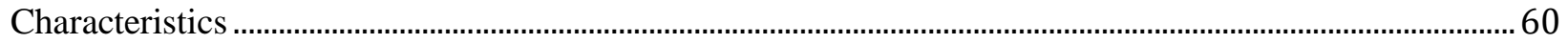

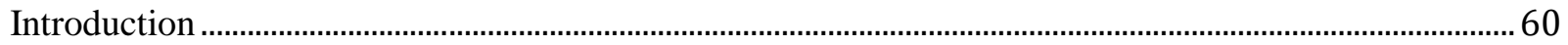

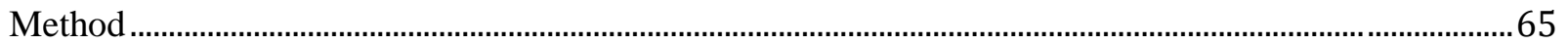

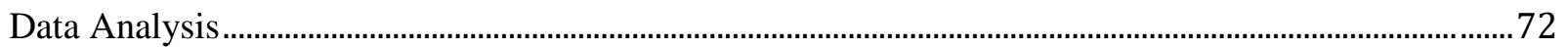

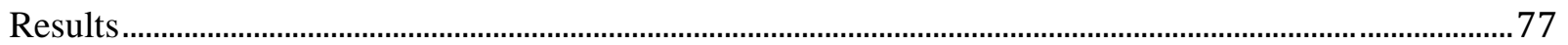

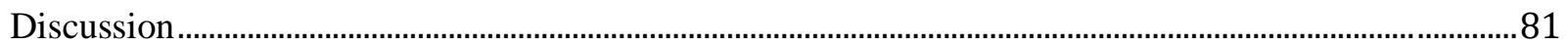

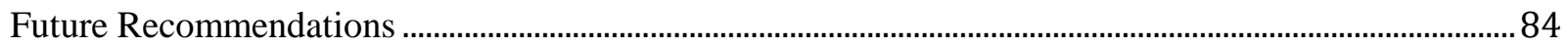

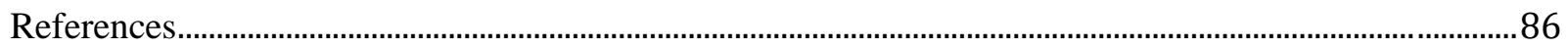

Chapter 5: Summary and Conclusions.......................................................................................................... 95

Chapter 6: Recommendations..................................................................................................................... 97

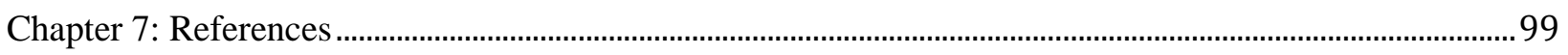

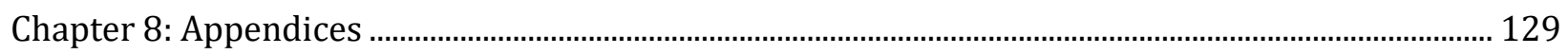




\section{List of Tables}

Table 1: A revised taxonomy for functional categories of assistance animals in society and the

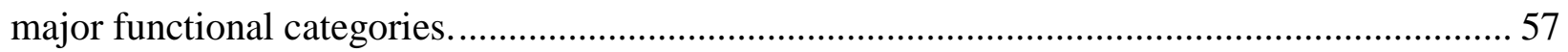

Table 2. Heart Rate Variability Measures and their interpretations. ............................................. 73 


\section{List of Figures}

Figure 1. Components of HRV shown in tachogram (Anderson, 2018)

Figure 2. Classification of animals in society showing the various assistive functions, the six major functional categories of assistance animals, and several commonly used labels or examples

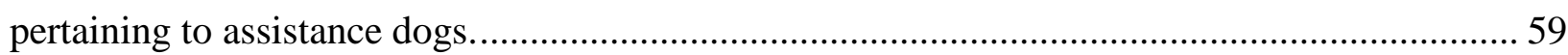

Figure 3. Timeline of procedures within laboratory session. BL= Baseline; TSX = NASA TLX71

Figure 4. Mean HR during task across conditions......................................................... 77

Figure 5. NASA TLX Performance effort scores across conditions. ...................................... 78

Figure 6. PANAS negative scores during BL across conditions. .......................................... 79

Figure 7. Correlation between difference of human and dog assertiveness and HF Recovery

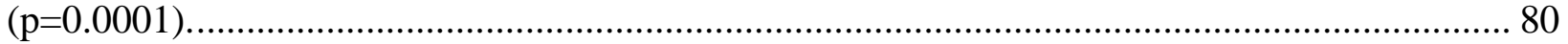

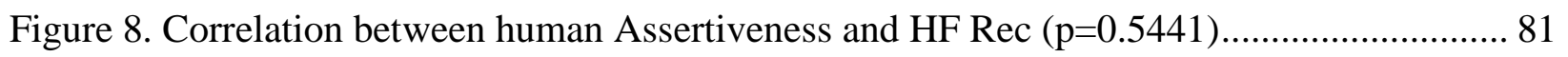

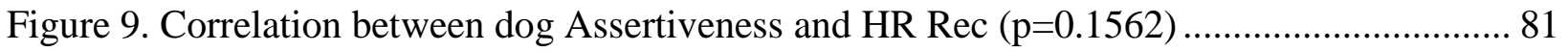




\section{List of Abbreviations}

AAA

AAI

AAT

ADA

ADI

ANS

APA

APDT

BH

BL

CBT

CES

CES-D

CO

CPAWW

DAST

ECG/EKG

EDMR

ESA

HF

HR

HRV
Animal assisted activity

Animal assisted intervention

Animal assisted therapy

Americans with Disabilities Act

Assistance Dogs International

Autonomic nervous system

American Psychiatric Association

Association of Professional Dog Trainers

Benjamini-Hochburg procedure

Baseline

Cognitive-behavioral therapy

Combat Exposure Scale

Center for Epidemiological Studies Depression Scale

Cardiac output

Canine Providing Assistance to Wounded Warriors

Drug Abuse Screening Tool

Electrocardiogram

Eye movement desensitization and reprocessing

Emotional support animal

High frequency power

Heart rate

Heart rate variability 
HUD

IAHAIO

IBI

LF

LVET

NA

NIOSH

PA

PANAS

PALS

PAS-M

PAWS

PCL

PEP

Project ROVER

PTSD

RAND

RM-ANOVA

RMSSD

R-R

RSA

SAAIA
US Department of Housing and Human Development

International Association of Human-Animal Interaction

Organizations

Inter-beat interval

Low frequency power

Left ventricular ejection time

Negative affect

National Institute for Occupational Safety \& Health

Positive affect

Positive and Negative Affective Scale

Pet Attachment \& Life Impact Scale

Pet Attitude Scale - Modified

Puppies Serving Wounded Service Members Act

PTSD Checklist

Pre-ejection period

Returning Our Veterans to Employment \& Reintegration

Post-traumatic stress disorder

RAND Corporation: A research organization

Repeated measures analysis of variance

Root mean square of successive differences

Heart rate interval

Respiratory sinus arrhythmia

Service Animal Adaptive Intervention Assessment 
SD

SDNN

SSRI's

SV

TLX

UD

VA

VLF

WHQOL-BREF

WVU
Service dog

Standard deviation of the R-R intervals

Selective Serotonin Reuptake Inhibitors

Stroke volume

NASA Task Load Index

Unfamiliar dog

US Department of Veterans Affairs

Very low frequency

World Health Quality of Life -Brief

West Virginia University 


\section{Chapter 1: Introduction}

Over 2.4 million service members have left the military service since 9/11 (Flournoy, 2014). According to a 2008 RAND study, nearly $20 \%$ of recently returned veterans screened positive for depression or post-traumatic stress disorder (PTSD; Tanielan \& Jaycox, 2008). Most likely, there are even more cases of veterans with PTSD that are undiagnosed. Research suggests that many veterans with PTSD struggle with reintegration (Sayer et al., 2010; Crowe et al., 2018), but are unlikely to seek help or complete treatment (Schottenbauer et al., 2008).

Employment has been shown to assist veterans reintegrating into society after deployment (Keyklamp, 2013), and is emphasized by the Department of Defense (DoD) as an important area of reintegration (DoD, 2011); however, veterans often struggle to find jobs (Stern, 2017). To make matters worse, available treatment options for PTSD are often time consuming, challenging, and/or linked with negative side effects (Carafano \& Hutchinson, 2017). For example, cognitive-behavioral therapy (CBT) has been shown to be an effective treatment for PTSD (Barlow \& Lehman, 1996; Hoffman \& Schmitts, 2008); however, it requires several sessions with a highly trained therapist over several weeks or even months. The high effort required, and the delayed potential positive consequences make it difficult for veterans to complete the treatment. Other treatments are associated with negative side effects (Citizens Commission on Human Rights International, 2014).

Animals have been shown to provide therapeutic benefits to a variety of populations, including individuals with PTSD (Krause-Parello, Sarni, \& Padden, 2016; Kloep, 2016; Kloep, Hunter, and Kertz, 2017). Using animals to assist veterans with PTSD is a topic of interest and may be an effective adjunct to standard treatment; however, several obstacles have hindered the 
advancement of this approach. One barrier is the lack of a standard taxonomy in the field, which inhibits research progress, leads to confusion and inconsistent application, and prevents the development of professional standards (International Association of Human-Animal Interaction Organizations (IAHAIO, 2013). Lastly, and likely the most crucial, is the need for empirical research to support the effectiveness of assistance animals for veterans. Research in this area is lacking methodological rigor (Sturn \& Chur Hansen, 2013). In addition, research outcomes have been inconsistent, with some studies reporting improvements of anxiety-related symptoms with assistance animals (Yount, Olmert, and Lee, 2012; Hyde, 2015), whereas others report no improvements (Gee, 2014; Grossberg, 1985; Cole et al, 2007; Hansen et al, 1999; Deshriver \& Riddick, 1990). Inconsistencies may be due to individual differences of the animal used, the person, or the relationship between them. The degree of compatibility between the human and animal impacts the therapeutic value of a human-dog partnership (Lloyd, 2004); however, the compatibility between veterans and assistance animals and its impact on therapeutic effects remains unclear.

This investigation attempts to fill these voids by proposing a novel taxonomy and classification system for assistance animals, exploring the effects of the presence of a dog on veterans' stress responses, and describing an innovative investigation of whether the compatibility between veteran and dog impacts the therapeutic benefits provided. I hypothesize that incompatibility between the human and animal may lead to some of the inconsistent findings and suggest factors that may impact the compatibility of a human-animal relationship. 


\section{Chapter 2: Review of Literature}

\section{Veterans with PTSD and Reintegration}

Post-traumatic stress disorder is a trauma-related disorder that can develop after experiencing a traumatic event (American Psychiatric Association [APA], 2013). Many returning veterans struggle with reintegration. Approximately 40\% of Iraq-Afghanistan combat veterans surveyed reported some to extreme overall difficulty in readjusting to civilian life recently, and approximately 90\% reported interest in assistance with reintegration problems (Sayer et al., 2010). Connection to a career upon returning assists veteran reintegration to society, but almost half of post-9/11 veterans indicate that finding a job is their biggest challenge (Stern, 2017). Various reports indicate that PTSD is associated with higher unemployment rates (Anderson, 2017; Prigerson, Maciejewski, \& Rosencheck, 2002). Veterans with PTSD report significantly more absence from work within the past month than those without PTSD (Hoge, Terhakopian, Castro, Messer, \& Engel, 2007). To make matters worse, employers report having significant knowledge gaps related to effective employment practices for employees with PTSD and other disabilities (Rudstam, Gower, and Cook, 2012). In fact, 61\% of hiring personnel at several businesses across the country reported feeling uncertain when hiring someone with PTSD (Anderson, 2014).

\section{PTSD Symptoms}

Reintegrating veterans into civilian life and employment is complicated by the symptomology of PTSD. Post-traumatic stress disorder symptoms include distracting intrusive thoughts and images, disturbing nightmares, hyper arousal (e.g. intense startle response, poor concentration and memory, hypervigilance, high irritability), avoidance of people (family, 
friends, co-workers), places (enclosed areas and crowds), and things (loud noises, sights, and smells). Factors that can make reintegration and returning to work difficult for veterans with PTSD include the changing nature of PTSD, the varying quality of symptoms, and the highly stigmatized nature of PTSD (Rudstam, Gower, \& Cook, 2012). The number of stimuli that may trigger PTSD is widespread and often generalized, and elimination of all triggers from a work environment is difficult, if not, impossible (Thorne, Devlin, \& Dingess, 2017). When considering PTSD symptoms and the stressful nature of many workplace environments, it is easy to understand the difficulties in reintegration. Amelioration of PTSD symptoms is necessary to facilitate reintegration of veterans into society and the workforce; relieving these symptoms may also contribute positively to veterans’ overall physical and psychological health.

\section{Treatment Options}

Treatment for PTSD typically focuses on reducing anxiety and stress responses. There is strong evidence that appropriate treatment of anxiety-related symptoms results in improved work performance (Waghorn, Chant, White, \& Whiteford, 2005). Common treatments for PTSD include pharmacological interventions, such as selective serotonin reuptake inhibitors (SSRI’s) and tricyclic antidepressants, and psychosocial treatments. Cognitive- behavioral therapy has been established as an effective treatment for many anxiety disorders including PTSD (Barlow \& Lehman, 1996; Hoffman \& Schmitts, 2008). Unfortunately, CBT typically takes several weeks or months of sessions with a skilled therapist and a high amount of effort from the patient, and still may not be effective in treating PTSD (Foa et al., 1999). Eye movement desensitization and reprocessing (EMDR) has also been reported as an effective treatment for PTSD (Shapiro, 2001). Exposure therapy is supported by empirical studies for treatment of PTSD but is controversial and rarely used clinically (Schottenbauer, et al., 2008). Exposure therapy involves repeated 
presentation of trauma-related memories over months or years (American Psychological Association, 2019), and may lead to exacerbation of symptoms.

Standard treatments for PTSD have been linked with an increased risk of suicides among veterans (Citizens Commission on Human Rights International, 2014). Medications may take several weeks to influence symptoms (Nierenberg, et al., 2008) and often come with unpleasant side effects (Carafano \& Hutchinson, 2017). In addition, medication alone isn't always effective. Very few veterans diagnosed with PTSD or other psychiatric issues seek out help (Tanelian \& Jaycox, 2008) or complete treatment. Drop out and non-response rates for conventional treatments of PTSD are reported to be up to 50\% (Schottenbauer et al., 2008). Barriers to care include a lack of information, the negative stigma associated with mental health problems, and avoidance of psychiatric medications (Crawford et al., 2015). Although there are several treatment options available that can assist veterans with reintegration, many veterans are still unemployed, struggling to readjust to civilian life, and suffering from symptoms of PTSD.

\section{Simulating Work Stress}

Mental stress testing procedures have not been standardized. Although there may be value of standardization for comparing results across studies, there are concerns that the standardization of procedures may reduce the maximization of stress reactions of an individual (Steptoe \& Vogele, 1991). Laboratory-based studies of stress typically evaluate the acute response to stress, as long-term exposure to stressful conditions is often not feasible in a laboratory setting. Laboratory-based stress research is a convenient, time efficient way to measure the acute effects of stress. Environmental conditions can be simulated in the laboratory that are thought to cause stress levels to rise. Potential confounds can be eliminated during laboratory-based studies that are present in real life. Despite these advantages, laboratory stress 
tests use artificial stimuli to induce stress, and focus only on the acute responses to stress, so the generalizability of the results to "real life" situations may be questioned (Steptoe \& Vogele, 1991). However, evidence suggests that results of laboratory stress procedures are generalizable and valid (Kidd, Carvalho, \& Steptoe, 2014; Chida \& Steptoe, 2010; Manuck, 1994; Steptoe, Cropley, \& Joekes, 2000).

Most laboratory studies investigating the effects of mental stress use cognitive demands as the stressor. Difficult cognitive demands such as the Stroop Color Word Test or mental arithmetic are known to increase stress responses (Hjortskov et al., 2004). These tasks can also be combined with other stressors, such as time pressure (Wahlstrom et al., 2002) and social stressors (Hjortskov et al., 2004). Mathematic tasks with a time requirement are often used to simulate stress in the laboratory (Liao, et al., 2005). The addition of loud noise is associated with higher psychological stress reactions (Evans and Johnson, 2000), especially in individuals with PTSD (Carson et al., 2007). Nurses with current PTSD produced significantly larger heart rate (HR) increases to tones with sudden onset compared to nurses without PTSD (Carson et al. 2007). Similarly, Orr et al (1995) found that veterans with PTSD produced larger physiological (skin conductance and HR) responses across 15 different startling tone presentations than veterans without PTSD.

It is generally recognized that responses to mental stress tests may diminish over time as participants become familiar with, or habituate to, the demands of the situation (Manuck, 1994); however, research is inconclusive (Steptoe \& Vögele, 1991). One study did not see habituation to startle responses in veterans across the study session, however, this may be due to the limited number of startle stimulus presentations (Robison-Andrew, et al., 2014). Previous studies have shown that patients with PTSD and other anxiety issues may be less likely to habituate to startle 
compared to controls (Jovanovic, et. al., 2009; Campbell et al., 2014). Regardless, habituation to the stimulus used to induce stress must be considered as a potential confound with stress research.

\section{Measuring Stress}

Stress is notoriously difficult to measure due to inconsistent definitions and because stress responses are different for everyone (El-Nokaly et al., 2007). In general, stress results when "environmental demands tax or exceed the adaptive capacity of an organism, resulting in psychological and biological changes... (Cohen, Kessler, and Gordon, 1995).” Stress is a condition that results from external or internal changes that threaten the organisms' stable internal environment, or homeostasis (Ewing, Lay, \& von Borell, 1999; Cannon, 1932). Stressors cause the brain and body to attempt to restore homeostasis (Ewing, Lay, \& von Borell, 1999). This leads to biological changes, such as the release of neurotransmitters and hormones, which then initiate physiological and behavioral changes.

There are three phases of a stress response: 1) alarm, 2) resistance, and 3) exhaustion, together called the "general adaptation syndrome (Selye, 1974)". Cognitive brain centers such as the cerebral cortex perceive threats and initiate responses. Other sensors in the brain and body detect changes that may disrupt homeostasis and respond by initiating actions for coping with the threat. More specifically, the sympathetic and parasympathetic divisions of the central nervous system work in opposition to maintain homeostasis. Upon detection of a potential stressor, the organism perceives the stimuli and evaluates it. If considered a threat to homeostasis, the sympathetic division releases norepinephrine, which leads to physiological changes, such as increased heart rate, increased blood flow to muscles, brain, and heart, and decreased blood flow to the skin, digestive tract, and kidneys. The parasympathetic division releases acetylcholine, 
which triggers muscle relaxation. The balance between these two divisions is responsible for normal minute-to-minute changes in bodily functions to maintain homeostasis. During the resistance stage, adaptation to the stressor typically occurs, in which symptoms of stress improve or disappear. In extreme cases of high stress, large quantities of epinephrine and norepinephrine may be released, causing a shift in autonomic tone towards the sympathetic. This is referred to as the sympatho-adrenal response and is a common feature of the stress response (Selye, 2013).

There are several approaches to measuring stress. The environmental perspective focuses on the description of environmental events that are typically associated with adaptive demands, such as major life events, and their effect on health. The psychological perspective uses an individual's subjective evaluation of their ability to cope with demands to measure stress. The biological tradition focuses on the activation of specific physiological systems that have been shown to be associated with psychological and physical demands. Each of these perspectives is important in understanding the overall effect of stress on the human body (Cohen, Kessler, \& Gordon, 1995).

\section{Psychological Measures}

The outcome of psychological appraisal of stimuli determines whether biological changes will occur. Psychological measures of stress result from the person's perception and evaluation of the event. When demands are perceived to exceed the existing abilities to cope, individuals label themselves as stressed and experience a negative emotional response (Cohen, Kessler, \& Gordon, 1995). Psychological measures of stress are typically self-report measures. These assessments may ask directly about the participant's stress response (how they feel), or they may measure the participant's perception of the difficulty, or workload, of the task. Perceived workload has been defined as “the cost incurred by a human operator to achieve a particular level 
of performance (Hart \& Staveland, 1988)" and is related to the concept of stress (GonzalezMunoz \& Gutierrez-Martinez, 2007). Subjective measures of mental effort, or workload, have been shown to be correlated with physiological measures of stress (Veltman and Gaillard, 1998). The NASA Task Load Index (TLX) is a 6-item, multidimensional scale designed to measure perceived workload during and after a task. The TLX provides a score for dimensions including mental demand, physical demand, temporal demand, effort, and frustration level (Hart \& Staveland, 1988). These dimensions are weighted based on each subjects' choice about which member of each paired combination are more related to their own definition of workload. This assessment has been administered verbally, in written form, and by computer, and has been evaluated independently for its reliability, sensitivity, and utility (Hart, 2006). The TLX has been tested in a variety of experimental tasks such as simulated flight and laboratory tasks. Task load index scores have been correlated with both physiological arousal (Brookings et al., 1996; Collet et al., 2009) and task performance (Perry, Sheik-Nainar, Segall, Ma, and Kaber, 2008; Singh et al., 2005).

In addition to perceived workload, positive and negative emotions have an impact on physiological changes when a person is under stress (Zautra, et al., 2005). The Positive and Negative Affect Scale (PANAS) is a brief 20-item scale designed to measure positive and negative mood states. Participants rate each adjective on the extent to which they experienced it during the specified time, with the response options of 1 (very slightly or not at all), 2 (a little), 3 (moderately), 4 (quite a bit), and 5 (extremely). Taken together, the PANAS results in a positive affect score (PA) and a negative affect score (NA). Internal consistencies (coefficient alpha) for momentary assessment of emotion have been reported at .85 or greater for both the positive and negative affect subscales, with 8-week test-retest reliability shown to be .63 for positive affect 
and .60 for negative affect assessed over the past year (Watson, et al., 1988). The PANAS has been used to measure affective responses to stressful tasks. For example, Feldman et al (1999) found that delivering a speech into a camera resulted in significantly higher NA scores and lower PA scores compared to a control group. They also found an association between the changes in affect during the stressful task and cardiovascular reactivity. Specifically, participants with a higher PA score during baseline showed less cardiovascular reactivity, suggesting that they may have evaluated the task as more aligned with their abilities, and therefore, less stressful, than those with a lower baseline PA. A meta-analysis of studies examining negative emotion and cardiovascular response during standardized laboratory stress tasks indicates a small to moderate relation between increased negative emotion and increased cardiovascular response (Feldman et al., 1999).

\section{Physiological Measures}

Biological or physiological measures of stress are based on the perspective that events perceived as stressful activate physiological systems. The activation of these systems results in measurable physiological changes that can indicate levels of stress (Cohen, Kessler, \& Gordon, 1995). As previously described, when a person is exposed to a stressor, the autonomic nervous system (ANS) is triggered: the parasympathetic nervous system is suppressed, and the sympathetic nervous system is activated (Akselrod et al, 1981). In extreme cases, this results in measurable physiological changes, such as vasoconstriction of blood vessels, increased blood pressure, increased muscle tension and a change in heart rate (HR) and heart rate variability (HRV; Cohen, Kessler, \& Gordon, 1995).

Heart rate variability has been used as an indicator of physiological changes due to mental stressors in several studies (e.g., Garde et al. 2002; Hoshikawa and Yamamoto 1997; 
Wahlström et al. 2002). Heart rate variability reflects the activity of the sympathetic and parasympathetic components of the ANS on the heart (Sztajzel, 2004). As discussed earlier, the sympathetic and parasympathetic divisions of the autonomic nervous system respond to maintain homeostasis when a stressor is perceived. The interaction between them is reflected in HRV, or the variation in time between heartbeats. This provides a measure of the activity of the ANS and may consequently provide a valid measure of an individual's perception of the stressor (Taelman et. al, 2009).

Heart rate variability measures are calculated from the tachogram, which is a plot of the sequence of time between heartbeats. Tachograms are derived from electrocardiographs (ECG). Within the tachogram, the P-wave depicts the electrical activity through the upper heart chamber, while the QRS complex depicts the movement of electrical impulses through the lower heart chamber. $R$ denotes a peak in the wave of the QRS complex. The variance in time between two consecutive R peaks reflects the status of the ANS. See Figure 1.

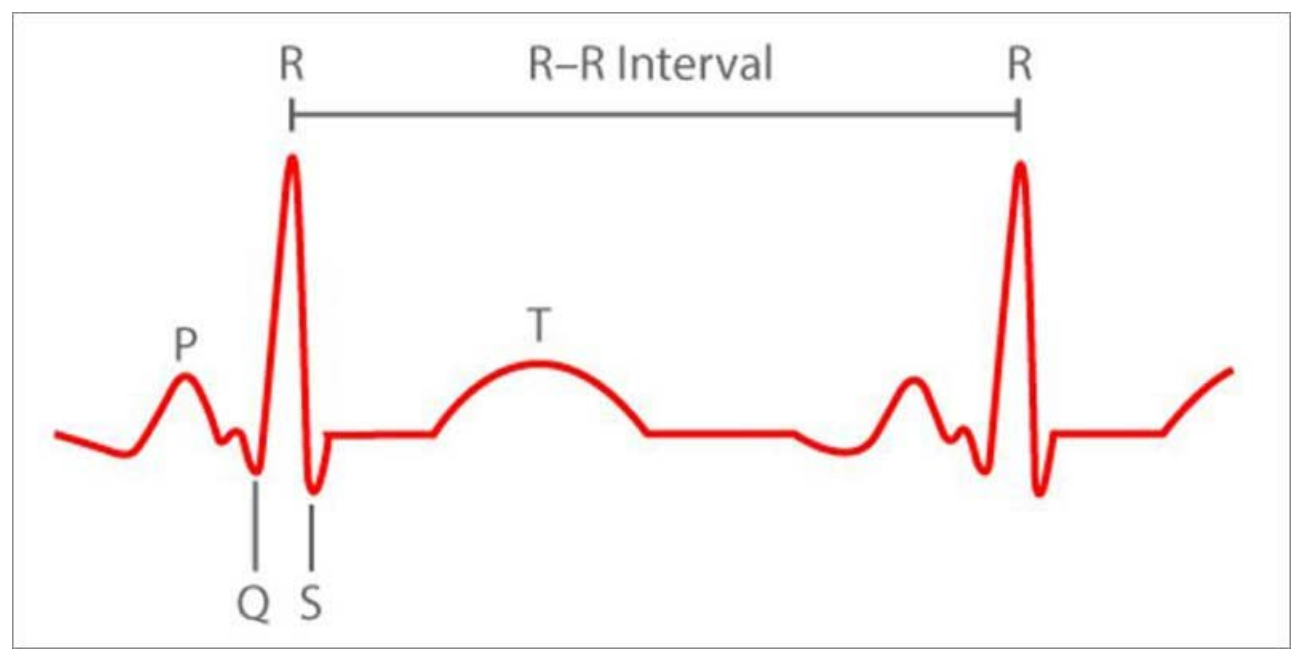

Figure 1. Components of HRV shown in tachogram (Anderson, 2018)

Calculations based on these measures result in quantitative values of HRV. High frequency power (HFP) reflects parasympathetic activity, while low frequency power (LFP) 
indicates the level of activity of the sympathetic nervous system (Pomeranz, Macaulay, \& Caudill, 1985; Kleiger, Stein, \& Bigger, 2005). However, activity in the parasympathetic nervous system seems also to contribute to LFP (Kleiger, Stein, \& Bigger, 2005). The ratio of LF/HF thus reflects the sympathovagal balance (Montano et al. 1994; Malliani et al. 1998). Mental stress has been shown to lower HRV and increase the LF/HF ratio (Kristal-Boneh et al. 1995). See Table 2.

Heart rate variability is a simple, non-invasive method to evaluate stimulus effects on the ANS (Sztajzel, 2004) and is a favorable physiological indicator of stress (Taelman, et al., 2009). It has been found to be a sensitive index of mental workload in several studies (Aasman, et. al., 1987, Backs \& Seljos, 1994). Decreased HRV has been associated with mental stress in laboratory experiments (Myrtek et al., 1996; Sloan et al., 1994), and has been found to be a more sensitive measure of mental stress than blood pressure (Myrtek et al., 2004). Heart rate variability is particularly relevant to PTSD because this disorder is characterized by hyperarousal and increased autonomic reactivity to stimuli (Bedi \& Arora, 2007).

\section{Behavioral Measures}

In addition to physiological and psychological changes, the perception of stress can result in behavioral changes, such as changes in health habits (smoking, diet, exercise and sleeping changes), changes (usually deficits) in task performance, and even changes in interpersonal behaviors (Cohen, Kessler, \& Underwood, 1995). The physiological response to a task is usually related to the individual's performance in the task (e.g., Robazza et al., 1998), and stress is known to contribute to detriments in job performance (Leveck \& Jones, 1996; Westman \& Eden, 1996). This may partially explain some of the difficulty veterans with PTSD face returning to work. 


\section{Animal Assisted Interventions/Activities}

A popular idea recently for helping veterans with PTSD is using assistance animals to reduce stress. Animals have been used in a variety of ways to assist individuals with disabilities. For example, animals are often taken to nursing homes and hospitals by volunteers to provide recreation. This type of animal assistance is often referred to as "animal assisted intervention or activity, or AAI/AAA.” Animals can also be used by trained therapists to supplement therapeutic goals. These types are typically called "animal assisted therapy, or AAT.” Dogs are commonly used for both AAA and AAT (O’Haire, Guerin, \& Kirkham, 2015). Emotional support animals, or ESAs, provide companionship and emotional support to individuals with disabilities. Service dogs are another type of AAA, in which the dog performs tasks specifically related to the handlers' disability. Assistance animals and pets have been reported to provide psychological and physiological benefits to a variety of populations.

\section{Benefits on Psychological Health}

The use of animals for psychological support has been an area of interest since the first paper that indicated dogs could play a role in psychotherapy by serving as a "co-therapist" (Levinson, 1962). Animal assisted activity programs have been designed and assessed for individuals with Alzheimer's disease (Batson, McCabe, Baun, \& Wilson, 1998; Fritz, Farver, Kass, \& Hart, 1995), HIV/AIDS (Carmack, 1991), infertility (Blenner, 1991), PTSD (Hamama et al., 2011), and schizophrenia (Lang, Jansen, Wertenauer, Gallinat, \& Rapp, 2010), among many others. Several anecdotal reports suggest that service dogs offer benefits for veterans with PTSD. For example, Yount et al. (2013) describes two veterans who reported improved PTSD symptomology after involvement with a service dog training program. They also saw reductions in startle responses and use of pain medication, as well as decreased stress levels (Yount, Olmert, 
\& Lee, 2012). A descriptive analysis of 71 individuals with psychiatric disabilities, including 42 individuals with PTSD, reported decreases in disability symptomology since the acquisition of a service dog (Esnayra \& Love, 2008). Woodward et al. (2017) found that the presence of a service dog was associated with a decrease of attention to aversive stimuli in individuals with military-related PTSD. Evidence from a pilot study suggests that service dogs can increase social and occupational functioning in individuals with PTSD (Hyde, 2015). A study of 15 veterans in Canada reported positive changes in sleep and PTSD symptoms 3 months after acquisition of a service dog (Vincent et al., 2017). O’Haire \& Rodriguez (2018) found clinically significant reductions in PTSD symptoms according to the PTSD Checklist (PCL) following acquisition of a service dog, but the reduction was not below the diagnostic cutoff on the PCL. Results of several studies suggest that animal-assisted activities provide benefits to individuals with PTSD (Miele, 2016; Krause-Parello, Sarni, and Padden, 2016; Kloep, Hunter, and Kertz, 2017); however, others have found little benefit (Kegel, 2016), or no benefits in certain areas. For example, Vincent et al (2017) found no effect on veterans' quality of life three months after acquisition of a service dog. In addition, many studies on AAAs are methodologically flawed, so conclusions must be drawn carefully (Sturn \& Chur-Hansen, 2013).

\section{Benefits on Physiological Health}

Although the potential psychological benefits of pets were reported first (Levinson, 1962; Serpell, 1991), they have also been found to have acute and long-term physiological benefits. In a landmark study, Friedmann, Katcher, Lynch, and Thomas (1980) assessed pet ownership and one-year survival following a heart attack and found that $28 \%$ of non-pet owners died compared to $6 \%$ of pet owners. The authors considered that dog owners may be more physically active, confounding the results; however, the relationship between pet ownership and survival remained 
significant even when pet dogs were removed from the analyses. Age, health status, social support, and measures of tension, anxiety, depression, confusion, rigor, and fatigue also did not contribute to the effect. Since the publication of these findings, several studies have examined the physiological effects of pets, particularly dogs. Laboratory studies have evaluated the shortterm effects of dogs on heart rate, blood pressure, and skin conductance, in addition to self-report psychological measures. In the typical laboratory protocol, following a short baseline period, the subject engages in a stressful task in the presence and absence of a dog, and physiological measurements are taken continuously. Studies have found that the presence of a dog compared with its absence mitigates physiological responses to social stressors (e.g. reading aloud, talking to the experimenter; Friedmann, Locker, \& Lockwood, 1993; Friedmann, Thomas, Cook, Tsai, \& Picot, 2007; Nagengast, Baun, Megel, \& Leibowitz, 1997) and mental stressors (e.g., mental arithmetic; Allen, Blascovich, \& Mendes, 2002; Allen, Blascovich, Tomaka, \& Kelsey, 1991; Demello, 1999). In one study, deceleration of heart rate occurred when a service dog was present compared to trials in which the dog was not present (Woodward, et al., 2017). In some cases, these effects were present even when an unfamiliar dog was used (Demello, 1999; Friedmann, Locker, \& Lockwood., 1993; Nagengast, et al., 1997). Alternatively, one study found that blood pressure decreased only in the presence of bonded dogs (Baun, Bergstrom, Langston, \& Thoma, 1984). Other studies found no differences between bonded and unbonded dogs (Barker, Knisely, McCain, Schubert, \& Pandurangi, 2010; Gaydos \& Farnham, 1988; Todd- Schuelke et al., 1992). Cunnighman \& Ramos (2013) suggest that the familiarity between the human and dog seems to affect the performance of the dyad; however, this is not clear. More research is needed to determine whether the familiarity of the dog impacts the benefits of the dogs' presence on the human. 


\section{Assistance Animals for Veterans with PTSD}

Some evidence supports the use of animals for veterans with PTSD, and the use of service dogs to ameliorate PTSD symptomology is becoming more widespread (Owen et al., 2016; Richie et al., 2016). The use of dogs to assist veterans' reintegration to civilian life is an emerging topic of interest, as reflected by a recent issue of The United States Army Medical Department Journal which was devoted to AAA interventions with veteran populations (The United States Army Medical Journal, 2012). In addition, the Canines Providing Assistance to Wounded Warriors (C-P.A.W.W.) program was developed in 2013 to investigate the effects of service dogs on veterans (Carafano \& Hutchinson, 2017). The development of therapeutic dogtraining programs for veterans, such as Paws for Purple Hearts and the Washington Humane Society’s Dog Tags program, in which veterans learn to train service and shelter dogs, reflects the growing acceptance and interest in this area. Taylor et al. (2013) found that the public is embracing the use of animals for mental health treatment. The interest has reached federal policymakers as well. The VA has been planning a randomized controlled trial aimed at determining the impact of service dogs on the functioning of veterans with PTSD (Saunders et al., 2017). Unfortunately, logistical issues have stalled the progress of the VA study (Carafano \& Hutchinson, 2017). This emerging interest has resulted in several studies that claim to support the use of trained dogs to assist veterans with PTSD (Crowe et al., 2018; O’Haire and Rodriguez, 2018; Owen et al., 2016).

Problems with Animal Assisted Interventions

Regardless of the growth and acceptance of the use of assistance animals, there are several issues that are stalling the advancement of the field. First, there is considerable variability in the terminology used in the field, creating confusion and making comparison across studies 
difficult (Lajoie, 2003; Sellers, 2005; Kruger \& Serpell, 2010). Lajoie (2003) found 20 different definitions of AAT, and 12 different terms used to describe AAT. The use of the term "animal assisted therapy" as a label for many programs that are not considered "therapy" by the medical definition has been criticized. Beck \& Katcher (1984) state that a distinction should be made between the recreational use of animals and "therapy" and that any event that is enjoyed by a patient is not considered therapy. Kruger \& Serpell (2010) continue the distinction between AAA and AAT, arguing that non-professional handlers using dogs to provide comfort or pleasure cannot ethically claim to be providing medical treatment or therapy. Additional confusion arises with the term "emotional support animal (ESA)," as this type of animal is protected under some laws but is not the same as a service animal protected under the Americans with Disabilities Act (ADA). Emotional support animal and psychiatric service dogs are often confused, although they are treated different legally (ESAs do not have public access according to the ADA, as service dogs do).

Some attempts have been made to standardize terminology in the field. The Delta Society (n.d.) publicized a distinction between AAT and AAA, reserving the term "therapy" to describe a goal-directed intervention that is directed by a health or human services professional. Assistance Dogs International has defined service dog and assistance dog, but these terms are not used consistently. The ADA defines service animal but does not define assistance animal or therapy animal (Mills \& Yeager, 2012). Mills \& Yeager (2012) propose their own classification system to differentiate between guide dogs, hearing dogs, service dogs, AAT animals, AAA animals, emotional support animals, residential/facility animals, companion animals, social or therapy dogs, recreational animals, and mascots. Regardless of these attempts, a standardized classification system to describe all the types of assistance animals has not been universally 
accepted (Parenti et al., 2013). A consistently-used, widely accepted taxonomy is essential to the advancement of research in the field.

Currently, empirical research on the effect of animals for veterans is scant (O’Haire, Guerin, \& Kirkham, 2015; O’Haire \& Rodriquez, 2018; Yeager \& Irwin, 2012; Sweaney, N.D.) and the research on AAA’s in general is lacking methodological rigor (Sturn \& Chur Hansen, 2013). For example, many studies in this area lack a control condition, allowing effects to be attributed to factors other than the animal, such as novelty or expectancy biases (O’Haire, Geurin, \& Kirkham, 2015). In addition, many studies have a small number of participants, reducing the generalizability of the results while also obscuring individual variability. Additional methodologically sound research is required to advance canine assistance as a treatment for veterans with PTSD (Krause-Parello, et al., 2016; Van Houtert et al., 2018).

Research outcomes on the benefits of animals are often inconsistent. Inconsistent research results may be due to individual differences in the response to animals or to the specific type of animal used in the study. Not all people appreciate all types of animals, just as not all people appreciate all types of people. The therapeutic value of client-service dog teams depends on multiple factors, including client preferences regarding breed of the service dog, compatibility of client needs to the abilities of the dog, and the ability of the dog and client to work together (Topal, Miklosi, \& Csanyi, 1997). The specific factors that are predictive of service dog-client team compatibility are largely unknown.

\section{Matching Dog and Human}

Not all client-service dog partnerships are successful (Lloyd, 2004). For example, Mowry, Carnahan, \& Watson (1994) reported a failure rate of $40 \%$ for hearing dogs and another researcher reported that approximately $25 \%$ of attempted guide dog placements were 
unsuccessful (Nicholson, Kemp-Wheeler, \& Griffiths, 1995). Unsuccessful compatibility between a service dog and an individual with a disability results in loss of assistance and emotional distress for the client, as well as time and significant financial costs for the service dog training organization (Nicholson, Kemp-Wheeler, \& Griffiths, 1995; Lloyd, 2004). Service dogs are typically trained until a minimum of 18 months of age, and training can cost anywhere from $\$ 10,000$ to $\$ 20,000$ (Allen \& Blasovich, 1996). Several authors have highlighted the need to assess and understand the factors affecting dog-handler interactions (Burrows, Adams, \& Millman, 2008; King, Marston, \& Bennett, 2012; Ley, McGreevy, \& Bennett, 2009; Lloyd, 2004; Marston \& Bennett, 2003; Mowry, Carnahan, \& Watson, 1994). A thorough understanding of these factors could change the way in which AAIs are arranged, how assistance animals are trained and placed, and maximize the efficiency of service dog training and placement.

There are several prerequisites to service dog effectiveness. First, the dog must have the appropriate morphological characteristics, temperament traits, and training (Parenti et al., 2015; Foreman et al., 2015). Also, the success of the team depends partially on the expectations of the human (Marston \& Bennett, 2003). For example, the human must be aware of the resources required to care for a service dog. Although there are several general factors of the dog that seem to predict success as a service dog (Asher et al., 2013; Parenti et al., 2016), when examining the interaction between human and dog characteristics, the ability to predict outcomes becomes much more complex.

It may seem that working dog-human relationships are unidirectional- they depend only on the dog's performance. However, it is likely that service dog-owner relationships are bidirectional (Kaminski \& Marshall-Pescini, 2014). Dalibard (2009) concluded that no individual characteristic of a service dog alone impacted the quality of service provided to their client. 
Factors of the human, factors of the dog, and the interaction of the human and dog's individual characteristics combine to affect the outcome. It is likely that owner and dog personality, attitude toward the dog, and even owner and dog sex will affect interaction styles and the performance of human-dog dyad (Hennessy, et al., 1998; Kotrschal, et al., 2009; Prato-Previde, Fallani, \& Valsecchi, 2006).

Some suggest that the familiarity of the human impacts the dogs' performance, and thus, the therapeutic effects provided by the dog. Dogs are more likely to follow cues when given by a familiar person than when given by a stranger (Cunningham \& Ramos, 2013). However, social familiarity by itself doesn't seem to account for a dog's responsiveness to their owner (Horn, Range, \& Huber, 2013). Dogs attend more to humans that they have a specific type of relationship with, not simply humans that are familiar to them. Dogs were found to be more responsive to familiar people that they shared activities and feeding time with than familiar people with whom they did not share these activities (Horn, Range, \& Huber, 2013). In fact, owner engagement with the dog has been reported as critical to a successful dog-human relationship (Lefebvre et al., 2007; Arhant et al., 2010). Dog owners who spent more time with their dogs, whether spending time on obedience training or otherwise, were found to have improved dog obedience and improved human-canine relationship after 8 weeks (Clark and Boyer, 1993). Additionally, some studies report that the presence of a dog reduces stress only if the dog is familiar to the person (Baun, Bergstrom, Langston, \& Thoma, 1984), while others reports no difference in therapeutic effect between familiar and unfamiliar dogs (Barker et al., 2010; Gaydos \& Farnham, 1988; Schuelke et al., 1992).

The degree of compatibility between human and dog impacts the satisfaction and therapeutic value of a human-dog partnership (Lloyd, 2004). There are several factors that may 
impact compatibility. There is consistent evidence for the 'similarity-attraction' hypothesis in humans, which suggests that more similar individuals are more attracted to one another (Byrne, Griffitt, \& Stefaniak, 1967; Turcsán, et al., 2012). This may be true for human-dog interactions as well; dog and owner personality profiles are often similar (Kis, et al., 2012; Turcsán, et al., 2012). Owners who are like their dogs in activity level and sociability were found to be more satisfied with their relationship with their pet (Curb, et al., 2013). It seems reasonable to hypothesize that matching human and dog personality traits would enhance the efficiency of the team (Hoummady et al., 2016). However, some research has found opposite personality traits in dogs and their owners. For example, O’Farrell (1997) found that owner anxiety was not correlated with fear in the dog. There is no research on the similarity between dog and owner personality characteristics and the success of the team. It seems likely that the success and personality characteristics of the team are connected (Hoummady et al., 2016). In fact, handler personality has been found to be correlated with the dog's behavior (Podberscek \& Serpell, 1997; Kis, et al., 2012). For example, neuroticism of the owner is associated with the amount of time the dog and human spend close together and the frequency with which the dog approaches the human (Wedl, et al., 2010), the amount of time they spend in shared activities, and their performance on a practical task (Kotrschal, et al., 2009). Owners with higher neuroticism were less efficient during tasks with their dogs than owners lower in neuroticism (Kotrschal, et al., 2009), and dogs of owners with high neuroticism had a higher latency to respond to commands than dogs of owners with lower neuroticism (Kis et al., 2012). Research has shown that owners of aggressive Cocker Spaniels tend to be tense, shy, and emotionally unstable while owners of non-aggressive Cocker Spaniels did not have these personality characteristics (Podberscek \& Serpell, 1997). Significant correlations have been observed between the human personality traits 
of openness and agreeableness and owner satisfaction with the dog-human relationship (Cavanaugh, Leonard, and Scammon, 2008). However, individuals with these personality characteristics may be less likely to report negative emotions in general. Curb et al. (2013) reported that owner satisfaction correlated with dog and owner matching on certain behavioral traits, such as having an active lifestyle, which relates to the personality characteristic of extraversion. Some researchers have suggested that the attachment level of the dyad affects performance (Mueller, 2014) and attenuation of stress parameters (Baun, et al., 1984). Owners who report weaker attachment for their pets are consistently less satisfied with most aspects of their dogs' behavior compared with those who report stronger attachments (Serpell, 1996). Others found conflicting evidence (Naderi, Miklósi, \& Dóka, 2002; Barker, et al., 2010; Gaydos \& Farnham, 1988; Todd- Schuelke et al., 1992). Owner reported responses to the Monash Dog Owner Relationship Scale have been shown to correlate with physiological parameters, such as oxytocin. They even found significant correlations between dog and owner oxytocin levels (Handlin et al., 2012). It is likely that many human behaviors, such as the use of reinforcement, produce positive affective states in the dog, leading to more favorable behavioral responses. As personality describes the general behavior of individuals, it may be an important factor to consider when matching humans and dogs; however, the influence of human psychological characteristics, such as personality, on the dog-human relationship remains unclear (Payne, Bennett, and McGreevy, 2015), and no studies have investigated the interaction of human and dog personality characteristics on the success of the team. Accounting for dog and human personalities when matching may reduce behavioral conflict and increase success and satisfaction in the dog-human team (Payne, Bennett, and McGreevy, 2015). 
Matching Service Dogs and Handlers

Service dogs and their handlers share a special relationship. They must work collectively to function effectively. Although the information regarding matching dogs and their humans remains unclear, some have attempted to create their own matching tools. Zapf \& Rough (2002) developed the Service Animal Adaptive Intervention Assessment (SAAIA) as a tool to match service dogs to clients. This assessment defines the client's functional needs, their level of experience with animals (positive, neutral, or negative), the client's typical activity level and affective state (calm or anxious, happy or depressed, tolerant or frustrated), and the resources of the person. The SAAIA showed acceptable inter-rater reliability and content validity. However it is a brief assessment that may exclude factors that are important to a successful service dogclient match. While others have investigated the match between service dog and handler, this is the only known published matching assessment. The research in this area is lacking; however, understanding the relationship between human and dog personality and its impact on therapeutic outcomes may be crucial to improve service dog-client matching.

It seems that, in humans, team members with similar personalities perform better than team members with disparate personalities. For example, Lykourentzou et al (2016) demonstrated that balancing personalities in two-person teams resulted in significantly better task performance. One approach of measuring personality in teams is assessing the social style of individuals and structuring interactions accordingly (Wilson Learning, 2004). This approach has been used by some service dog training organizations to match service dogs to clients (B. Bergin, personal communication, July 2006). The social styles assessment was designed to measure human social styles in the areas of assertiveness, responsiveness, and versatility by assessing others' perceptions of the target individual's general behavior. This tool has been used to 
improve workplace performance and improve productivity (Wilson Learning, 2004). When used as a tool for matching service dogs to clients, the assessment is completed for both client and service dog prospects by at least 3 individuals that know the handler and dog well. Matches are made by selecting dogs that are less assertive than the client and like the client in responsiveness (B. Bergin, personal communication, July 2006). The versatility scale is used as a measure of whether the person or dog could tolerate deviations from the ideal match. This method has been used by Bergin University since the 1980’s, has been taught to several hundred students of the Bergin University training program, and seems, anecdotally, to be effective, but has yet to be empirically validated.

Measuring the “Success” of a Dog-Handler Dyad

The "success" of a service dog team has not been clearly defined, and there are no standards for measurement. According to the Puppies Assisting Wounded Service Members (PAWS) Act, the effectiveness of a service dog placement would be determined by symptom and medication reduction and improvement in social functioning of the client (Carafano \& Hutchinson, 2017). For veterans returning to work, social functioning necessarily includes anxiety reduction during stressful situations. It is also important that the presence of the dog improves the veteran's quality of life overall.

There are several assessments available to assess PTSD symptoms and general quality of life. The World Health Quality of Life scale (WHOQOL-BREF; WHOQoL Group, 1998) consists of 26 self-report items that assess four quality-of-life domains: physical health, psychological health, social relationships, and environment. The 26-item scale is a shortened version of the WHQOL-10o assessment and has been shown to have good to excellent psychometric properties of reliability and validity (Skevington, Lofty, and O’Connell, 2004). 
Depression can be assessed using a short tool called The Center for Epidemiologic Studies Depression Scale (CES-D). It is a short self-report scale that is designed to measure depressive symptomatology in the general population. The scale is made up of symptoms of depression which have been used in previously validated longer scales (Radloff, 1977). It was found to have high internal consistency, adequate test-retest reliability, as well as validity with other self-report measures and clinical ratings of depression. Collins et al (2006) did not find a difference in depression scores between groups of individuals with and without service dogs; however, among participants with depression, service dog partnership was associated with higher positive affect scores. The Pet Attachment and Life Impact Scale (PALS; Cromer \& Barlow, 2013) measures the positive or negative impact that an animal has on the owner's life (whether the animal is a source of comfort and security, or stress) as reported by the owner. The PALS includes 39 items scored on a scale of 1 (not at all) to 5 (very much). Questions concern the impact that a specific (“favorite") pet has on the person's health, stress, trust, emotions and sociability, among other life dimensions. Factors measured by the PALS are Love, Regulation, Personal Growth, and Negative Impact. Convergent validity for the love, regulation, and personal growth factors were found when PALS was compared to other scales of pet attachment. The PALS was found to reflect current relationships with a specific pet, as opposed to a general attitude about pets (Cromer \& Barlow, 2013), making it a useful tool to measure the impact of a specific pet separately from a person's general attitude toward pets and/or animals. These assessments may be useful tools for assessing the success of a service dog team.

\section{Importance of the Research}

Due to advances in technology and medical care, individuals with a wide range of disabilities are living longer than ever before (Smart, 2001). Medical advances have changed the 
focus of individuals with disabilities from basic survival to the search for meaning and independence. Young adults with disabilities who want to become independent are often stalled by a lack of assistance (Stubbins, 1988). The men and women who have sacrificed their lives to serve our country are finding themselves disabled and struggling to find effective treatment. The US Department of Veterans Affairs (VA) does not provide financial benefits to support service dogs for those with mental disabilities, such as PTSD and traumatic brain injury (Veterans Affairs Department, 2012). The VA cited a lack of research verifying the benefits of service dogs for mental health as the reason for denying financial support (McCune, Espositio, \& Griffin, 2017). Thus, research supporting the ability of dogs to ameliorate symptoms of PTSD and other mental disabilities is needed. This area of research is complicated due to the complex nature of measuring individual stress responses, the varied nature PTSD symptoms, the variability in human and dog personality characteristics, the logistical difficulties of designing methodologically sound research using individuals with disabilities and dogs, and the lack of standardized definition and/or measurement of success of a service dog team. The specific factors that are predictive of service dog-client team compatibility are largely unknown and no standardized assessments are currently being used to match dog to client (Zapf \& Rough, 2002). Common techniques used to match service dogs with clients have not been empirically evaluated.

More research is clearly needed in this area. First, a consistent classification system is needed to describe the interventions in the field and to promote research growth. Next, additional empirical research is needed to clarify the impact of dogs on veterans with PTSD and to identify the most efficient way to match veterans and dogs to optimize therapeutic benefits. As the use of animals to assist our veterans increases, and more research promotes its effectiveness, 
we have a responsibility to ensure that growth occurs simultaneously with evidence-based

methodology to maximize the availability of this resource for our veterans returning to society. 


\title{
Chapter 3: A Revised Taxonomy of Assistance Animals
}

\author{
Lindsay Parenti, M.A., BCBA ${ }^{1}$ \\ Anne Foreman, Ph.D. ${ }^{1}$ \\ B. Jean Meade, M.D., D.V.M., M.P.H., Ph.D. ${ }^{2,3}$ \\ Oliver Wirth, Ph.D. ${ }^{1}$ \\ ${ }^{1}$ Health Effects Laboratory Division, National Institute for Occupational Safety and Health, \\ Morgantown, West Virginia \\ ${ }^{2}$ Office of the Director, National Institute for Occupational Safety and Health, \\ Morgantown, West Virginia \\ ${ }^{3}$ Davis College, Division of Animal and Nutrition Sciences, West Virginia University, \\ Morgantown, West Virginia
}

Address correspondence to: Oliver Wirth, Ph.D, CDC\NIOSH, 1095 Willowdale Road (MS 2027), Morgantown, WV 26508. EMAIL: owirth@cdc.gov

Author Contributions:

Literature review and initial outline and draft of the manuscript (Parenti and Foreman).

Conceptualization of the taxonomy, figures and tables, and final draft of the manuscript (Meade and Wirth). 


\begin{abstract}
The use of animals in various assistive, therapeutic, and emotional support roles has contributed to the uncoordinated expansion of labels used to distinguish these animals. To address the inconsistent vocabulary and confusion, this paper proposes a concise taxonomy for classifying assistance animals. Several factors were identified to differentiate categories including: (1) whether the animal performs work or tasks related to an individual's disability, (2) the typical level of skill required by the animal performing the work or task, (3) whether the animal is used by public service, military, or health professionals, (4) whether training certifications or standards are available, and (5) the existence of legal public access protections for the animal and handler. Acknowledging that some category labels have been widely accepted or codified, six functional categories were identified: (1) service animal, (2) public service animal, (3) therapy animal, (4) visitation animal, (5) sporting, recreational, or agricultural animal, and (6) support animal. This taxonomy provides a clear vocabulary for use by consumers, professionals working in the field, researchers, policy makers, and regulatory agencies.
\end{abstract}

Keywords: Assistance animal, assistance dog, nomenclature, public access rights, service animal, service dog, support animal, taxonomy, therapy animal, vocabulary. 


\section{Introduction}

Service dog, assistance dog, guide dog, seeing-eye dog, hearing dog, mobility assistance dog, seizure-alert dog, police dog, search-and-rescue dog, drug-detection dog, bomb-detection dog, working dog, therapy dog, visitation dog, emotional support dog, sport dog, show dog, hunting dog, companion dog, and pet are examples of various labels given to dogs in our society. Dogs have been used by humans throughout history for companionship, hunting and herding, sport and recreation, security and protection, military support, emotional support, and assistance with physical and psychiatric disabilities (Anderson, 2008; Chumley, 2012; Serpell, 2010). There has been a recent increase in the use of dogs in many different therapeutic, assistive, and emotional support roles (Arkow, 2011) and a subsequent uncoordinated expansion of labels used to distinguish the dogs. The arising inconsistency in the taxonomy has created confusion among consumers, professionals working in the field, researchers, policy makers, and regulatory agencies (Ensminger, 2010).

Others have recognized the confusion and have attempted to make distinctions by defining common labels. One assistance dog advocacy organization, Assistance Dogs International (ADI), has promoted definitions of assistance dog and service dog that are widely cited and accepted by many service dog trainers, but the definitions are not universally used among laypeople or health-care personnel, nor are they aligned with definitions that appear in federal or state laws. Others have attempted to distinguish therapy dogs (used for hospital and nursing home visitations) from dogs used in recreational or other therapeutic activities (Beck \& Katcher, 1984; Kruger \& Serpell, 2010; Pet Partners, 2012). But no standard or universally accepted taxonomy has emerged. More recently, Mills and Yeager (2012) classified at least 12 different types of animals used in healthcare and military settings. Although comprehensive and 
inclusive of many different types of assistance animals, this classification scheme does not adequately capture the essential characteristics that differentiate and define the types of assistance animals.

The objectives of this paper are to identify possible sources of inconsistency or confusion that arise from the existing labels given to assistance animals and suggest a revised taxonomy to better classify and differentiate the multiple assistive, work, and recreational functions that animals, and especially dogs, offer humans.

\section{The Vocabulary of Assistance Animals in Society}

It must be acknowledged that not every label or term currently used causes confusion. Many labels are accepted and widely used without much risk of being misunderstood. Labels for animals that provide assistance in sports and various work-related activities are often sufficiently descriptive. For example, dogs that assist with hunting activities are commonly referred to as hunting dogs, dogs used to assist with herding other animals are called herding dogs, dogs that participate in competitive activities such as conformation and obedience are called show dogs, and dogs that assist in seeking, locating, and rescuing activities are called search-and-rescue dogs. Although slight variations can and do exist among these labels, there is an obvious correspondence between the labels and the assistive function they specify.

Similar correspondences exist with labels given to animals that provide assistance to individuals with physical and psychological impairments. The first documented reports of assistance dogs described dogs used for vision impairments (Ensminger, 2010). These dogs are typically referred to as guide dogs, leader dogs, or seeing-eye dogs. As methods were developed and dogs were trained to assist individuals with hearing impairments, the labels hearing dogs, signal dogs, hearing-ear dogs, and alert dogs emerged (Cusak, 1988). More recently, the label 
psychiatric service dog has been used for dogs trained to help individuals with psychiatric disorders such as posttraumatic stress disorder (PTSD), traumatic brain injury, and autism. Similarly, the label seizure-alert dog has been used for dogs that have been purported to detect the onset of seizures. Because these labels unambiguously identify the disability for which the dog provides assistance, the labels have a certain amount of face value that minimizes confusion or inconsistency. On the other hand, a limitation of some specific labels is that they do not convey the relevant functional group or category to which the dogs belong. For example, an emotional support dog may indeed provide some type of comfort or assistance to an individual with a psychological disorder, but it may or may not meet legal definitions of a service dog.

Confusion seems to arise more often when the labels do not clearly specify the assistive function of the animal. In these cases, the labels may be either too generic (i.e., can refer to more than one kind of assistive function) or misleading (i.e., specifies an unrelated function). For example, the label guide dog is most typically used to refer to a dog that assists an individual with vision impairment, but it has also been used to describe a dog that assists an individual with Alzheimer's disease (Naderi et al., 2001) and a dog that is specially trained to assist a hearingimpaired individual (Rights of Blind and Physically Disabled Persons, 2012). Dogs used to assist individuals with mobility impairments are often labeled generically as service dogs (Bergin, 1998), assistance dogs (Livestock Disease Control, 2002), and support dogs (White Cane Law, 2003) but, in these cases, the labels do not provide sufficient information to identify the assistive function. Service dogs have been described as a mobility assistant only (Service Dog Central, 2012) or any type of dog that provides assistance for a disability other than for seeing or hearing impairments (Assistance Dogs International, 2012). Because these category labels do not specify the dog's specific function, they can refer to any dog that provides service, support, or assistance 
to people, such as police dogs, hunting dogs, herding dogs, military dogs, and emotional support dogs. As another example, the label therapy dog is used by some to identify a dog that visits individuals in a nursing home or hospital (Pet Partners, 2012), but it has also been used to identify dogs used within the scope of a health or allied health care treatment plan (Kruger \& Serpell, 2010; Fine, 2010).

Confusion also arises with the use of multiple labels for animals performing the same function. Dogs that visit individuals in nursing homes and hospitals have been called therapy dogs and visitation dogs, among other labels. Likewise, several different terms have become popular to describe the variety of assistances a dog can provide for individuals with psychiatric impairments (i.e., therapy dogs, pet adjuncts, emotional support dog, etc.). In a review of animal assisted therapy, as many as 20 different definitions and 12 different terms were found, including animal-assisted therapy, animal-facilitated counseling, pet therapy, pet psychotherapy, petfacilitated therapy, pet-facilitated psychotherapy, pet-mediated therapy, pet-oriented therapy, animal recreation, pet visitation, and others (LaJoie, 2003).

Labels may also be misleading. The use of the term therapy dog for dogs that visit nursing homes or hospitals to provide comfort and support is misleading because these types of animal visitation programs do not constitute therapy in a strict sense of the word. Therapy is defined as the "treatment of a disease or disorder (Spraycar, 1995)" or "treatment of a bodily, mental, or behavioral disorder (Mish, 1997).” In distinguishing therapy from other events that have positive emotional effects, Beck and Katcher (1984) stated "It should not be concluded that any event that is enjoyed by the patients is a kind of therapy... Ice cream, motion pictures, children, and electronic games all produce positive emotional responses in institutionalized elderly patients, yet none of those events would be called therapeutic in the scientific sense of the 
word." Others have argued that the individuals involved in what many describe as dog therapy could not ethically claim to be diagnosing or changing the course of a disease (Kruger \& Serpell, 2010). According to Kruger \& Serpell (2010), animal recreation and visitation programs should not be called therapy “just as we would not refer to a clown's visit to a pediatric hospital as clown-assisted therapy”. Organizations such as Pet Partners have also supported these notions by recommending explicitly that animal-assisted therapy and animal-assisted activities be clearly differentiated (Pet Partners, 2012). Nevertheless, the category of therapy dogs has evolved into an accepted term in both casual and professional vocabularies.

\section{The Vocabulary of Assistance Animals in Federal and State Statutes}

The vocabulary is also inconsistent across federal and state statutes pertaining to the rights of individuals and their service animals to access public spaces. In 2011, an updated definition of service animal in the U.S. Americans with Disabilities Act (ADA) of 1990 was enacted. Under the new definition, service animals are "dogs that are individually trained to do work or perform tasks for people with disabilities, including a physical, sensory, psychiatric, intellectual, or other mental disability (Americans with Disabilities Act, 2010).” As explained in the federal register notice that pertains to the ADA, doing work is intended to include activities that may not involve physical actions, whereas tasks are actions that can be physically exhibited (Nondiscrimination on the Basis of Disability in State and Local Government Services, 2011). Pulling a wheelchair is an example of a task, whereas calming an individual during a panic attack is an example of work. The ADA grants public access to dogs providing assistance to individuals with a variety of disabilities, and psychiatric service dogs are explicitly included. Dogs whose sole function is emotional support are explicitly excluded. Unlike the relatively clear and concise ADA definition, the definitions in U.S. regulations for public housing and transportation are 
vague (Ensminger, 2010) and in some cases conflict with the ADA. The Department of Housing and Urban Development (HUD) permits access to "animals that assist, support, or provide service to those with disabilities" including both service and assistance animals, but these labels are not specifically defined or differentiated. HUD regulations state that an assistance animal is one that provides "emotional support to persons who have a disability-related need for such support (Pet Ownership for the Elderly and Persons With Disabilities, 2008).” Likewise, according to the Air Carrier Access Act, a dog qualifies as a service dog if the individual needs the animal only for emotional support (Nondiscrimination on the Basis of Disability in Air Travel, 2003). Similar variations exist in the definitions of service animals and public access protections in the laws of other nations (Disability Discrimination Act, 1992; Guide Animal Act, 1996; Accessibility Standards for Customer Service; Dog Control Amendment Act, 2006).

State laws and regulations pertaining to service animals are no more consistent than those among the federal agencies. Massachusetts is the only state that directly cites the ADA in its statute: "A person accompanied by and engaged in the raising or training of a service animal, including a hearing, guide or assistance dog, shall have the same rights, privileges and responsibilities as those afforded to an individual with a disability under the ADA (Mass. Gen. Laws, 2002).” Many states have laws that are inconsistent with the current ADA. Some state laws and regulations are more restrictive. In 10 states (AK, AR, CO, GA, ID, LA, MS, OH, OK, and OR ), service animals are only classified as dogs that assist individuals with physical disabilities; there are no provisions for dogs that assist individuals with psychiatric disorders. Some cities and states have enacted breed bans, which conflict with the ADA access protections for individuals with a service dog regardless of breed (Sak v City of Aurelia, 2011). On the other hand, in some state laws, the specified functions of service dogs are more inclusive. Seven states 
(CA, ME, MD, NJ, ND, UT, and WV) include minimal protection as a qualifying task for service dogs even though the current ADA law states “the crime deterrent effects of an animal's presence...do not constitute work or tasks (Americans with Disabilities Act, 2010).” The specific labels used to identify service animals are inconsistent across the states. For example, the label service dog is used in five states (CO, ID, KS, NM, and RI), assistance dog or assistance animal is used in six states (CT, GA, KY, LA, NC, and OR) and support dogs or support animals is used in two states (DE and IA).

The lack of consistency and, in some cases, ambiguity in the laws and regulations gives rise to legal challenges. Common court cases involve complaints against public accommodations that refuse access to individuals and their service animals. For example, an appellate court found that a grocery store chain discriminated against an individual with posttraumatic stress disorder by not permitting her to shop while accompanied by a service dog (Storms v Frey Meyer Stores, Inc, 2005). The main issue in this case was whether the individual had provided sufficient evidence of dog's training to distinguish it from an ordinary pet. Cases such as this are likely to increase as the role of assistance animals expands beyond assistance for obvious physical disabilities. These issues are not confined to the United States; similar cases have also occurred in Japan (Koda \& Shimoju, 2008) and the United Kingdom (Dilley, 2011). The development and acceptance of a standard taxonomy is needed to provide a foundation for sound public policy and help guide public awareness. A clear vocabulary is necessary to advance the science and communicate findings across disciplines. 


\section{Methods}

Recommendations for a Standardized Taxonomy

Table 1 shows a system that provides a novel structure for classifying categories of assistance animals. The table includes a recommended label for each functional category of animal, followed by various factors that differentiate them. Although others have identified other factors or considerations that further encompass or differentiate additional categories of assistance and companion animals (see Mills and Yeager, 2012), we purposively restricted the factors to a minimum set of considerations that sufficiently differentiates the mutually exclusive categories. These factors include: (1) whether the animal performs work or tasks that are related to an individual's disability, (2) the typical level of skill required by the animal in performing the work or task, (3) whether the animal is used by public service, military, or health professionals, (4) whether training certifications or standards are available, and (5) the existence and scope of legal public access protection for the animal and handler. Incorporating distinctions promoted by others in the field where possible and acknowledging that some category labels have been widely accepted or codified, we identified six major functional categories of assistance animal: (1) service animal, (2) public or military service animal, (3) therapy animal, (4) visitation animal, (5) sporting, recreational or agricultural animal, and (6) support animal. It is important to note that although the functional category of sporting, recreational, or agricultural animal is similar to the sporting and working breed groups of the American Kennel Club, the functional categories in our taxonomy do not imply any breed association. The categories herein are based solely on the function of the animal in society. Although the revised taxonomy may be adapted for primates, equines, felines, avians, bovines, and other species of animals used for assistance or companionship, much of the following discussion and examples will focus on dogs because they 
are the most commonly recognized assistance animal (Mills \& Yeager, 2012; Adams \& Rice, 2011). Although pets can have therapeutic benefits for individuals with and without disabilities (Serpell, 1991; Siegel, 1990) and can often serve an important role in families (Cain, 1991), they are not included in this taxonomy.

\section{Differentiating Factors}

The first factor that helps to differentiate the function of animals is whether the animal provides assistance that is related to an individual's disability. To be consistent with the ADA, assistance herein refers to work or tasks that are directly related to a physical or mental disability such as retrieving items, alerting to the presence of others, assisting with balance, alerting to sounds, disrupting flashbacks, or guiding to a specific location.

The second factor is whether the assistance or support provided by the animal requires either a basic or advanced skill level. Basic skills include tasks that are synonymous with basic obedience. Basic skills can be assessed with a practical exercise such as the Canine Good Citizen Test (Volhard \& Volhard, 1997). To pass this test, dogs must be able to sit, stay, and lie down, walk on a loose leash, come when called, accept friendly strangers, sit for petting, and react appropriately to distractions, strange dogs, and other people. Dogs exhibiting basic skills are not aggressive toward individuals or other animals, do not jump on people, and are housetrained. Advanced skills are more complex or specialized tasks that go beyond the level of basic obedience. These tasks require more extensive or advanced training methods usually under the direction or assistance of an experienced or professional animal trainer.

The third factor is whether a public service, military, or health professional uses the animal to assist in the implementation of a specific public service task or health-related treatment plan. The animal in this case is handled or accompanied by the professional, who is conducting 
their job according to standard or accepted practices. Public service professionals include firefighters, police officers, emergency medical technicians, and other public protection or safety workers. Military professionals include active duty soldiers, reservists, or military contract personnel. Health professionals include physicians, psychologists, social workers, counselors, physical or occupational therapists, and other allied-health professionals.

The fourth factor is whether certifications or standards are available to help guide the training or use of the assistance animal. For some categories of assistance animal, certifications and training standards exist, but these have been developed and promulgated by service dog organizations or advocacy organizations for voluntary compliance only. For example, many hospitals and health care facilities require that dogs used in their animal visitation programs obtain 'certification' to ensure that they are well behaved and have basic obedience skills. Many facilities accept certification by organizations such as Pet Partners (formerly known as the Delta Society) or Therapy Dogs International, but explicit requirements for certification or adherences to a training standard have not been codified into any federal or state statutes.

The fifth factor addresses whether public access for individuals with an animal is legally protected by federal or state statute and whether the access is limited or unlimited. Although the laws regarding public access for assistance animals will likely change over time, we believe that including this factor in the revised taxonomy helps to differentiate the functional categories. Furthermore, future policy debates and decisions regarding legal access protections for any category of assistance animal should consider of all five differentiating factors.

Undoubtedly, there are numerous other features of various categories of assistance animals that are not mentioned or described herein. Figure 1 illustrates how our proposed 
taxonomy of the various assistive functions of animals and the corresponding functional categories align with other commonly used labels for assistance animals.

\section{Results: Functional Categories of Assistance Animals}

Service Animal

Service animals have been trained to provide work or tasks related to an individual's disability. When accompanied by their handler, who is an individual with a disability, service animals are afforded public access protections. Although standards have been recommended for training and certifying service animals, currently there are no legally recognized standards available. This definition of service animal is consistent with the current ADA.

The individual with a disability is also the primary handler and caregiver of the animal. Indeed, most service dogs are specifically trained to ignore commands given by individuals other than their handler to solidify the bond between the individual and their service dog. Within this functional category, other more specific and commonly used labels (e.g., seeing-eye dog, hearing dog, seizure-alert dog, and psychiatric service dog) may reveal an individual's disability or the tasks the dog can perform; however, consistent with the ADA, the more generic label service animal grants the individual and their dog public access without disclosing the individual's specific disability, if desired (Duncan, 2000).

Although the training that a service animal receives varies, most service dogs are trained to perform multiple tasks. Many tasks requiring advanced training methods. For example, service dogs can be trained to assist individuals with mobility impairments by turning lights on and off, opening doors, and retrieving and carrying items. They also can be trained to assist with laundry and bed making by picking up clothes and pulling or tugging on sheets. A service dog can be trained to alert a hearing-impaired individual to a doorbell or a ringing telephone or safely guide 
a visually-impaired individual across a street. Additionally, service animals can be trained to assist individuals with psychiatric disorders or mental disabilities, such as panic disorder, schizophrenia, Alzheimer's disease, and PTSD. Psychiatric service dogs (Tedeschi, Fine, \& Helgeson, 2010) have been trained to assist an individual with PTSD by alerting the individual of an approaching stranger, surveilling the home prior to the individual entering, or offering a distraction during flashbacks (Ensminger, 2010). Dogs that have been trained to assist children with autism may alert caregivers when repetitive behaviors occur or serve as a tether to prevent children from fleeing by going into a 'down- stay’ position if the child runs (Ensminger, 2010). Service dogs can also be trained to alert individuals to impending seizures or panic attacks, and assist incapacitated individuals by barking until help arrives, pushing a 911 call button, or alerting a specific individual (Kirton et al., 2008).

Despite the ADA requirement that service animals be trained to perform work or tasks related to a disability, the ADA does not specify or mandate that a service animal be certified or receive any specialized training. Nevertheless, many service dog providers 'certify' service dogs that successfully complete their programs, even though the requirements of these programs can vary widely. To protect the safety of the public, handler, and dog, it is important that behavioral and training standards be developed for service dogs. Towards this end, ADI has promoted a set of minimum training recommendations that include the ability to perform at least three tasks, remain in close proximity of the handler at all times when in public, and exhibit no fear responses to noises or other distractions when in public (Assistance Dogs International, 2012).

Currently, federal and state laws protect the public access rights of individuals with disabilities and their service dogs. Access to any public place is generally allowed; however, there are some exceptions. For example, access with service dogs is not legally protected in 
churches or in federal, state, or local government property. Service dogs may also be prohibited when their presence results in changes to normal business practice or when their presence poses health or safety risks. This assessment is made on an individual basis by considering the nature, duration and severity of risk and whether reasonable modifications will mitigate the risk (Nondiscrimination on the Basis of Disability in State and Local Government Services, 2011). This concern extends to the use of service animals by employees in a workplace. Title I of the employment section of the ADA does not require employers to allow employees to bring their service animal to work. Instead, service dogs are considered a reasonable accommodation, one that would not cause undue hardship on the operation of the business (Americans with Disabilities Act, 2010).

\section{Public Service or Military Animal}

Public service or military animals have been trained advanced skills to provide work or tasks to assist public service or military professionals in performing their duties. Public service or military animals are afforded limited public access protections when on duty with their handler. Standards for training and certifying some types of public service or military animals are available.

Examples of public service or military animals include search-and-rescue dogs, cadaver dogs, police dogs, drug-detecting dogs, and military working dogs. Public service or military animals do not provide skills related to a disability. Their skills are related to public or military service and safety and may include tasks such as helping border guards inspect incoming vehicles, searching a disaster site for living or deceased individuals, or finding a lost hiker. Public service or military animals have specialized skills and require advanced training. For 
example, detection dogs are trained in sophisticated scent discrimination, and police dogs are trained in skills related to apprehending and controlling suspects.

Public service or military animals work directly with public service or military professionals (i.e., police officers, military personnel, and search-and-rescue professionals) in the performance of their duties. The military and many public service organizations have policies or guidelines that specify training and handling requirements of the service professional prior to working with these animals to assure public safety.

The availability of training and certification standards for public service or military animals depends on the function of the animal and, in some cases, the organization using their services. For example, there are industry-wide minimum training standards for police dogs (United States Police Canine Association, 2012). The federal government created the Scientific Working Group on Dog and Orthogonal Detector Guidelines to create recommended guidelines and best practices for the training of detector dogs (Greb, 2012). The Federal Emergency Management Agency has their own certification protocols for dogs deployed in disaster areas under their purview (Federal Emergency Management Agency, 1999) and the U.S. Army has outlined specific standards for military working dogs and their handlers (US Department of Army, 2007).

There are no explicit federal public access protections for public service or military animals. In general, access is protected only when the animal is in a location where the handler is on duty and legally present. Some states have created specific statutes. New Hampshire, for example, has granted public access protections to search-and-rescue dogs when they are performing their duties or traveling to and from the sites where they are performing their duties (Hearing Ear Dogs, Guide Dogs, Service Dogs, and Search and Rescue Dogs), and California has 
protected access under these circumstances for police dogs, firefighters' dogs and search-andrescue dogs (Blind and Other Physically Disabled Persons, 2010). Otherwise, off duty public service or military animals are regarded as pets when considering public access protections.

\section{Therapy Animal}

Therapy animals have been trained either basic or advanced skills to assist a health care or allied health care professional within the scope of a therapeutic treatment plan. Therapy animals are not afforded public access protections; permission to access public or private property must be sought on a cases-by-case basis. Some recommended standards for training and certifying therapy animals are available, but these are not codified.

Physical therapists, occupational therapists, social workers, nurses, psychiatrists, psychologists, and other professionals may use dogs to help their clients obtain treatment goals. For example, a physical therapist may use a therapy dog to encourage a child with muscular dystrophy to throw a ball for the dog to retrieve or have a patient brush a dog to improve their motor skills (The Delta Society, 1997). Social workers and psychologists may use therapy dogs to create an environment of trust and acceptance during consultation or psychotherapy (Kruger \& Serpell, 2010; Corson et al., 1975; Mason \& Hagan, 1999) or to encourage a child’s compliance in a behavioral modification program (Davis, 2002).

The term therapy is included in this category label to imply that the animal is used animal-assisted therapy (Pet Partners, 2012) as part of a medical or allied health care treatment (Beck \& Katcher, 1984; Kruger \& Serpell, 2010). This further emphasizes that the therapy is conducted under the guidance and responsibility of a health care or allied-health care professional as part of a formal treatment plan. As a professional activity, the treatment is 
conducted according to accepted practices and ethical principles, which includes adequate training of the professionals to work with the animal.

The minimum necessary skill requirements for therapy animal are basic, including obedience and socialization. For example, a dog used to provide emotional support to a child during a psychotherapy session does not need to perform complex tasks, but they might be required to sit still for long periods and accept frequent petting. In some cases, although not required, a therapy dog may perform advanced skills, such as bracing to assist an individual with mobility impairment to stand during physical therapy.

Some training standards or certifications for therapy animals are available. For example, the U.S. Army has established specific health and behavioral requirements for animals used in what was referred to as animal-facilitated therapy (US Department of Army, 2003). Many of the requirements for therapy animals are similar to or overlap with standards developed by Pet Partners and Therapy Dogs International (Pet Partners, 2012). Many hospitals and medical facilities have policies or protocols that require minimum standards such as the Canine Good Citizens certification (Arkow, 2011).

There are no federal protections for public access pertaining to therapy animals. Kansas is the only state that specifically addresses public access issues pertaining to therapy animals. Using a definition of therapy animal that is similar to that presented herein, the Kansas statute grants professionals using professional therapy dogs the same public access protections as individuals with service animals (Physically Disabled Persons, 2003). Some have advocated expanding legal access protections to include therapy dogs in unique situations where their services are needed such as disaster sites Ensminger (2010). 
Visitation Animal

Visitation animals are trained in basic skills to provide comfort and support to individuals through companionship and social interaction primarily in nursing homes, hospitals, and schools. Visitation animals are not afforded public access protections; permission to access public or private property must be sought on a cases-by-case basis. Standards for training and certifying visitation therapy animals are available but not universally accepted.

The term therapy was excluded in this category label in deference to existing and widespread acceptance of the distinction between animal-assisted therapy and animal-assisted activity (Pet Partners, 2012; US Department of Army, 2003). The present taxonomy uses the modifier visitation for this functional category to help distinguish animals used in hospital or nursing home visitation programs from therapy animals used by health and allied health care professionals as part of a professional therapy activity. This vocabulary should minimize much of the existing confusion.

The skills performed by visitation animals are not specific to an individual's disability. Although only basic obedience and socialization skills are necessary, the animal must be well behaved in a variety of settings and with a variety of people. This requires an ability to accept prolonged petting and attention by individuals of various ages, appearances, and ethnic backgrounds and familiarity with items frequently found in the particular setting, such as intravenous poles and wheelchairs in hospitals and nursing homes.

Visitation animals are not required to be accompanied by health or allied health care professionals. Although the animals can be frequent visitors in nursing homes, hospitals, and other facilities, they are typically accompanied, handled, and owned by community volunteers. 
There are established and well-accepted certification programs pertaining to visitation dogs, even though they are not required by federal or most state statutes. Several organizations, such as Therapy Dogs International and Pet Partners, have developed thorough training protocols and testing standards that lead to certification. For example, one organization certifies dogs and their owners as visitation animal teams based on a skills and aptitude test. This test requires that the team demonstrate the dog's basic skills such sit, down, and stay. The ability to accept large crowds of people, being bumped by objects, being petted by multiple people at a time, and taking treats appropriately is also required (Pet Partners, 2012). Most hospitals, nursing homes, and other facilities accept these certifications, but specific requirements may.

Visitation animals are not typically granted public access. Some argue that visitation animals should have limited public access, especially when being taken to and from appointments and when traveling to distant locations to provide services (Ensminger, 2010).

Sporting, Recreational, or Agricultural Animal

Sporting, recreational, or agricultural animals have been trained basic or advanced skills to provide work or tasks associated with competition, transportation, farm work, or recreation. Sporting, recreational, or agricultural animals are not afforded public access protections. Standards for training and certifying these animals are available and usually associated with specific sporting or show organizations.

Sporting, recreational, or agricultural dogs may be trained to stand for inspection by a show judge, perform agility tasks, pull a sled, track a scent, or herd other animals. Hunting dogs, herding dogs, agility dogs, dock diving dogs, fly-ball dogs, and Frisbee dogs are all examples. Although many of these skills require advanced, complex, or rigorous training methods, the work or tasks performed do not benefit an individual with a disability, and they do not work with 
health or allied-health professionals as part of a treatment or therapy program. Sporting, recreational, and agricultural animals are usually trained by professional trainers or their owners and work for their owners or appointed handlers.

Certifications and standards for some types of sporting, recreational, and agricultural animals are available by their respective organizations, but they usually are not required except when the animal participates in competitions. Organizations like the American Kennel Club have developed standards and certifications for their conformation, herding, and agility competitions. Similarly, sled dog organizations provide certifications for sled dogs (e.g., Alaskan Malamute Club of America).

Sporting, recreational, and agricultural animals do not have public access protections. Because legal public access protections for service animals and, to limit extent, other categories of assistance animals originated with the desire to accommodate individuals with disabilities, access protections for these dogs are not likely to be considered imperative.

\section{Support Animal}

Support animals provide physical, psychiatric, or emotional support to individuals in need primarily in the home. Support animals with or without basic or advance skills are afforded protections for access to private residences and public housing projects. There are no standards for training and certifying support animals. Common labels used for dogs include emotional support dogs, social therapy dog, skilled companions, and home-help dogs. Although pets may provide similar levels of support, there must be a nexus between the owner's disability and the presence of the animal for it to be considered a support animal.

The support, aid, or comfort provided by support animals must be directly related to an individual's disability or need. The animal may assist an individual in activities of daily living or 
perform more complex tasks such as retrieving items or reminding the owner to take

medications, but the animal need not be trained to perform specialized tasks. The mere presence of the animal may be sufficient.

There are no certifications or training standards available for support animals nor do the housing regulations require or specify any level of training.

In general, support animals serve a direct function to individuals in their residences. Thus, support animals have received limited protections under federal regulations to reside in both public and private housing (Pet Ownership for the Elderly and Persons with Disabilities, 2008). The definition of support animal herein is consistent with federal housing regulations in which the more specific label emotional support animal often appears. It is important to note that federal housing regulations define the term support broadly to include emotional, psychiatric, or physical assistance. Thus, the term support in the functional category is already codified and widely accepted; however, additional modifiers that specify the type or nature of support (i.e., physical, psychiatric, or emotional) were deemed to be unnecessary in the present taxonomy. A more generic category label serves to identify a support animal for the purposes of gaining access to residential facilities without revealing an individual's disability or emotional needs if desired.

Under HUD regulations, an animal qualifies as a support animal if an individual has a disability, an animal is needed to assist with a disability, and the individual demonstrates that there is a relationship between the disability and the assistance that the animal provides (Pet Ownership for the Elderly and Persons with Disabilities, 2008). Proof of need is most easily conveyed with a letter from the individual's physician describing the necessity of the animal to the person’s specific disability, but this is not legally required. 


\section{Discussion}

Multiple reasons exist for the development and broad acceptance of a standardized and comprehensive taxonomy for animals in our society. Aside from their role as invaluable companions, dogs especially are gaining increasing importance and recognition for their service to humankind in a variety of personal, social, occupational, and health-related pursuits. Whereas the benefits of some of these services are obvious and do not require validation, other purported benefits are supported only by anecdotal information. More rigorous scientific evaluations will be required before many of these benefits are widely accepted and supported by policy makers, government and public service agencies, and health care providers. The first step in this process is the establishment of an effective taxonomy that sufficiently defines and differentiates the categories of dogs across various assistance, support, and companionship roles. We believe the revised taxonomy offered herein works well for dogs, and additional, slightly modified, versions would work well for other animals (e.g., miniature horses, cats, and primates) that serve assistive or therapeutic functions. This taxonomy is also consistent with the revised Department of Defense Human-Animal Bond Principles and Guidelines (TB MED 4), which is expected to be released in 2013 (Chumley, 2012). Likewise, we have attempted to align this taxonomy with the vocabulary recommended by others in the field where possible.

Society's increasing recognition and acceptance of the wide range of assistive functions that dogs can provide is a positive development, perhaps reflecting our long-time collective concern for and desire to help individuals with physical and emotional challenges and the important roles that canines have played in the evolution of mankind. Indeed, the benefits of dog assistance are being tried and tested in many different novel applications, the breadth of which is seemingly limited only by the dedication and creativity of the professionals involved. Currently, 
our legal system protects the public access rights of individuals with disabilities when accompanied by a service animal. Despite these protections, the laws or regulations do not consistently or clearly define service animal, specify the type of training or skills required, or list the inclusionary or exclusionary criteria that might apply. This inconsistency, frequently coupled with a lack of awareness, causes confusion for many business and property owners and creates obstacles for individuals with service animals. These problems are likely to be exacerbated with the expanding therapeutic uses of animals. Some advocates have already called for expanded public access protections for dogs in other therapeutic settings (Ensminger, 2010).

\section{Conclusions}

As the interest in and demand for assistance animals increases, dogs and other animals are being trained for multiple assistive functions without adequate guidelines and with little, if any, oversight. The potential risks associated with insufficiently trained animals or animals that are not properly socialized to interact safely with the public are likely to be exacerbated by the rapid growth in this emerging industry. Although some organizations are attempting to establish guidelines for training and certification, any standard will be difficult to promote and enforce without a universally accepted taxonomy on which policy and practice can be built.

\section{Acknowledgments}

We thank COLONEL Perry R. Chumley, DVM, MPH, Diplomate ACVPM, Chief, Human Animal Bond programs, DOD Veterinary Service Activity, Office of the Surgeon General and Margaret Glenn, EdD, CRC, Associate Professor of Rehabilitation Counselor Education, Department of Counseling, Rehabilitation Counseling, and Counseling Psychology, West Virginia University for their thoughtful comments and contributions to previous drafts of 
this manuscript. The findings and conclusions in this report are those of the authors and do not necessarily represent the views of the National Institute for Occupational Safety and Health.

\section{References}

Accessibility Standards for Customer Service, O. Reg 429/07 (Can.).

Adams, K. \& Rice, S. A (2011). A brief informational resource on assistance animals for the disabled. Retrieved from http:॥www.nal.usda.gov/awic/companimals/assist.htm on May 15, 2012.

Americans with Disabilities Act of 1990. (2010). Stat. 42 U.S.C. § 12186 et seq.

Anderson, P.E. (2008). The powerful bond between people and pets. In J. Kuriansky (Ed.), Our boundless connections to companion animals. Westport, CT: Praeger.

Arkow, P. (2011). Animal-assisted therapy and activities: A study, resource guide, and bibliography for the use of companion animals in selected therapies (10 $\left.{ }^{\text {th }} \mathrm{ed}.\right)$. Stratford, NJ: self-published.

Assistance Dogs International (2012). Retrieved from http://www.assistancedogsinternational.org/standards/ on August 30, 2012.

Beck, A.M. \& Katcher, A.H. (1984). A new look at pet-facilitated therapy. Journal of the American Veterinary Medical Association, 184 (4), pg. 414-421.

Bergin B. (1998). The Smartest Dog: The Selection, Training and Placement of Service Dogs. Santa Rosa, CA: The Assistance Dog Institute.

Blind and Other Physically Disabled Persons (2010). Stat. Cal. Ann. Civ. Code $§$ 54.25.

Cain, A.O. (1991). Pet and the family. Holistic Nursing Practice, 5(2), pg. 58-63.

Chumley, P.R. (2012). Historical perspectives of the human-animal bond within the department of defense. The United States Medical Department Journal, April-June, pg 18-20. 
Chumley P.R. (2012) Chief, Human Animal Bond programs, DOD Veterinary Service Activity, Office of the Surgeon General.

Corson, S.A., Corson, E.O., Gwynne, P.H. \& Arnold, L.E. (1975). Pet-facilitated psychotherapy in a hospital setting. Current Psychiatric Therapies, 15, pg. 277-86.

Cusak, O. (1988). Pets and Mental Health. New York: The Haworth Press.

Davis, K.D. (2002). Therapy dogs: Training your dog to reach others. (2 ${ }^{\text {nd }}$ ed.). Wenatchee, WA: Dogwise.

The Delta Society (1997). Animal-Assisted Therapy: Therapeutic Interventions. Bellevue, WA: The Delta Society.

Dilley S. (2011). Admit my guide dog, says blind journalist Sean Dilley. BBC News. April 27, 2011.

Disability Discrimination Act (1992). (Cth) s 9 (Austl.).

Dog Control Amendment Act (2006). S 2 (N.Z.).

Duncan, S.L. (2000). APIC State-of-the-Art Report: The implications of service animals in health care settings. American Journal of Infection Control, 28(2), pg. 499-504.

Ensminger, J.J. (2010). Service and therapy dogs in American society: Science, law, and the evolution of canine caregivers. Springfield, IL: Charles C. Thomas.

Federal Emergency Management Agency (1999). Disaster Search Canine Readiness Evaluation Process. Retrieved September 11, 2012 from http://leerburg.com/pdf/crep_bdy.pdf.

Fine, A.H. (ed). (2010). Handbook on Animal Assisted Therapy: Theoretical Foundations and Guidelines for Practice ( $3^{\text {rd }}$ ed.). San Diego, CA: Elsevier.

Greb, J. (2012). Scientific working group on dog and orthogonal detector guidelines. Retrieved from http://www.uspcak9.com/certification/pd1_certification_2012.pdf on September 12, 2012. 
Guide Animal Act (1996). R.S.B.C., C 177 (Can.).

Hearing Ear Dogs, Guide Dogs, Service Dogs, and Search and Rescue Dogs (1996). Stat. N. H. Rev. Stat. Ann. § 167-D:3.

Kirton, A., Winter, A., Wirrell, E. \& Snead, O.C. (2008). Seizure response dogs: Evaluation of a formal training program. Epilepsy \& Behavior, 13(3), pg. 499-504.

Koda, N. \& Shimoju, S. (2008). Public knowledge of and attitudes toward accessibility of assistance dogs for physically impaired people in Japan. Asian Journal of Disable Sociology (7), 74-85.

Kruger, K.A. \& Serpell, J.A. (2010). Animal assisted interventions in mental health: Definitions and theoretical foundations. In J. Serpell (Ed.), Handbook on Animal Assisted Therapy ( $3^{\text {rd }}$ ed.). New York: Elsevier.

Lajoie, K.R. (2004). An evaluation of the effectiveness of using animals in therapy (doctoral dissertation). Retrieved from Google Scholar on August 30, 2012.

Livestock Disease Control (2002). Stat. Mass. Stat. § 129-39F.

Mason, M.S. \& Hagan, C.B. (1999). Pet-assisted psychotherapy. Psychological Reports, 84(3), pg. 1235-45.

Mass. Gen. Laws (2002). Stat. 129 § 39F.

Mills, J.T. \& Yeager, A.F. (2012). Definitions of animals used in healthcare settings. The United States Army Medical Journal, April-June, pg. 12-17.

Naderi, S., Miklosi, A., Doka, A. \& Csanyi, V. (2001). Cooperative interactions between blind persons and their dogs. Applied Animal Behavior Science, 74 (1), pg. 59-80.

Nondiscrimination on the Basis of Disability in Air Travel (2003). Stat. 14 C.F.R. pt. 382. 
Nondiscrimination on the Basis of Disability in State and Local Government Services. (2011). Stat. 28 C.F.R Part 35, Appendix A.

Pet Ownership for the Elderly and Persons With Disabilities (2008). Fed Regist, 70:63834.

Pet Partners (2012). Retrieved from: http://www.deltasociety.org/page.aspx?pid=183 on June 10, 2012.

Physically Disabled Persons (2003). Stat. Kan. Ann. Stat. § 39-1110.

Rights of Blind and Physically Disabled Persons (2012). Stat. D.C. Code Ann. § 7-1009.

Sak v. City of Aurelia (2011). W.D. Iowa.

Serpell, J.A. (1991). Beneficial effects of pet ownership on some aspects of human health and behavior. Journal of the Royal Society of Medicine, 84 (12), pg. 717-720.

Serpell, J.A. (2010). Animal-assisted interventions in historical perspective. In A. Fine (Ed.), Handbook on Animal-Assisted Therapy ( $3^{\text {rd }}$ ed.). New York: Elsevier.

Service Dog Central (2012). Retrieved from http://servicedogcentral.org/content/node/35 on August 30, 2012.

Siegel, J.M. (1990). Stressful life events and use of physician services among the elderly: The moderating role of pet ownership. Journal of Personality and Social Psychology, 58(6), pg. 1081-1086.

Storms v. Fred Meyer Stores, Inc. (2005). Wash. Ct. App.

Tedeschi, P., Fine, A.H. \& Helgeson, J.T. (2010). Assistance animals: Their evolving role in psychiatric service applications. In A.H. Fine (Ed.). Handbook on Animal Assisted Therapy: Theoretical Foundations and and Guidelines for Practice ( $3^{\text {rd }}$ ed.). San Diego, CA: Elsevier, pg. 421-438. 
Therapy (1997). In F.C. Misch (Ed.), Merriam-Webster’s Collegiate Dictionary (10 $0^{\text {th }}$ ed.).

Springfield, MA: Merriam- Webster.

Therapy (1994). In M. Spraycar (Ed.), Stedman’s Medical Dictionary (26 ${ }^{\text {th }}$ ed.). Baltimore:

Williams and Wilkins.

United States Department of Army (2007). Military Working Dog Program. Stat. Reg. 190-12.

U.S. Dep't of Army (2003). Stat. Technical Bulletin Med. No. 4, DOD Human-Animal Bond

Principles and Guidelines.

United States Police Canine Association (2012). PDI and EDD Certification Package. Retrieved from http://www.uspcak9.com/certification/pd1_certification_2012.pdf on September 12, 2012.

Volhard, J. \& Volhard, W. (1997). The Canine Good Citizen: Every Dog Can be One. (2 ${ }^{\text {nd }}$ ed.). New York: Wiley Publishing.

White Cane Law (2003). Stat. Ill. Stat. § 775-3. 
Table 1: A revised taxonomy for functional categories of assistance animals in society and the major functional categories.

\section{Major Differentiating Factors}

\begin{tabular}{|c|c|c|c|c|c|}
\hline $\begin{array}{l}\text { Functional } \\
\text { Category }\end{array}$ & $\begin{array}{c}\text { Assistance } \\
\text { Related to } \\
\text { a Disability }\end{array}$ & $\begin{array}{c}\text { Typical } \\
\text { Level of } \\
\text { Dog Skills }\end{array}$ & $\begin{array}{c}\text { Assists a } \\
\text { Public } \\
\text { Service, } \\
\text { Military, } \\
\text { or Health } \\
\text { Professional }\end{array}$ & $\begin{array}{c}\text { Certificatio } \\
\text { n or } \\
\text { Standards } \\
\text { Available }\end{array}$ & $\begin{array}{c}\text { Scope of } \\
\text { Current Access } \\
\text { Protections }\end{array}$ \\
\hline Service Animal & yes & advanced & no & yes & broad $^{1}$ \\
\hline $\begin{array}{l}\text { Public Service or } \\
\text { Military Animal }\end{array}$ & no & advanced & $\begin{array}{l}\text { public service } \\
\text { or military }\end{array}$ & yes & limited $^{2}$ \\
\hline Therapy Animal & varies & varies & $\begin{array}{l}\text { health or } \\
\text { allied health }\end{array}$ & yes & none \\
\hline Visitation Animal & no & basic & no & yes & none \\
\hline $\begin{array}{l}\text { Sporting, } \\
\text { Recreational, or } \\
\text { Agricultural Animal }\end{array}$ & no & varies & no & yes & none \\
\hline Support Animal & yes & varies & no & no & limited $^{3}$ \\
\hline
\end{tabular}

${ }_{1}$ Access to public locations is protected by the federal Americans with Disabilities Act (ADA) with some exceptions.

2 Access for Public Service or Military Animals is limited in most states to locations where the handler and animal are on duty and otherwise legally present; in some states broad access is protected regardless of duty status.

3 Support animals have protection under federal regulations to reside in both public and private housing (Fair Housing Amendments Act of 1988, Pet Ownership for the Elderly and Persons with Disabilities, 2008). The resident is required to verify that the animal is needed to assist with a physical, psychiatric, or emotional need. 
Animals in Society

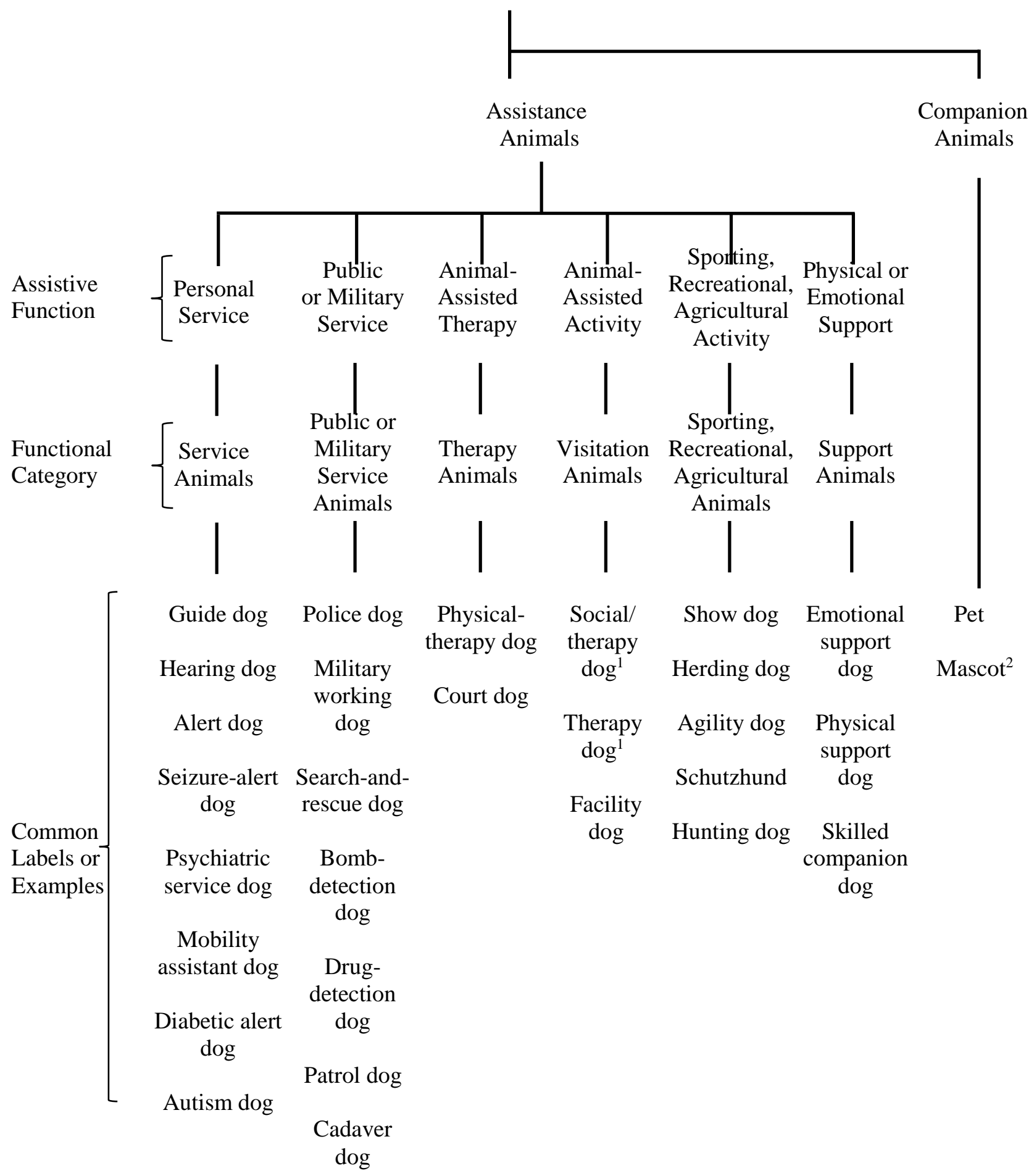


Figure 2. Classification of animals in society showing the various assistive functions, the six major functional categories of assistance animals, and several commonly used labels or examples pertaining to assistance dogs.

${ }^{1}$ Although still common, therapy is not a preferred label in this functional category.

${ }^{2}$ A mascot is an animal used for spirit-de-corps and as a morale booster. In the military, mascots are official government-owned animals that are placed on orders. 


\title{
Chapter 4: The Effect of Dogs on Veteran Stress and the Impact of Veteran and Service Dog Personality Characteristics
}

\begin{abstract}
This study investigated the role that dogs play in ameliorating the acute stress responses of veterans with PTSD, and whether individual traits impact whether the dog is helpful in reducing stress. A laboratory design was used to assess veteran stress responses before, during, and after performing a time-based math task. Each veteran completed a baseline, the task, and a recovery period while in the presence of no dog, their own service dog, and an unfamiliar dog. Several personality measures were used to assess both veteran and dog personality characteristics. Spearman's correlation analysis was completed on several physiological and psychological stress parameters and veteran and dog personality characteristics. Results found that the presence of the veterans' service dog affected some indictors of stress and that the relationship between dog and veteran assertiveness scores may be an important factor moderating this effect. However, several factors limit the interpretation of these results. More research is needed to determine whether the presence of a dog reduces acute stress responses in veterans and to identify the factors important to a service dog-veteran match and their success as a team.
\end{abstract}

Keywords: dog, veteran, stress response, service dog, HRV, matching

\section{Introduction}

Over 2.4 million service members have left the military service since 9/11 (Flournoy, 2014). Reintegrating Post-9/11 veterans into civilian life is complicated by recent exposure to war zone stressors (e.g., combat, bombs, improvised explosive devices, injury and death of military personnel and civilians) and development of clinical disorders such as post-traumatic 
stress disorder (PTSD) and depression. Post-traumatic stress disorder is typified by symptoms such as re-experiencing war zone stressors (flashbacks), hyper arousal, general anxiety, intense startle response, poor concentration and memory, hypervigilance, disturbed sleep, high irritability, and avoidance of people, places, and things. Post-traumatic stress disorder is associated with higher unemployment rates, which further exacerbates veterans' difficulty reintegrating into society (Anderson, 2017). This disorder is also associated with higher rates of suicide (Kemp \& Bossarte, 2013) and higher healthcare costs (Rosencheck, 2008). The lifelong cost of treatment for veterans with PTSD and depression has been estimated to cost from $\$ 5,900$ \$25,760 per case (White, 2011).

Common treatments for PTSD include pharmacological interventions, such as selective serotonin reuptake inhibitors and tricyclic antidepressants, and psychosocial treatments. Medications may take several weeks to influence symptoms (Nierenberg, et al., 2008) and often come with unpleasant side effects (Carafano \& Hutchinson, 2017). In addition, medication alone isn’t always effective. Cognitive- behavioral therapy (CBT) has been established as an effective treatment for many anxiety disorders including PTSD (Barlow \& Lehman, 1996; Hofmann \& Smits, 2008). Unfortunately, CBT is a treatment that typically takes several weeks or months of sessions with a skilled therapist and a high amount of effort from the patient. In addition to the unpleasant side effects and high response effort required for these conventional treatments, there seems to be a stigma associated with seeking help among the veteran population (Crawford et al., 2015), with low rates of veterans seeking treatment. Some estimate that less than half of service members scoring above the PTSD cut-off score entered some type of treatment program (Litz, 2007; Tanielian et al., 2008). One novel approach for helping veterans with PTSD is that of using 
therapy and/or service dogs for assistance and support. The non-stigmatizing qualities of animals may be a key advantage of this treatment modality for the veteran population (Velde et al., 2005).

The use of animals for psychological support has been an area of interest since the first paper that indicated dogs could play a role in facilitating talk therapy, or serving as a "cotherapist” (Levinson, 1962). These types of treatments are typically defined as either animalassisted activities (AAAs) or animal-assisted therapies (AATs). Animal Assisted Activities are more casual meet-and-greet encounters, whereas AATs involve specific goals and objectives with measurable outcomes. Animal assistance programs have been assessed for individuals with Alzheimer’s disease (Batson, McCabe, Baun, \& Wilson, 1998; Fritz, Farver, Kass, \& Hart, 1995), HIV/AIDS (Carmack, 1991), infertility (Blenner, 1991), PTSD (Hamama et al., 2011), and schizophrenia (Lang, Jansen, Wertenauer, Gallinat, \& Rapp, 2010), among many others.

Although the potential psychological benefits of animals were reported first (Levinson, 1962; Serpell, 1996), acute and long-term physiological benefits also have been documented. In a landmark study, Friedmann, Katcher, Lynch, and Thomas (1980) assessed pet ownership and one-year survival following a heart attack and found that $28 \%$ of non-pet owners died compared to $6 \%$ of pet owners. Since the publication of these findings, several studies have examined the physiological effects of pets, particularly dogs. Laboratory studies have evaluated the short-term effects of dogs on heart rate, blood pressure, and skin conductance, in addition to self-report psychological measures. In the typical laboratory protocol, following a short baseline period, the subject engages in a stressful task in the presence and absence of a dog, and physiological measurements are taken continuously. Studies have found that the presence of a dog compared with its absence attenuates physiological responses to social stressors (e.g. reading aloud, talking to the experimenter; Friedmann, Locker, \& Lockwood, 1993; Friedmann, Thomas, Cook, Tsai, 
\& Picot, 2007; Nagenast, Baun, Megel, \& Leibowitz, 1997) and mental stressors (e.g., mental arithmetic; Allen, Blascovich, \& Mendes, 2002; Allen, Blascovich, Tomaka, \& Kelsey, 1991; Demello, 1999). Alternatively, Gee et al (2015) found no differences in stress responses during a memory task while touching a dog when compared with touching a stuffed dog or a person; however, the dog used in this study was unfamiliar to the participant. In some cases, benefits were present when an unfamiliar dog was used (Demello, 1999; Friedmann, Locker \& Lockwood, 1993; Nagenast et al., 1997). Other studies have directly compared the physiological effects of bonded (i.e., familiar) dogs versus unbonded (i.e., unfamiliar) dogs with mixed results; one study found that blood pressure decreased only in the presence of bonded dogs (Baun, et al 1984), whereas other studies found no differences between bonded and unbonded dogs (Barker, Knisely, McCain, Schubert, \& Pandurangi, 2010; Gaydos \& Farnham, 1988; Todd-Schuelke et al., 1992). These discrepant findings may be due to different methodologies and outcome measures, or unanalyzed factors of the dog, the handler, or the interactions between them that may modify the therapeutic effect of dogs.

Ineffective dog-human matches have been reported with service dogs. Mowry et al., (1994) reported a success rate of $60 \%$ for hearing dogs matched to handlers. Another author reports that approximately 25\% of attempted guide dog placements were unsuccessful (Lloyd, 2004). Mismatched dyads create a substantial cost in resources for all involved. Several authors have highlighted the need to assess and understand the factors affecting dog-handler interactions (Burrows, Adams, \& Millman, 2008; King, et al., 2012; Ley, McGreevy, \& Bennett, 2009; Lloyd, 2004; Marston \& Bennett, 2003; Mowry, et al., 1994; Mueller, 2014). A thorough understanding of these factors could change the way in which AAAs and AATs are arranged and how assistance animals are trained and placed. 
A traditional method of matching service dogs to handlers is the use of an old version of the Social Style Assessment (Wilson Learning, 2004). This assessment measures the social style of the dog and client by assessing others' perceptions of their general behavior. Results provide measurements of assertiveness, responsiveness, and versatility. Matches are made by selecting dogs that are less assertive than the client and similar to the client in responsiveness (Bergin, personal communication, July 2007). This method has been used by Bergin University (formerly the Assistance Dog Institute) since the 1980's, has been taught to several hundred students of the Bergin University training program, and seems, anecdotally, to be effective, but has yet to be empirically validated.

The purpose of this study was to investigate the role that dogs play in ameliorating the acute stress responses of veterans with PTSD, and to assess whether individual traits of the dog and/or the veteran impact the success of the veteran-service dog team. The present study evaluated client and service dog personality characteristics to identify which factors, if any, may predict the therapeutic impact of client-service dog teams. More specifically, this study investigated the factors that may be predictive of the success of a veteran-service dog partnership. Currently, there are no studies that have systematically assessed the individual factors of the dyad in veteran-service dog partnerships. Results obtained from this study will begin to address the efficacy of using dogs to reduce veterans' response to stress, including the potential impact of the individual characteristics of the dog and veteran team, and may lead to a better understanding as to why some service dog partnerships are successful while others are not. This information can be used to better utilize service dogs as a therapeutic tool for veterans with psychiatric disabilities. Improved success in matching is expected to initiate better mental and 
physical health outcomes for veterans while resulting in more effective service dog - client matching procedures.

\section{Method}

This project was funded by a contract from the Health Effects Laboratory Division, National Institute for Occupational Safety and Health (NIOSH) to the Division of Animal and Nutritional Sciences, Davis College of Agriculture, Natural Resources, and Design, West Virginia University (Contract \# 200-2011-41348). This study was approved by West Virginia University’s Institutional Animal Care and Use Committee (Protocol \# 12-1104) and NIOSH Institutional Review Board (14-HELD-04).

Participants

Veterans with service dogs were enrolled in this study $(\mathrm{N}=6)$. Dogs were considered service dogs when they met the following definition: "Service animals have been trained to provide work or perform tasks related to an individual's disability (Parenti, Foreman, Jean Meade, \& Wirth, 2013).” Participants were male veterans in the United States from any service branch who served in Operation Iraqi Freedom (OIF) or Operation Enduring Freedom (OEF). Eligible participants were required to be male, combat-exposed veterans, 18 years of age or older, able to attend a session in Morgantown, West Virginia, had a service dog for at least 6 months, and could be separated from their service dog for brief periods. Individuals were excluded from the study if they did not meet the above listed criteria or if they did not have PTSD (measured by a score of at least a 38 on the PTSD checklist). They were also excluded if they scored positive on the Drug Abuse Screening Test (DAST), lower than 3 on the Combat Exposure Scale (CES), or if they were unable to be in the presence of unfamiliar dogs. Participants were offered an incentive for their time in the form of a Visa gift card. 
Participants were recruited through flyers posted at and emails distributed to local veterans’ organizations. Because veterans who already own service dogs are limited in number, the catchment area included West Virginia and neighboring states (e.g., Virginia, Ohio, Pennsylvania, Kentucky, or beyond). Once verified as eligible based on their answers to the initial contact form, each participant was sent a link to an online Pre-Screening Survey Battery to collect further information regarding their drug and alcohol use, combat exposure, and personality characteristics of themselves and their service dog. Unfortunately, we were only able to recruit 6 veterans to participate in this study. Time and funding were limited, so we were unable to extend the research to recruit additional veterans with service dogs. Materials

Pre-Screening Instruments. The Pre-Screening Survey Battery consisted of several surveys to determine eligibility and others to gather information regarding characteristics of the veteran and dog. These items were available to the participant online via Survey Monkey.com. Participants were to complete these assessments prior to their arrival at the laboratory. The Combat Exposure Scale (CES) is a 7-item self-report measure that is designed to assess wartime stressors experienced by combatants (Keane et al., 1989). Each item is rated according to a 5point scale in which low scores indicate limited combat exposure and higher scores indicate greater combat exposure. The scores can range from 0-41. To qualify for this study, the individual must score at least a 3 on this measure. The PTSD Check List-5 (PCL-5) is a 20-item self-report measure of the 20 DSM-V symptoms of PTSD in response to stressful military experiences (Weathers, Litz, Herman, Huska, \& Keane, 1993). Each item corresponds to one of the symptoms. The respondent rated his experience with that symptom according to a 5-point scale in which $0=$ "Not at all" and $4=$ "Extremely." This measure was used to determine 
eligibility. Scores below 38 resulted in disqualification from the study. The Drug Abuse Screening Test (DAST; Skinner, 1982) consists of 28 self-report yes-or-no questions that are concerned with the individual's involvement with drugs during the past 12 months. Higher scores indicate a substance abuse problem. Scores above 12 disqualified the subject from the study, based on recommendations on the DAST tool instrument. No participants were excluded from the study. The completion of these surveys took approximately 20 minutes.

In addition to the eligibility information, the prescreening battery also consisted of several additional scales. The World Health Organization Quality of Life (WHOQOL-BREF; WHOQoL Group, 1998) consists of 26 self-report items that assess four quality-of-life domains: physical health, psychological health, social relationships, and environment. The Pet Attachment Scale-Modified (PAS-M; Templer et al., 1981; Templer et al., 2004) is an 18-item assessment with items rated on a Likert scale from 1 (strongly disagree) to 7 (strongly agree). The PAS-M is designed to measure an individual's general attitude about pets. The Pet Attachment and Life impact Scale (PALS; Cromer \& Barlow, 2013) assessment measures the positive or negative impact that an animal has on the owner's life (i.e., whether the animal is a source of comfort and security) as reported by the owner. The PALS includes 39 items scored on a Likert scale of 1 (not at all) to 5 (very much). Questions concern the impact that a specific ("favorite”) pet (current service dog in this case) has on the person's health, stress, trust, emotions and sociability, among other life dimensions. Factors measured by the PALS are Love, Regulation, Personal Growth, and Negative Impact. The word "pet” in the PALS survey was changed to "service dog" for the purposes of this study; no other changes were made to the PALS. The Social Style - Self is a 30- question survey that asks the rater to score the target individual on a Likert scale of 1 (low) to 7 (high) on multiple statements, such as "is a risk taker," and "is 
dependable.” In this study, the participant rated themselves. Based on responses, each participant is scored on assertiveness, responsiveness, and versatility scales and results are plotted to a graph. This survey is used by the Bergin University of Canine Studies as a tool to match service dogs to clients. Typically, each target person (and dog candidate) is rated by 3-5 other people and the average is taken to calculate the assertiveness and responsiveness scores. Then, dogs are matched with people who are more assertive than the dog and an attempt is made to match responsiveness scores in service dog-handler teams. The Social Style - Service Dog is the same survey used with the veterans above, with each statement changed to apply to a service dog. The veterans filled out this form with their service dog in mind. Completion of these items took approximately 40 minutes.

Computer Task. The task was a commonly used laboratory stress task called the Pauli Test presented using the ALS Work Performance Series (Schuhfried GmbH, Moedling, Austria). The respondent's task was to carry out as many additions or subtractions of two numbers as possible in the time provided. The numbers were displayed one above the other on the computer screen. Three test versions are available that allow manipulation of the task difficulty. In the version used here, the Pauli Test, the sum of an upper and a lower number must be calculated and entered using a number pad on the computer input device. This task requires the participant to answer math questions under time pressure. Similar tasks have been used to assess performance under stressful working conditions (e.g., emergency room doctors with and without rest over 16 hour working day; Frey et al., 2002). This task was chosen based on results of a pilot study comparing the Pauli test with a signal detection task. The Pauli test showed the largest increase in stress measures during the pilot test, so it was chosen as the stress task for this study. At two or three randomly selected times during the task, an un-signaled acoustic startle 
stimulus was presented through headphones. The startle stimulus was an auditory tone (50-ms, 105-dB burst of white noise).

Psychological Measures of Stress

The Positive and Negative Affect Scale (PANAS; Watson, Clark, \& Tellegen, 1988) is a brief 20-item scale designed to measure positive and negative mood states. It can be used to assess mood on various time scales by altering the instructions (Watson, Clark, \& Tellegen, 1988). The present-state version was used in this study. This measure was used to indicate stress levels, as positive emotions have been shown to improve physiological recovery after stress (Fredrickson, et al., 2000). The NASA-TLX is a self-report measure of perceived workload (Hart, 2006; S.G. Hart \& Staveland, 1988). A positive relationship between perceived stress and workload has been reported in the literature (Kausar, 2010). Performance parameters during the math task in each condition were collected automatically by the computer software and included number answered and number of errors. Task performance measures were used as another indicator of stress level, as there is strong evidence that appropriate treatment of anxiety-related symptoms results in improved work (Waghorn et al., 2005).

\section{Physiological Measures of Stress}

A MindWare Ambulatory Impedence Cardiography device (MW1000A, Lafayette Instruments, Lafayette, IN) was used to collect several waveforms for electrocardiogram (ECG), Z0, and dZ/dt. Impedance Cardiography Analysis Software (MW6-1101, Lafayette Instruments, Lafayette, IN) and Heart Rate Variability (HRV) Analysis Software (MW6-1100, Lafayette Instruments, Lafayette, IN) were used to calculate several cardiac measures, such as left ventricular ejection time (LVET), pre-ejection period (PEP), stroke volume (SV), cardiac output (CO), heart rate (HR), dZ/dt max (peak of the ascending aortic blood flow), mean inter-beat 
interval (IBI), respiratory sinus arrhythmia (RSA), and other selected respiratory measures. Heart rate and heart rate variability (HRV) are the main cardiovascular measures we used, as these metrics are commonly used in stress research. They were calculated or derived from the ECG recordings off line using the analysis software.

\section{Procedure}

Once eligibility was confirmed and pre-screening materials complete, participants attended a laboratory study in which their stress responses were measured during the computer task. The laboratory study was conducted in a $5.5 \mathrm{~m}$ by $5.5 \mathrm{~m}$ space set up as an office-like environment with several computer workstations installed in separate but adjacent cubicles. Participants were seated upright in a comfortable office chair located $0.5 \mathrm{~m}$ in front of a 20-in. $(50.8 \mathrm{~cm})$ computer monitor. A keyboard and a custom input device were used for response input during the computer tasks. Researchers could observe and monitor the subjects from a $3.5 \mathrm{~m}$ by 2 $\mathrm{m}$ room adjacent to the main workspace through a one-way window.

Before the session began, an investigator reviewed the consent form with the subject. Subjects were informed that their participation in the study was strictly voluntary and they could leave the study at any time and for any reason without penalty. No participant discontinued the study prematurely. Each subject was given a signed copy of the consent document, which included contact information for the principal investigators and chair of the NIOSH Human Subjects Review Board in case they have any questions or concerns about the study. Next, surface electrodes were placed on the subject for physiological measurements, and the data collection instruments were tested briefly. Thereafter, the subject was provided instructions for the remaining portion of the session. Only 1 subject participated in a session at a time. 
The timeline of the procedures within the session is shown in Figure 9. The session began with a demonstration of rating procedures, electrode attachment, baseline recordings and administration of a baseline Positive and Negative Affect Schedule. After viewing instructions for the task, subjects then completed the Dog Absent condition. Baseline began with a screen prompt instructing the participant to sit quietly for 10 minutes. Immediately following baseline, the computer task began. Completion of the

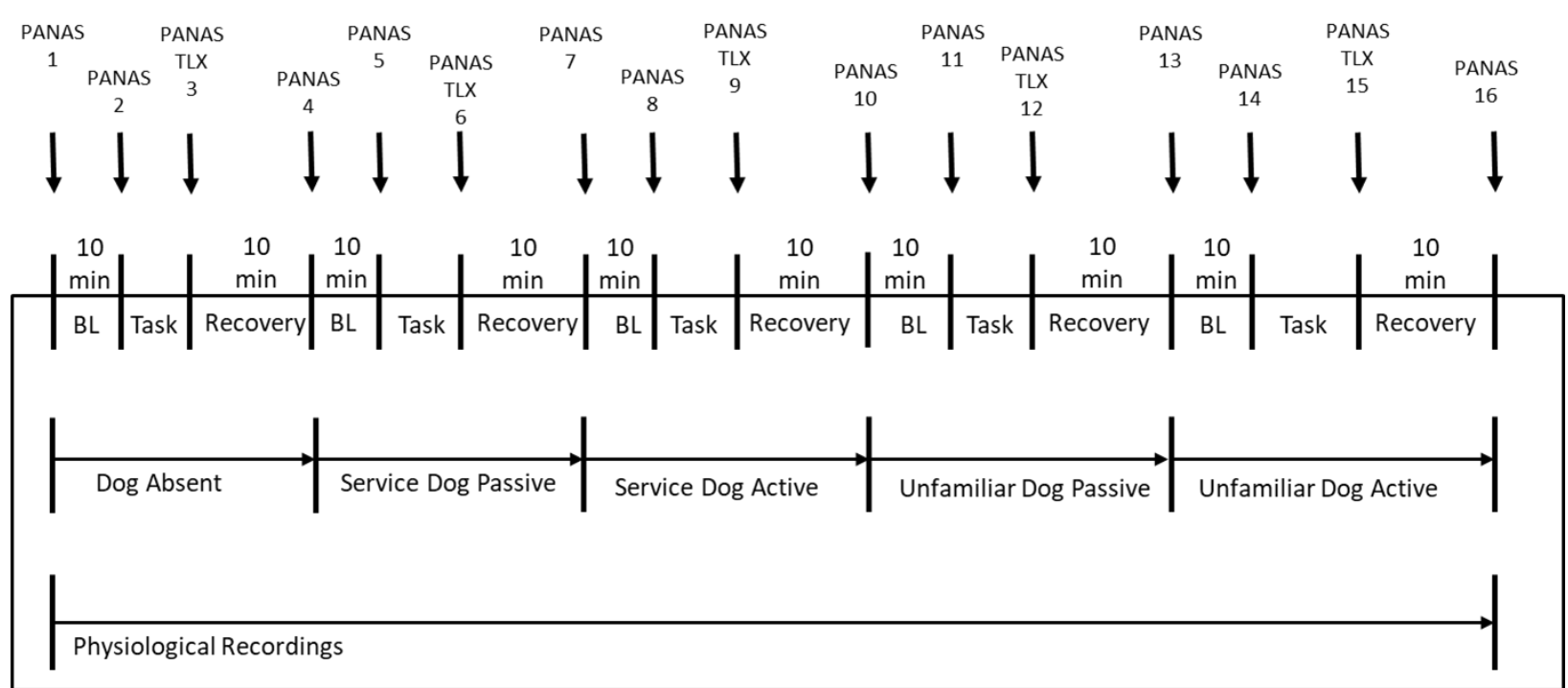

Figure 3. Timeline of procedures within laboratory session. BL= Baseline; TSX = NASA TLX task prompted the presentation of the PANAS and NASA Task Load Index and the recovery period. The baseline period for the next condition then began (SD Passive), followed by the task, and recovery. This sequence of events continued until completion of all conditions (Alone, Service Dog (SD) Passive, SD Active, Unfamiliar Dog (UD) Passive, and UD Active).

Conditions were presented in the same order for all participants. Five- to 10- minute breaks were offered between dog conditions to minimize fatigue. Baseline and recovery periods lasted 10 
minutes each. The task took approximately 20 min to complete, and the entire procedure took approximately 5 hours.

In the SD and UD Passive conditions, the dog remained in a down position next to the veteran. Veterans were instructed to avoid interacting with the dog during passive conditions. In the SD and UD active conditions, the dog remained in a sit or visit position next to the veteran while he was seated at the workstation. During active conditions, the veteran was encouraged to interact physically and verbally with the dog. During the absent conditions and before the session, the dog was kept in a large plastic Vari-Kennel in a room adjacent to the laboratory or walked inside or outside the facility.

After each session, the investigator debriefed the participant and answered any questions he had about the study. Participants were given a list of veteran resources in case of any distress caused by the study and a token of appreciation in the form of a gift card to thank them for the time and effort involved in participating in the study.

\section{Data Analysis}

Physiological Data - Cardiac Function

After obtaining the raw heart rate interval (R-R) files for all subjects, each file was visually reviewed and manually edited using previously published guidelines for artefact correction based on error type (Giles et al., 2016). These procedures help to minimize any artefacts in the data due to movement of the participant. The median five minutes of each R-R file was then selected for use in analysis. The selected datasets did not contain more than $5 \%$ corrected errors and no portions of interval data with more than three consecutive errors were included. 
Several measures were used to evaluate heart rate variability (HRV), as is recommended (Task Force of the European Society of Cardiology and the North American Society of Pacing and Electrophysiology, 1996). These included measures in the time domain [heart rate (HR), average R-R interval (RR), root mean square of successive differences (RMSSD), and standard deviation of the R-R intervals (SDNN)] and frequency domain [low frequency power (LF), high frequency power (HF), and their ratio (LF/HF)]. Datasets were imported as .csv files in Kubios HRV standard (Kubios Oy, Kuopio, Finland), a free HRV analysis software, and detrended using first-order differencing to obtain approximate stationarity required by the majority of the HRV measures used (except HR and RR). For spectral frequency analysis, each dataset was resampled at $4 \mathrm{~Hz}$ for fixed interval sampling prior to undergoing Fast Fourier Transformation. The spectral limits were set to match widely used and recommended values for HRV frequency analysis (Task Force of the European Society of Cardiology and the North American Society of Pacing and Electrophysiology, 1996): VLF (0-0.04Hz), LF (0.04-0.15Hz), and HF (0.15-0.4 Hz). A Welch’s periodogram window of 150 seconds with 50\% overlap was used for spectral estimation. See Table 7 for an explanation of HRV measures.

Table 2. Heart Rate Variability Measures and their interpretations.

\begin{tabular}{|l|l|l|}
\hline Measure & Acronym & Interpretation \\
\hline Average Heart Rate (bpm) & HR & The mean heart rate over a period of time. \\
\hline Average R-R Interval (ms) & RR & The mean R-R interval over a period of time. \\
\hline $\begin{array}{l}\text { Root Mean Square of Successive } \\
\text { Differences (ms) }\end{array}$ & RMSSD & $\begin{array}{l}\text { A measure of short-term standard deviation } \\
\text { between successive R-R intervals. Higher } \\
\text { values generally indicate more } \\
\text { parasympathetic activity. }\end{array}$ \\
\hline $\begin{array}{l}\text { Standard Deviation of R-R } \\
\text { Intervals (ms) }\end{array}$ & SDNN & $\begin{array}{l}\text { A measure of long-term standard deviation } \\
\text { for the dataset. Estimates the change in } \\
\text { overall HRV over a period of time. }\end{array}$ \\
\hline Low Frequency Power (ms $\left.{ }^{2}\right)$ & LF & $\begin{array}{l}\text { Generally used as an indicator of both } \\
\text { sympathetic and parasympathetic activity. } \\
\text { However, other factors such as respiration can } \\
\text { affect this measure. Therefore, it is not }\end{array}$ \\
\hline
\end{tabular}




\begin{tabular}{|l|l|l|}
\hline & & $\begin{array}{l}\text { usually used as a standalone measure of } \\
\text { autonomic activity. }\end{array}$ \\
\hline High Frequency Power $\left(\mathrm{ms}^{2}\right)$ & HF & $\begin{array}{l}\text { Generally used as an indicator of } \\
\text { parasympathetic activity. Higher values } \\
\text { indicate more parasympathetic activity. } \\
\text { However, other factors such as respiration can } \\
\text { affect this measure. Therefore, it is not } \\
\text { usually used as a standalone measure of } \\
\text { autonomic activity }\end{array}$ \\
\hline $\begin{array}{l}\text { Ratio Between LF and HF } \\
\text { Powers }\end{array}$ & LF/HF & $\begin{array}{l}\text { Used to evaluate the balance between the } \\
\text { parasympathetic and sympathetic branches of } \\
\text { the autonomic nervous system. Higher values } \\
\text { are generally thought to indicate higher } \\
\text { sympathetic activity. Given the effect of } \\
\text { additional factors (baroreceptors and } \\
\text { respiration) on LF spectral power, this } \\
\text { measure should be interpreted carefully. } \\
\text { Average respiration rate should be included in } \\
\text { statistical models if available, otherwise, } \\
\text { noted in the discussion section as a drawback } \\
\text { of the study. }\end{array}$ \\
\hline
\end{tabular}

Change in HR. The difference in HR from BL to task was calculated by subtracting the mean HR during the task from the mean HR during BL. The difference in HR from task to recovery was calculated by subtracting the mean HR during recovery from the mean HR during the task. The difference in HR from BL to recovery was calculated by subtracting the mean HR during the task from the mean HR during recovery.

\section{HR Ratio}

A ratio of HR was created to reflect the amount of change in HR between conditions while taking into consideration the individual's BL heart rate. This ratio was calculated for change in HR from BL to task by dividing mean HR during the task by mean HR during BL. This was repeated for HR from task to recovery, and again for HR from recovery to BL.

All physiological data variables, including HRV (Table 7), change in HR and HR ratios were first screened using goodness-of-fit for normal distribution, using the Shapiro-Wilk W test. 
Skewed variables were Ln-transformed (LF/HF ratio, LF, HF, SDNN, RMSSD and Total). All HRV variables were analyzed by repeated measures ANOVA (RM-ANOVA), separately at baseline, task and recovery, using an autoregressive correlation structure to account for correlation of measurements across the dog groups within each veteran, accounting for possible habituation. The type of dog (No Dog, Service Dog, and Unfamiliar Dog) was a focus of analysis, while the effect of activity of the dog (active or passive) was not evaluated. The RMANOVA was followed by four custom contrasts based on the hypotheses, which enabled us to test the following differences:

i. No Dog group vs. all Dog conditions,

ii. Service Dog groups vs. Unfamiliar Dog conditions,

iii. No Dog group vs. Service Dog condition, and

iv. No Dog vs. Unfamiliar Dog condition.

The same analyses were conducted for change in HR and ratios.

Psychological Measures

PANAS positive and negative scores were calculated as indicated on the PANAS questionnaire. PANAS measurements were taken for each dog group at three time points: at baseline, after the task, and after recovery. PANAS measurements were analyzed for each time point separately. Additional variables were created to investigate the change in positive and negative affect from baseline to task and from task to recovery during each condition. PANAS scores during the task were subtracted from the baseline score to yield the BL-Task variable, and PANAS scores during recovery were subtracted from the task score to yield the Task - Recovery variable. NASA TLX scores included raw scores for each domain - mental demand, physical demand, temporal demand, performance, effort, and frustration level. The average score of all 
the subscales is reported as the “overall TLX (Bustamante \& Spain, 2008).” NASA TLX data were collected at one time point (after the task) for each dog group. Both PANAS and NASA TLX variables were analyzed using RM-ANOVA (dog group as a repeated factor) followed by the four contrasts to test specific hypotheses, as specified above.

Task Performance Measures

Task performance measures included answers per minute, errors per minute, corrections per minute, and proportion of answers correct. Variables not fitting normal distribution (answers per minute, and corrections per minute) were Ln-transformed before the repeated measures ANOVA with custom orthogonal contrasts as specified earlier.

Results (p-values) from (47) repeated measures ANOVA analyses (all except for the 4 PANAS created variables - BL-Task and Task-Recovery) were subjected to BenjaminiHochberg's (BH) procedure with 0.2 false discovery rate to control for Type I error rate with multiple analyses (Benjamini \& Hochberg, 1995).

\section{Personality Characteristic Measures}

Six new variables were created to highlight the relationship between the veteran and the dog personality. The difference between human and dog assertiveness and the ratio of human and dog assertiveness were calculated (as measured by the Social Style-Self and Social Style Dog). The same was done for the social style measures of responsiveness and versatility. Scores from all personality characteristic measures and stress measures were averaged across participants in the SD conditions (SD active and passive) and entered into a correlation matrix. Sixty-one combinations resulted with p-values of 0.1 or lower, and 18 combinations resulted with p-values of 0.05 or lower. A BH correction procedure was completed on all correlation results, leaving one significant correlation at $\mathrm{p}=0.0001$. 
Data were analyzed using JMP and SAS software (JMP®, Version Pro 12.2, SAS Institute Inc., Cary, NC, Copyright @2015; SAS®, Version 9.3, SAS Institute Inc., Cary, NC, Copyright (C2002-2010). Significance criterion alpha for all tests was $\mathrm{p}<0.1$.

\section{Results}

Mean HR. There was no main effect of dog group for HR at baseline $(p=0.73)$ or recovery $(\mathrm{p}=0.15)$. There was a main effect of dog group for heart rate during the task among groups ( $\mathrm{p}=0.01)$. More specifically, HR during the no dog group was higher than during dog groups, SD groups, and UD groups during the task. HR during SD groups was higher than during UD groups during the task. See Figure 10.

Mean Heart Rate during Task by Group

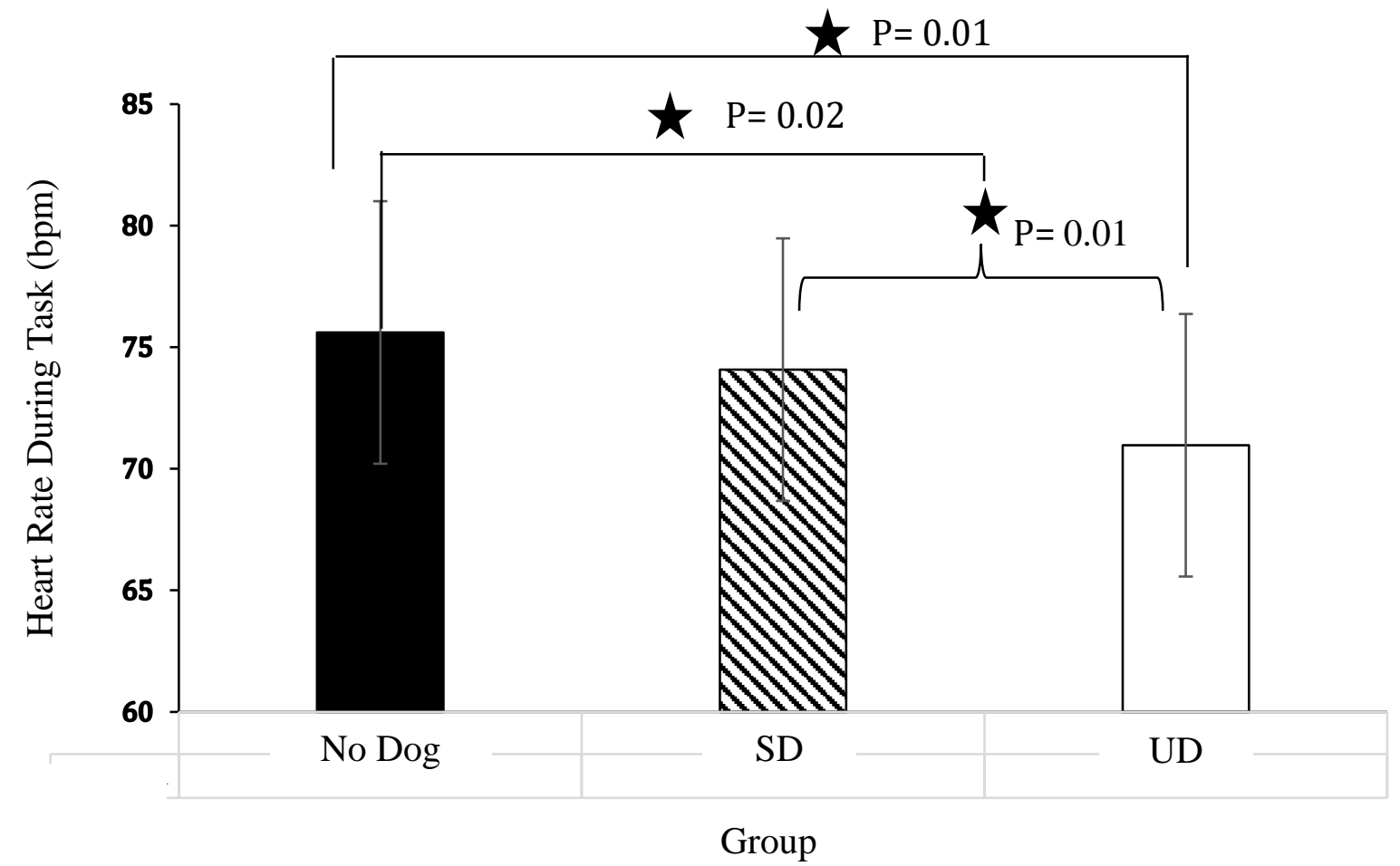

Figure 4. Mean HR during task across conditions. 
There were no significant effects of dog group in change in HR from BL to task $(\mathrm{p}=0.4)$, from task to recovery $(\mathrm{p}=0.81)$, or from baseline to recovery $(\mathrm{p}=0.79)$. There were no significant differences among dog groups in the ratio of HR from task to $\mathrm{BL}$ ( $\mathrm{p}=0.31$ ), from task to recovery $(\mathrm{p}=0.83)$, or from recovery to $\mathrm{BL}(\mathrm{p}=0.70)$. There were no significant differences among dog group in LF/HF ratio, mean RR, SDNN, RMSSD, LF, HF, or Total during any condition. There were no differences between conditions in any of the task performance measures. No effects were found for TLX overall scores, mental workload, physical workload, temporal workload, effort, or frustration; however, there was a trend for performance effort. NASA TLX performance effort scores tended to be higher in UD groups than in SD groups. This difference was not statistically significant $(\mathrm{p}=0.08)$. See Figure 11 .

\section{Performance Effort By Group}

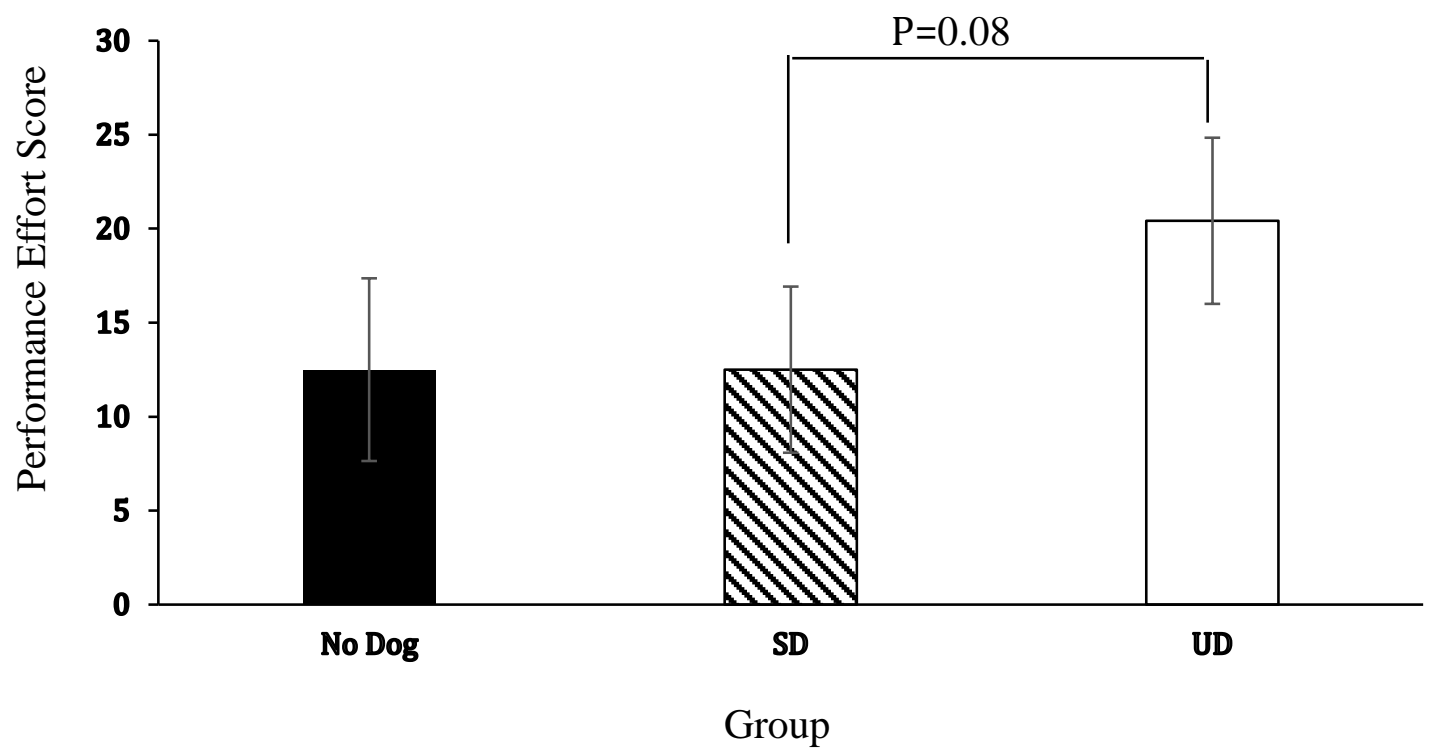

Figure 5. NASA TLX Performance effort scores across conditions.

There were no differences in positive affect scores during BL, or in the change from BL to task or task to recovery. There were no differences in negative affect scores during task 
$(\mathrm{p}=0.25)$ or recovery $(\mathrm{p}=0.25)$, or in the change in negative affect scores from BL to task and from task to recovery. There were differences in negative affect scores during baseline ( $\mathrm{p}=0.01)$. Negative affect scores were higher in no dog groups than in any group with dog and SD and UD groups. See Figure 12. Descriptive data for all variables in Appendix.

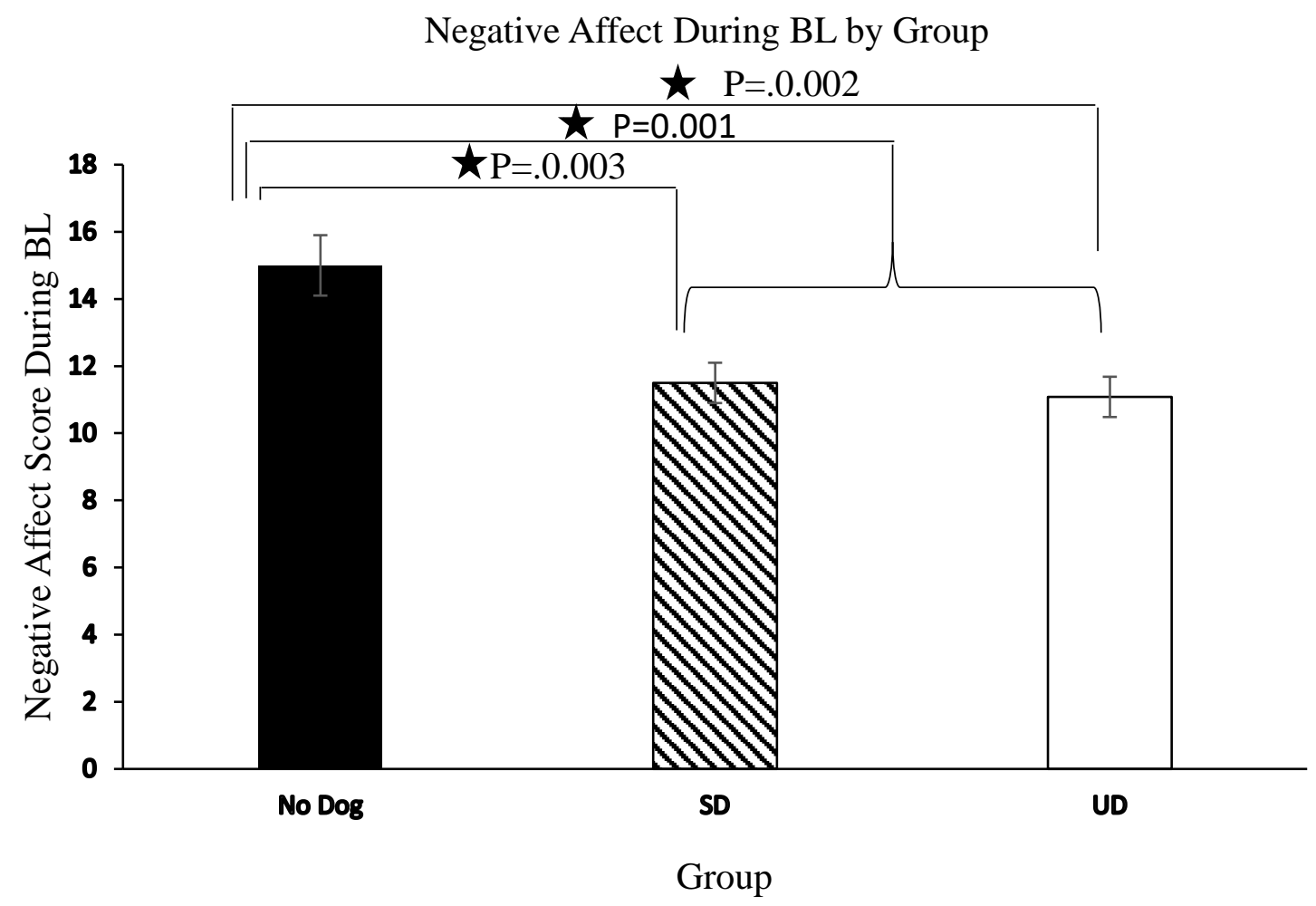

Figure 6. PANAS negative scores during BL across conditions.

Fourteen combinations were significant; however, after correction for multiple comparisons, HF during Recovery and the difference between Human and Dog Assertiveness scores on the social style survey were significantly correlated at $\mathrm{Q}=0.1$. $(\mathrm{p}=0.0001)$. See Figure 13. This correlation was not due to the human or dog assertiveness score alone (see Figure 14 and 15). Additional correlations in Appendix. 


\section{Human-Dog Assertiveness and HF Recovery}

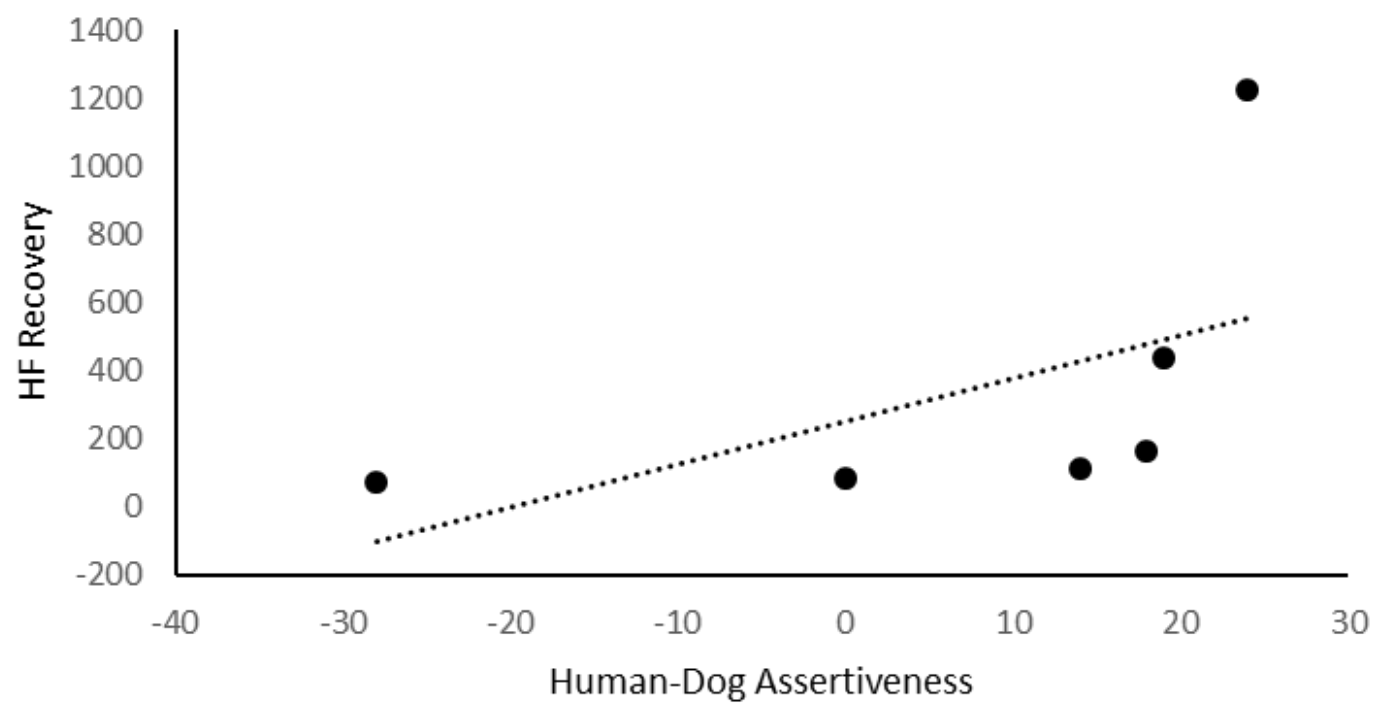

Figure 7. Correlation between difference of human and dog assertiveness and HF Recovery $(p=0.0001)$.

Correlation between Human Assertiveness and HF Recovery

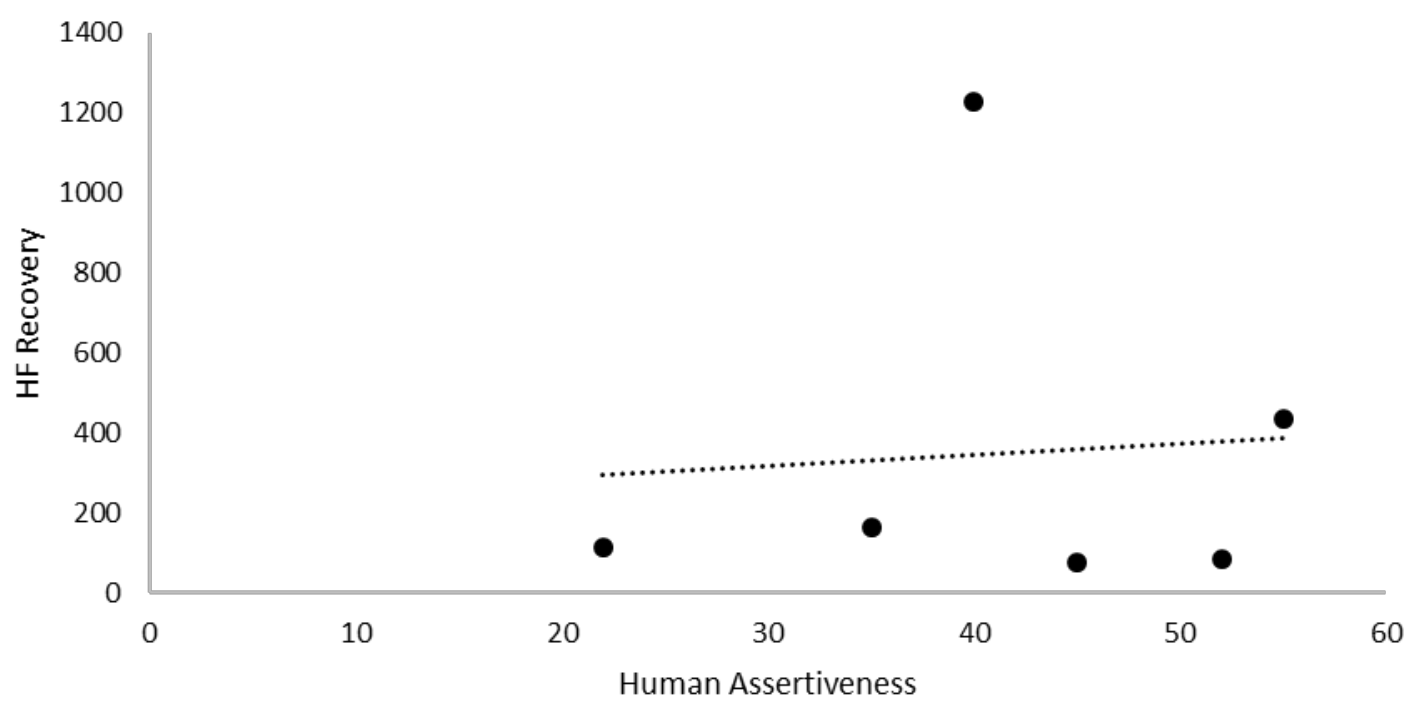


Figure 8. Correlation between human Assertiveness and HF Rec ( $\mathrm{p}=0.5441)$

Correlation between Dog Assertiveness and HF Recovery

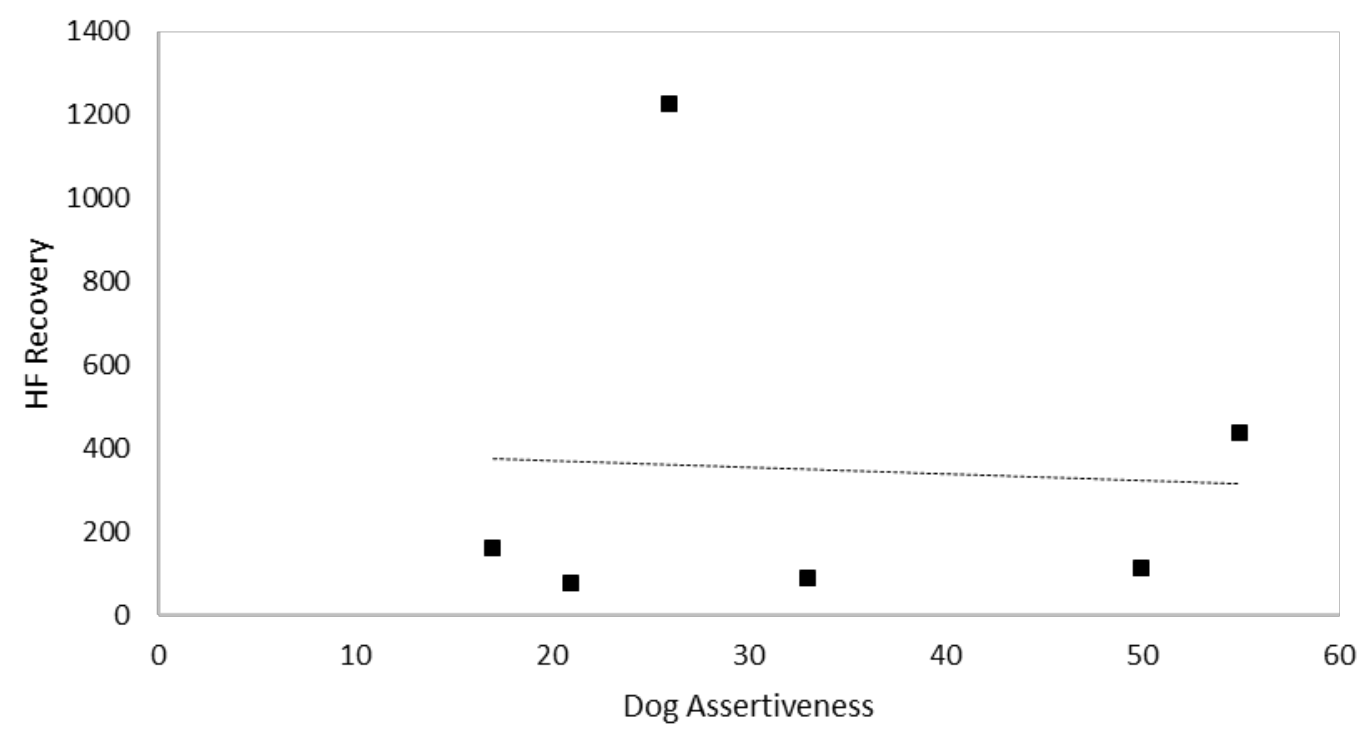

Figure 9. Correlation between dog Assertiveness and HR Rec $(\mathrm{p}=0.1562)$

\section{Discussion}

In this study, some stress indicators were lower when a dog was present. For example, negative affect scores were significantly lower during the dog conditions than during conditions with no dog, regardless of whether the dog was the participants' own dog or an unfamiliar dog, suggesting that participants felt less negatively during the task when a dog was present. Similarly, average heart rate was significantly lower during both or either of the dog conditions than during alone conditions, suggesting reduced stress when a dog was present compared to when no dog was present. These findings are consistent with other research. For example, one study found lower negative affect when a dog was present throughout a traumatic film clip. Female participants that were accompanied by a dog while watching the traumatic film clip 
reported less negative affect afterward than the females accompanied by a toy dog and the females that were alone (Lass-Hennemann et al., 2014). In another study of 67 university students, interacting with a dog resulted in large mood benefits. Students either interacted with a dog, viewed the same dog, or neither. Interacting with the dog resulted in lower negative mood and increased positive mood relative to the other conditions (Crossman, Kazdin, and Knudson, 2015).

Some stress indicators in this study suggest less stress when the participant's service dog was present compared to when an unfamiliar dog was present. For example, performance effort was rated higher with UD than with SD. In addition, negative affect was lowest during BL when the SD was present, suggesting that the veterans felt less negative during BL when their service dog was present than when the UD or no dog was present. Higher positive affect when in the presence of one's SD is reported elsewhere. For example, participants with progressive conditions that had SDs demonstrated higher positive affect scores than participants without SDs. Additionally, among participants with depression, those with a SD scored higher in positive affect (Collins et al., 2006). However, this could be due to a third variable. For example, it is possible that more positive individuals are more likely to seek out a service dog for themselves. These studies also examined long-term affective states, whereas the current study measured affect several times throughout a short period, making direct comparison difficult. Some data in this study and other studies have found that the familiarity of the dog has no impact on the benefits (Barker, Knisely, McCain, Schubert, \& Pandurangi, 2010; Gaydos \& Farnham, 1988; Todd-Schuelke et al., 1992). These inconsistent results may be due to individual differences in human and dog personality and/or the "match," or lack thereof, between human and dog. 
Not much is known regarding factors that contribute to successful human-dog relationships (Payne, Bennett, and McGreevy, 2015). This study found a significant correlation between the difference of human and dog assertiveness and HF during recovery. Higher values of HF indicate more parasympathetic activity, or less stress. The correlation between human-dog assertiveness and HF during recovery suggests that the more dog and human differ in assertiveness, the lower the level of stress during recovery for the veteran. This effect is not due to higher human or dog assertiveness alone.

Several studies have investigated the relationship between dog owner personality and performance or satisfaction with the dyad; however, there is no research on the assertiveness of dog and owner relative to each other and its association with the success of the dyad. Siniscalchi, Stipo, and Quaranta (2016) found that the confidence of the owner impacted the dog's behavior in an attachment test; however, performance on an attachment test does not inform the "success" of the dyad. In addition, confidence and assertiveness are very different personality characteristics.

Intuitively, it seems that an assertive dog owner would be more likely to follow through with commands, resulting in a higher performing, more obedient dog. A service dog owner with a reliably obedient dog may have less stress than a service dog owner with a misbehaving dog. In this study, the one service dog-owner dyad in which the dog was more assertive than the owner had the most stress (lowest HF) during recovery. This is an interesting finding; however, more research is needed to determine if this is consistent among others.

Unfortunately, the findings in the current study cannot be unraveled from the potential confound of sequence effect. Each participant experienced the same order of conditions - Alone, SD, and UD. Results demonstrate a general decline in stress indicators across the session, so the 
results may be due to the participants adapting to the research environment more than the condition. However, the conditions were arranged in a conservative order. We hypothesized that the presence of the veteran's service dog would lead to the most stress reduction, so we arranged the SD condition in the middle. This way, if there is an order effect, the results would not confirm our hypothesis. Even so, some of the data seems to be strong enough to overcome the order effect. Second, this study only includes 6 participants, a very small sample. Averaging the data over such a small sample may not be sufficient to show statistical effects. The collection of personality data for the dog and veteran relied on the veterans’ self-report, which must be interpreted with caution (Nisbett \& Wilson, 1977). Heart rate variability is often used to indicate chronic stress and may not be an accurate measure of acute stress responses (Billman, 2013). In addition to these methodological weaknesses, measuring stress is notoriously difficult. Although this study attempted control by using a simulated laboratory setting, several factors are difficult to control when live animals and humans are used.

\section{Future Recommendations}

Future studies should attempt to recruit a larger number of participants and eliminate confounds. Additional stress measures, such as blood pressure, skin conductance, and startle response, may better illustrate the acute stress response. Additionally, it would be worth confirming that the task is stressful for each individual participant prior to incorporating the treatment conditions. The use of self-report measures should be limited, and instead, an average of others' perspectives used to measure veteran and dog personality. Behavioral measures, such as the amount of time the veteran engages with the dog, could also add important information and/or inform the stress response. It would be interesting to conduct the same study with veterans 
that do not have a service dog as a control group to see if the presence of a dog impacts their stress response differently. 


\section{References}

Allen, K., Blascovich, J., \& Mendes, W. B. (2002). Cardiovascular reactivity and the presence of pets, friends, and spouses: The truth about cats and dogs. Psychosomatic medicine, 64(5), 727-739.

Allen, K. M., Blascovich, J., Tomaka, J., \& Kelsey, R. M. (1991). Presence of human friends and pet dogs as moderators of autonomic responses to stress in women. Journal of personality and social psychology, 61(4), 582.

Anderson, B. (2017). Employment Retention as a Remedy for Returning Veterans with Cognitive Impairment (Doctoral dissertation, Northcentral University).

Anderson, G (2018). Image from: https://bygeorgeanderson.com/heart-rate-variability/ on March 7, 2019.

Barker, S. B., Knisely, J. S., McCain, N. L., Schubert, C. M., \& Pandurangi, A. K. (2010). Exploratory study of stress-buffering response patterns from interaction with a therapy dog. Anthrozoös, 23(1), 79-91.

Barlow, D. H., \& Lehman, C. L. (1996). Advances in the psychosocial treatment of anxiety disorders: Implications for national health care. Archives of General Psychiatry, 53, 727735.

Batson, K., McCabe, B., Baun, M.M., \& Wilson, C. (1998). The effect of a therapy dog on socialization and physiological indicators of stress in persons diagnosed with Alzheimer's disease. Companion animals in human health, (pp. 203-215). Thousand Oaks, CA: SAGE Publications, Inc. doi: 10.4135/9781452232959.n13

Baun, M. M., Bergstrom, N., Langston, N. F., \& Thoma, L. (1984). Physiological effects of human/companion animal bonding. Nursing research, 33(3), 126-129. 
Benjamini, Y., \& Hochberg, Y. (1995). Controlling the False Discovery Rate: A Practical and Powerful Approach to Multiple Testing. Journal of the Royal Statistical Society. Series B (Methodological), 57(1), 289-300. Retrieved from http://www.jstor.org/stable/2346101, $8 / 24 / 2018$.

Billman, GE. (2013). The LF/HF ratio does not accurately measure cardiac sympatho-vagal balance.

Fredrickson, BL., Mancuso, RA., Branigan, C., Tugade, MM. (2000). The undoing effect of positive emotions.

Blenner, J. (1991). The therapeutic functions of companion animals in infertility. Holistic Nurs Pract, 5 (2), 6-10.

Bustamante, E.A. Spain, R.D. (September 2008). Measurement invariance of the NASA TLX. Proceedings of the Human Factors and Ergonomics Society Annual Meeting. 52 (19), 1522-1526. ㅁoi:10.1177/154193120805201946.

Burrows, K. E., Adams, C. L., \& Spiers, J. (2008). Sentinels of safety: Service dogs ensure safety and enhance freedom and well-being for families with autistic children. Qualitative health research, 18(12), 1642-1649.

Carmack, B. (1991). The role of companion animals for persons with AIDS/HIV. Holistic Nrus Pract, 5 (2), 24-31.

Collins, D. M., Fitzgerald, S. G., Sachs-Ericsson, N., Scherer, M., Cooper, R. A., \& Boninger, M. L. (2006). Psychosocial well-being and community participation of service dog partners. Disability and Rehabilitation: Assistive Technology, 1(1-2), 41-48.

Crawford, E. F., Elbogen, E. B., Wagner, H. R., Kudler, H., Calhoun, P. S., Brancu, M., \& Straits-Troster, K. A. (2015). Surveying treatment preferences in US Iraq-Afghanistan 
veterans with PTSD symptoms: A step toward veteran-centered care. Journal of Traumatic Stress, 28(2), 118-126.

Cromer, L. D., \& Barlow, M. R. (2013). Factors and convergent validity of the pet attachment and life impact scale (PALS). Human-animal interaction bulletin.

Crossman, M. K., Kazdin, A. E., \& Knudson, K. (2015). Brief unstructured interaction with a dog reduces distress. Anthrozoös, 28(4), 649-659.

Demello, L. R. (1999). The effect of the presence of a companion-animal on physiological changes following the termination of cognitive stressors. Psychology and Health, 14(5), 859-868.

El-Nokaly, Magda, Michael Lee Hilton, Kevin Lee Doyle, Daniel Raymond Schaiper, Abel Saud, and Diane Lynn Prickel. "Method and apparatus for measuring acute stress." U.S. Patent 7,213,600, issued May 8, 2007.

Flournoy, M. (2014) We aren’t doing enough to help veterans transition to civilian life. Retrieved from: http://www.washingtonpost.com/opinions/we-arent-doing-enough-tohelp-veterans-transition-to-civilian-life/2014/04/02/d43189e2-b52a-11e3-b89920667de76985_story.html. Accessed 2 Aug 2016).

Fredrickson, BL., Mancuso, RA., Branigan, C., Tugade, MM. (2000). The undoing effect of positive emotions.

Frey, R., Decker, K., Reinfried, L., Klösch, G., Saletu, B., Anderer, P., ... \& Laggner, A. N. (2002). Effect of rest on physicians’ performance in an emergency department, objectified by electroencephalographic analyses and psychometric tests. Critical care medicine, 30(10), 2322-2329. 
Friedmann, E., Thomas, S. A., Cook, L. K., Tsai, C. C., \& Picot, S. J. (2007). A friendly dog as potential moderator of cardiovascular response to speech in older hypertensives. Anthrozoös, 20(1), 51-63.

Friedman, E., Katcher, A., Lynch, J., \& Thomas, S. (1980). Animal companions and one-year survival of patients after discharge from a coronary care unit. Public Health Reports, 95(4), 307-312.

Friedmann, E., Locker, B. Z., \& Lockwood, R. (1993). Perception of animals and cardiovascular responses during verbalization with an animal present. Anthrozoös, 6(2), 115-134.

Fritz, C., Farver, T., Kass, P., \& Hart, L. (1995). Association with companion animals and the expression of noncognitive symptoms in Alzheimer's patients. The Journal of Nervous and Mental Disease, 183 (7).

Gaydos, L. S., \& Farnham, R. (1988). Human-animal relationships within the context of Rogers' principle of integrality. Advances in Nursing Science, 10(4), 72-80.

Gee, N. R., Friedmann, E., Stendahl, M., Fisk, A., \& Coglitore, V. (2014). Heart rate variability during a working memory task: Does touching a dog or person affect the response?. Anthrozoös, 27(4), 513-528.

Giles, D., N. Draper, and W. Neil (2016). Validity of the Polar V800 heart rate monitor to measure RR intervals at rest. European Journal of Applied Physiology, 116, 563-571.

Hamama, L., Hamama-Raz, Y., Dagan, K., Greenfeld, H., Rubinstein, C. \& Ben-Ezra, M. (2011). A preliminary study of group intervention along with basic canine training among traumatized teenagers: A 3-month longitudinal study. Children and Youth Services Review, 33, 1975-1980.

Harris, J. I., Strom, T. Q., Ferrier-Auerbach, A. G., Kaler, M. E., Hansen, L. P., \& Erbes, 
C. R. (2017). Workplace social support in job satisfaction among veterans with posttraumatic stress symptoms: A preliminary correlational study. PloS one, 12(8), e0181344.

Hart, S. G. (2006). NASA-Task Load Index (NASA-TLX): 20 Years Llater. Paper presented at the Human Factors and Ergonomics Society.

Hart, S. G., \& Staveland, L. E. (1988). Development of NASA-TLX (Task Load Index): Results of Empirical and Theoretical Research. In P. A. H. N. Meshkati (Ed.), Human Mental Workload. Amsterdam, The Netherlands: Elsevier North Holland.

Hofmann, S. G., \& Smits, J. A. J. (2008). Cognitive-behavioral therapy for adult anxiety disorders: A meta-analysis of randomized placebo-controlled trials. Journal of Clinical Psychiatry, 69, 621-632.

Kausar, R. (2010). Perceived Stress, Academic Workloads and Use of Coping Strategies by University Students. Journal of Behavioural Sciences, 20(1).

Keane, T. M., Fairbank, J. A., Caddell, J. M., Zimering, R. T., Taylor, K. L., \& Mora, C. A. (1989). Clinical evaluation of a measure to assess combat exposure. Psychological Assessment: A Journal of Consulting and Clinical Psychology, 1(1), 53-55. doi: 10.1037/1040-3590.1.1.53

Kemp, J., \& Bossarte, R. (2013). Suicide data report: 2012. Washington, DC: Department of Veterans Affairs, Mental Health Services, Suicide Prevention Program.

King, T., Marston, L. C., \& Bennett, P. C. (2012). Breeding dogs for beauty and behaviour: Why scientists need to do more to develop valid and reliable behaviour assessments for dogs kept as companions. Applied Animal Behaviour Science, 137(1-2), 1-12. 
Kleykamp, M. (2013). Unemployment, earnings and enrollment among post 9/11 veterans. Social Science Research,42(3), 836-851. doi:10.1016/j.ssresearch.2012.12.017

Lang, U., Jansen, J., Wertenauer, F., Gallinat, J., \& Rapp, M. (2010). Reduced anxiety during dog assisted interviews in acute schizophrenic patients. European Journal of Integrative Medicine, 2, 123-127.

Lass-Hennemann, J., Peyk, P., Streb, M., Holz, E., \& Michael, T. (2014). Presence of a dog reduces subjective but not physiological stress responses to an analog trauma. Frontiers in psychology, 5, 1010.

Levinson, B. M. (1962). The dog as a "co-therapist." Mental Hygiene. New York.

Ley, J. M., McGreevy, P., \& Bennett, P. C. (2009). Inter-rater and test-retest reliability of the Monash Canine Personality Questionnaire-Revised (MCPQ-R). Applied Animal Behaviour Science, 119(1-2), 85-90.

Lloyd, J. K. F. (2004). Exploring the match between people and their guide dogs: a thesis presented in fulfilment of the requirements for the degree of Doctor of Philosophy in Veterinary Science at Massey University, Turitea, Aotearoa/New Zealand (Doctoral dissertation, Massey University).

Marston, L. C., \& Bennett, P. C. (2003). Reforging the bond-towards successful canine adoption. Applied Animal Behaviour Science, 83(3), 227-245.

Mowry, R. L., Carnahan, S., \& Watson, D. (1994). Contributions of hearing assistance dogs to improving the independent living and rehabilitation of persons who are hearing impaired. In Project Final Technical Report No. H133B10001 (p. 77). National Institute for Disability and Rehabilitation Research. 
Mueller, M. K. (2014). The relationship between types of human-animal interaction and attitudes about animals: an exploratory study. Anthrozoös, 27(2), 295-308.

Nagengast, S. L., Baun, M. M., Megel, M., \& Leibowitz, J. M. (1997). The effects of the presence of a companion animal on physiological arousal and behavioral distress in children during a physical examination. Journal of Pediatric Nursing, 12(6), 323-330.

Nierenberg, A. A., Ostacher, M. J., Huffman, J. C., Ametrano, R. M., Fava, M., \& Perlis, R. H. (2008). A brief review of antidepressant efficacy, effectiveness, indications and usage for major depressive disorder. Journal of Occupational and Environmental Medicine, 50, 428-436.

Nisbett, R. E., \& Wilson, T. D. (1977). Telling more than we can know: Verbal reports on mental processes. Psychological Review, 84, 231-259.

Parenti, L., Foreman, A., Meade, B. J., \& Wirth, O. (2013). A revised taxonomy of assistance animals. Journal of rehabilitation research and development, 50(6), 745.

Payne, E., Bennett, P. C., \& McGreevy, P. D. (2015). Current perspectives on attachment and bonding in the dog-human dyad. Psychology research and behavior management, 8, 71.

Peer, J. E., \& Tenhula, W. (2016). Return to work in depression and anxiety. Handbook of Return to Work (pp. 633-652). Springer US.

Rosenheck, R. A. (2008). Posttraumatic stress disorder and employment in veterans participating in Veterans Health Administration Compensated Work Therapy. Journal of rehabilitation research and development, 45(3), 427.

Rudstam, H., Gower, W. S., \& Cook, L. (2012). Beyond yellow ribbons: Are employers prepared to hire, accomodate and retain returning veterans with disabilities? Journal of Vocational Rehabilitation, 36, 87-95. 
Savych B., Klerman J.A., Loughran D.S. (2008) Recent trends in veteran unemployment as measured in the current population survey and the American community survey. Retrieved from: http://www.rand.org/pubs/technical_reports/TR485.html.

Serpell, J. A. (1996). Evidence for an association between pet behavior and owner attachment levels. Applied Animal Behaviour Science, 47(1), 49-60.

Shaffer, F. \& Ginsberg, J.P. (2017). An overview of heart rate variability metrics and norms. Front. Public Health, 5: 258. https://doi.org/10.3389/fpubh.2017.00258. Accessed 3/8/2018.

Siniscalchi, M., Stipo, C., \& Quaranta, A. (2013). " Like Owner, Like Dog": Correlation between the Owner's Attachment Profile and the Owner-Dog Bond. PloS one, 8(10), e78455.

Skinner, H. A. (1982). The drug abuse screening test. Addictive behaviors, 7(4), 363-371.

Stern, L. (2017). Post 9/11 Veterans With Service-Connected Disabilities and their Transition to the Civilian Workforce: A Review of the Literature. Advances in Developing Human Resources, 19(1), 66-77.

Taelman, J., Vandeput, S., Spaepen, A., \& Van Huffel, S. (2009). Influence of mental stress on heart rate and heart rate variability. Paper presented at the 4th European conference of the international federation for medical and biological engineering.

Task Force of the European Society of Cardiology and the North American Society of Pacing and Electrophysiology (1996). Heart rate variability: Standards of measurement, physiological interpretation, and clinical use. European Heart Journal, 17, 354-381.

Templer, D. I., Salter, C. A., Dickey, S., Baldwin, R., \& Veleber, D. M. (1981). The construction of a pet attitude scale. The Psychological Record, 31(3), 343-348. 
Templer, D., Arikawa, H., Canfield, M., Munsell, K., \& Tangan, K. (2004). Modification of the pet attitude scale. Society \& Animals, 12(2), 137-142.

Todd-Schuelke, S., Trask, B., Wallace, C., Baun, M. M., Bergstrom. N. \& McCabe, B. (1992). Physiological effects of the use of a companion animal dog as a cue to relaxation in diagnosed hypertensives. http://www.deltasociety.org/AnimalsHealthAdultsPhysiological.htm.

Waghorn, G., Chant, D., White, P., \& Whiteford, H. (2005). Disability, employment and work performance among people with ICD-10 anxiety disorders. Australian and New Zealand Journal of Psychiatry, 39, 55-66.

Watson, D., Clark, L. A., \& Tellegen, A. (1988). Development and validation of brief measures of positive and negative affect: The PANAS scales. Journal of Personality and Social Psychology, 54(6), 1063-1070. doi: 10.1037/0022-3514.54.6.1063.

Weathers, F. W., Litz, B. T., Herman, D. S., Huska, J. A., \& Keane, T. M. (1993, October). The PTSD Checklist (PCL): Reliability, validity, and diagnostic utility. In annual convention of the international society for traumatic stress studies, San Antonio, TX (Vol. 462).

White, M. (2011). The human-animal bond and combat-related posttraumatic stress symptoms (Doctoral dissertation). Retrieved from: https://scholarworks.waldenu.edu/dissertations/1093/.

Wilson Learning (2004). The social styles handbook: Find your comfort zone and make people feel comfortable with you. Canada: Nova Vista Publishing.

WHOQoL Group. (1998). Development of the World Health Organization WHOQOLBREF quality of life assessment. Psychological medicine, 28(3), 551-558. 


\section{Chapter 5: Summary and Conclusions}

The incidence of veterans returning to society with PTSD and struggling to reintegrate is concerning. Post-traumatic stress disorder has been associated with functional problems among veterans (Zaztick et al., 1997) and has a significant impact on quality-of-life outcomes (Rapaport et al., 2005). Employment is an important area of reintegration for veterans (DoD, 2011) and may even be therapeutic (Keyklamp, 2013). However, veterans struggle to gain and keep employment due to troubling PTSD symptoms. Treatment options for PTSD are limited and there are many barriers to veterans seeking out and continuing treatment. Therefore, veterans are continuing to struggle to reintegrate into society, find jobs, and function socially.

The use of dogs as assistive technology for veterans with PTSD is becoming increasingly popular. Unfortunately, little is known about the availability of different types of assistance animals in the Unites States, there is no universally accepted classification system, and the evidence for the effectiveness of animals in the treatment of PTSD in veterans is inconsistent. Some of this inconsistency found in therapeutic effectiveness may be due to inappropriate matches between dog and veteran. This research suggests a novel classification system and taxonomy to clarify the various animal assisted interventions, conducted a laboratory study of the effect of a dogs' presence on veteran stress, and investigated the role of the individual characteristics of the veteran and dog on the therapeutic effects of the presence of the dog.

Evidence supporting its effectiveness is needed to increase acceptance and funding of service dogs for veterans (Krause-Parello, et al., 2016; McCune, Espositio, \& Griffin, 2017). A pre-requisite to expanding the empirical support for the use of service dogs in treatment of PTSD is a concise, clear, standardized taxonomy. The use of inconsistent terms to describe different types of treatment protocols using dogs has led to confusion in the field and has made 
comparison across research studies difficult, if not impossible (IAHAIO). Although others have attempted to remedy the confusing nomenclature (IAHAIO; Fine, 2015), no classification system has been universally accepted (McCune, Esposito, \& Griffin, 2017).

Dogs have been shown to provide stress-reducing benefits to a variety of populations using psychological, physiological, and behavioral indicators of stress. However, the research in this area is lacking methodological rigor, which has limited the acceptance of using animals as adjuncts for the treatment of PTSD and other psychological disorders. The laboratory study described here used an acceptable design and several outcome measures of stress to investigate the effect of a dog on veterans' stress responses. This study is limited by a small number of participants. Like other studies in this area, results were inconsistent and must be interpreted cautiously.

The disparity in findings here and in other studies may be due to individual differences in treatment effects. There are several potential moderating variables when considering service dog and client matching. The personality of the dog and handler separately, or in relation to each other, may impact the therapeutic benefit. For example, Hunt \& Chizkov (2014) found that more introverted participants seemed to benefit more from the presence of a dog than less introverted participants. This study is the first known to compare the interaction of dog and human social styles to outcomes of the presence of the dog. A correlation was found between the difference of human and dog assertiveness and a physiological stress indicator, HF, during the recovery phase. This preliminary finding suggests the need for more research into the social styles or personality characteristics of service dogs and their clients, their interaction, and their impact on the success of the service dog team. 


\section{Chapter 6: Recommendations}

As stated elsewhere, more methodologically rigorous research is needed to demonstrate the effectiveness of animals as a treatment modality or adjunct for veteran reintegration. This research should consider the individual differences between veterans and animals, and the impact the interaction of personality characteristics may have on the success of the team.

Future research should attempt to recruit a larger number of participants and have a control group of participants that do not receive the treatment component. The measurement of acute changes in stress is difficult, so it may be more useful to measure different outcomes of "success," such as medication usage or symptom reduction over a longer time period.

Future research could uncover individual differences in service dog-client teams by using single-subject research designs instead of averaging results across participants. This study was designed initially for a larger number of participants; however, recruitment was difficult, and time precluded the redesign of the study. Future studies could use a multiple baseline design, in which each participant receives the "treatment (the presence of the dog)" at different time points. This would allow researchers to be prepared for trends in the data before implementing the treatment. It would also permit researchers to see if the treatment itself coincides with changes in outcome (as opposed to changes occurring over time).

Research should also consider the mechanisms by which AAAs have therapeutic effects. A theoretical framework for AAAs would guide future research and uses (Geist, 2011) and help render AAAs a more legitimate area of scientific investigation (Geist, 2011). Several mechanisms have been theorized to explain the therapeutic benefits of animals. Proposed mechanisms fall into four theoretical categories: the biophilia hypothesis, cognitive theory, attachment theory, and learning theory. Levinson was the first to suggest that humans have an 
innate need to be around animals (Levinson, 1972). This has been referred to as "biophilia" by others and is not generally supported as a valid explanatory mechanism (Joy, 2011; Brickel, 1982). Although potentially true, the biophilia hypothesis seems too vague to explain why animals produce therapeutic effects in humans. Others have proposed that animals serve as social support for their humans (Lago, 1994), which has been shown to "buffer" the effects of stress (Cohen \& McKay, 1984); however, when compared to the presence of a spouse or friend, the presence of dogs have been shown to produce more relaxation during a stressful task (Allen et al., 1991). Another theory that animals help reverse distorted cognitions. For example, the use of AAAs may challenge a person's negative self-thoughts by promoting confidence and selfefficacy (Geist, 2011). Learning theory suggests that animals serve as positive stimuli, are associated with pleasure, and serve as distractions, thus allowing exposure to anxiety-producing stimulus instead of avoidance (Brickell, 1982). This may provide a useful framework for the use of animals as adjuncts in difficult therapies, such as CBT. Future research should consider these theoretical frameworks when designing investigations of AAAs. 


\section{Chapter 7: References}

Aasman, J., Mulder, G., \& Mulder, L. J. (1987). Operator effort and the measurement of heartrate variability. Human Factors, 29(2), 161-170.

Accessibility Standards for Customer Service, O. Reg 429/07 (Can.).

Adams K, Rice S. A brief information resource on assistance animals for the disabled. 2011 [cited 2012 May 15]; Available from: http:॥www.nal.usda.gov/awic/companimals/assist.htm.

Akselrod, S., Gordon, D., Ubel, F. A., Shannon, D. C., Berger, A. C., \& Cohen, R. J. (1981). Power spectrum analysis of heart rate fluctuation: a quantitative probe of beat-to-beat cardiovascular control. Science, 213(4504), 220-222.

Allen, K., Blascovich, J., \& Mendes, W. B. (2002). Cardiovascular reactivity and the presence of pets, friends, and spouses: The truth about cats and dogs. Psychosomatic Medicine, 64(5), 727-739.

Allen, K. M., Blascovich, J., Tomaka, J., \& Kelsey, R. M. (1991). Presence of human friends and pet dogs as moderators of autonomic responses to stress in women. Journal of Personality and Social Psychology, 61(4), 582.

Anderson, B. (2017). Employment Retention as a Remedy for Returning Veterans with Cognitive Impairment (Doctoral dissertation, Northcentral University).

Anderson, P.E. (2008). The Powerful Bond between People and Pets. Kuriansky J, editor. Westport, Connecticut: Praeger.

American Psychiatric Association. (2013). Diagnostic and statistical manual of mental disorders (DSM-5®). American Psychiatric Pub. 
American Psychological Association (2019). Prolonged exposure. Retrieved from https://www.apa.org/ptsd-guideline/treatments/prolonged-exposure, accessed March 7, 2019.

Americans with Disabilities Act of 1990, (2010). Stat. 42 U.S.C. § 12186 et seq.

Anderson, G. (2018). Image from: https://bygeorgeanderson.com/heart-rate-variability/ on March 7, 2019.

Arhant, C., Bubna-Littitz, H., Bartels, A., Futschik, A., \& Troxler, J. (2010). Behaviour of smaller and larger dogs: Effects of training methods, inconsistency of owner behaviour and level of engagement in activities with the dog. Applied Animal Behaviour Science, 123(3-4), 131-142.

Arkow, P. (2011). Animal-assisted Therapy and Activities: A Study, Resource Guide and Bibliography for the Use of Companion Animals in Selected Therapies. 10th ed. Stratford, NJ: self-published.

Asher, L., Blythe, S., Roberts, R., Toothill, L., Craigon, P. J., Evans, K. M., ... \& England, G. C. (2013). A standardized behavior test for potential guide dog puppies: Methods and association with subsequent success in guide dog training. Journal of Veterinary Behavior: Clinical Applications and Research, 8(6), 431-438.

Assistance Dogs International. 2012 [cited 2012 August 30]; Available from: http://www.assistancedogsinternational.org/standards/.

Backs, R. W., \& Seljos, K. A. (1994). Metabolic and cardiorespiratory measures of mental effort: the effects of level of difficulty in a working memory task. International journal of psychophysiology, 16(1), 57-68. 
Barker, S. B., Knisely, J. S., McCain, N. L., Schubert, C. M., \& Pandurangi, A. K. (2010). Exploratory study of stress-buffering response patterns from interaction with a therapy dog. Anthrozoös, 23(1), 79-91.

Barlow, D. H., \& Lehman, C. L. (1996). Advances in the psychosocial treatment of anxiety disorders: Implications for national health care. Archives of General Psychiatry, 53, 727735.

Batson, K., McCabe, B., Baun, M.M., \& Wilson, C. (1998). The effect of a therapy dog on socialization and physiological indicators of stress in persons diagnosed with Alzheimer's disease. Companion animals in human health, (pp. 203-215). Thousand Oaks, CA: SAGE Publications, Inc. doi: 10.4135/9781452232959.n13

Batt, L. S., Batt, M. S., Baguley, J. A., \& McGreevy, P. D. (2008). Factors associated with success in guide dog training. Journal of Veterinary Behavior: Clinical Applications and Research, 3(4), 143-151. doi: 10.1016/j.jveb.2008.04.003

Baughman, P., Foreman, A., Parenti, L., Scotti, J.R., Meade, B.J., Wilson, M. \& Wirth, O. (2015). APDT Research Spotlight: Project ROVER’s Survey of Assistance Dog Providers. Association of Professional Dog Trainers: The Chronicle of the Dog. Summer, 2015.

Baun, M. M., Bergstrom, N., Langston, N. F., \& Thoma, L. (1984). Physiological effects of human/companion animal bonding. Nursing Research, 33(3), 126-129.

Beck, A. M., \& Katcher, A. H. (1984). A new look at pet-facilitated therapy. Journal of the American Veterinary Medical Association, 184(4), 414.

Bedi, U. S., \& Arora, R. (2007). Cardiovascular manifestations of posttraumatic stress disorder. Journal of the National Medical Association, 99(6), 642. 
Benjamini, Y., \& Hochberg, Y. (1995). Controlling the False Discovery Rate: A Practical and Powerful Approach to Multiple Testing. Journal of the Royal Statistical Society. Series B (Methodological), 57(1), 289-300. Retrieved from http://www.jstor.org/stable/2346101, $8 / 24 / 2018$.

Bergin B. (1998). The Smartest Dog: The Selection, Training and Placement of Service Dogs. Santa Rosa, CA: The Assistance Dog Institute.

Billman, G. E. (2013). The LF/HF ratio does not accurately measure cardiac sympatho-vagal balance. Frontiers in Physiology, 4, 26.

Blenner, J. (1991). The therapeutic functions of companion animals in infertility. Holistic Nurs Pract, 5 (2), 6-10.

Blind and Other Physically Disabled Persons, Stat. Cal. Ann. Civ. Code § 54.25 (2010).

Brickel, C. M. (1982). Pet-facilitated psychotherapy: A theoretical explanation via attention shifts. Psychological Reports, 50(1), 71-74.

Brookings, J. B., Wilson, G. F., \& Swain, C. R. (1996). Psychophysiological responses to changes in workload during simulated air traffic control. Biological Psychology, 42(3), $361-377$.

Bustamante, E.A. Spain, R.D. (September 2008). Measurement invariance of the NASA TLX. Proceedings of the Human Factors and Ergonomics Society Annual Meeting. 52 (19), 1522-1526. 미:10.1177/154193120805201946.

Burrows, K. E., Adams, C. L., \& Millman, S. T. (2008). Factors affecting behavior and welfare of service dogs for children with autism spectrum disorder. Journal of Applied Animal Welfare Science, 11(1), 42-62. 
Burrows, K. E., Adams, C. L., \& Spiers, J. (2008). Sentinels of safety: Service dogs ensure safety and enhance freedom and well-being for families with autistic children. Qualitative Health Research, 18(12), 1642-1649.

Byrne, D., Griffitt, W., \& Stefaniak, D. (1967). Attraction and similarity of personality characteristics. Journal of Personality and Social Psychology, 5(1), 82.

Cain AO. (1991). Pets and the family. Holistic Nursing Practice, Jan;5(2):58-63.

Campbell, M. L., Gorka, S. M., McGowan, S. K., Nelson, B. D., Sarapas, C., Katz, A. C., ... \& Shankman, S. A. (2014). Does anxiety sensitivity correlate with startle habituation? An examination in two independent samples. Cognition \& Emotion, 28(1), 46-58.

Carafano, J. J., \& Hutchinson, M. (2017). Service Dog Solutions: Next Steps in Federal Support for Veterans with PTSD. The Heritage Foundtaion: The Backgrounder, 3125. Retrieved from https://www.heritage.org/sites/default/files/2017-05/BG3125.pdf on February 2, 2019.

Carmack, B. (1991). The role of companion animals for persons with AIDS/HIV. Holistic Nursing Practice, 5 (2), 24-31.

Carson, M. A., Metzger, L. J., Lasko, N. B., Paulus, L. A., Morse, A. E., Pitman, R. K., \& Orr, S. P. (2007). Physiologic reactivity to startling tones in female Vietnam nurse veterans with PTSD. Journal of Traumatic Stress, 20(5), 657-666.

Cavanaugh, L. A., Leonard, H. A., \& Scammon, D. L. (2008). A tail of two personalities: How canine companions shape relationships and well-being. Journal of Business Research, 61(5), 469-479. 
Chan, D., Cheadle, A., Reiber, G., Unützer, J., \& Chaney, E. (2009). Health care utilization and its costs for depressed veterans with and without comorbid PTSD symptoms. Psychiatric Services, 60(12), 1612-1617.

Chida, Y., \& Steptoe, A. (2010). Greater cardiovascular responses to laboratory mental stress are associated with poor subsequent cardiovascular risk status: a meta-analysis of prospective evidence. Hypertension, 55(4), 1026-1032.

Chumley, P.R. Chief, Human Animal Bond programs, DOD Veterinary Service Activity, Office of the Surgeon General. October 12, 2012.

Chumley, P.R. (2012). Historical perspectives of the human-animal bond within the department of defense. The United States Army Medical Department Journal,18-20.

Citizens Commission on Human Rights International, “A Review of How Prescribed Psychiatric Medications Could Be Driving Members of the Armed Forces and Vets to Acts of Violence \& Suicide,” April 2014, https://www.veterans.senate.gov/imo/media/doc/For\%20the\%20 Record\%20-\%20CCHR\%204.30.14.pdf (accessed March 15, 2017).

Clark, G. I., \& Boyer, W. N. (1993). The effects of dog obedience training and behavioural counselling upon the human-canine relationship. Applied Animal Behaviour Science, 37(2), 147-159.

Cohen, S., Kessler, R. C., \& Gordon, L. U. (1995). Strategies for measuring stress in studies of psychiatric and physical disorders. Measuring stress: A guide for health and social scientists, 3-26.

Cohen, S., \& McKay, G. (1984). Social support, stress and the buffering hypothesis: A theoretical analysis. Handbook of Psychology and Health, 4, 253-267. 
Cole, K.M., et al. (2007). Animal-assisted therapy in patients hospitalized with heart failure. American Journal of Critical Care, 16(6), 575.

Collet, C., Clarion, A., Morel, M., Chapon, A., \& Petit, C. (2009). Physiological and behavioural changes associated to the management of secondary tasks while driving. Applied Ergonomics, 40(6), 1041-1046.

Collins, D. M., Fitzgerald, S. G., Sachs-Ericsson, N., Scherer, M., Cooper, R. A., \& Boninger, M. L. (2006). Psychosocial well-being and community participation of service dog partners. Disability and Rehabilitation: Assistive Technology, 1(1-2), 41-48.

Coppinger, R., \& Coppinger, L. (2001). Dogs: A startling new understanding of canine origin, behavior \& evolution. New York: Simon and Schuster.

Corson SA, Corson EO, Gwynne PH, Arnold LE. (1975). Pet-facilitated psychotherapy in a hospital setting. Current Psychiatric Therapies, 15:277-86.

Crawford, E. F., Elbogen, E. B., Wagner, H. R., Kudler, H., Calhoun, P. S., Brancu, M., \& Straits-Troster, K. A. (2015). Surveying treatment preferences in US Iraq-Afghanistan veterans with PTSD symptoms: A step toward veteran-centered care. Journal of Traumatic Stress, 28(2), 118-126.

Cromer, L. D., \& Barlow, M. R. (2013). Factors and convergent validity of the pet attachment and life impact scale (PALS). Human-Animal Interaction Bulletin, 9(2), 34-56.

Crossman, M. K., Kazdin, A. E., \& Knudson, K. (2015). Brief unstructured interaction with a dog reduces distress. Anthrozoös, 28(4), 649-659.

Crowe, T. K., Sanchez, V., Howard, A., Western, B., \& Barger, S. (2018). Veterans transitioning from isolation to integration: a look at veteran/service dog partnerships. Disability and Rehabilitation, 40(24), 2953-2961. 
Cunningham, C. L., \& Ramos, M. F. (2014). Effect of training and familiarity on responsiveness to human cues in domestic dogs (Canis familiaris). Animal Cognition, 17(3), 805-814.

Curb, L. A., Abramson, C. I., Grice, J. W., \& Kennison, S. M. (2013). The relationship between personality match and pet satisfaction among dog owners. Anthrozoös, 26(3), 395-404.

Cusak O. (1988). Pets and Mental Health. New York: The Haworth Press.

Dalibard, G. H. (2009). Parameters influencing service dogs' quality of response to commands: Retrospective study of 71 dogs. Journal of Veterinary Behavior, 4(1), 19-24.

Davis, K.D. (2002). Therapy dogs: Training your dog to reach others. 2nd ed. Wenatchee, WA: Dogwise.

Delta Society. (n.d.). About animal-assisted activities \& animal-assisted therapy. Available at http://www.deltasociety org/aboutaaat.htm.

Demello, L. R. (1999). The effect of the presence of a companion-animal on physiological changes following the termination of cognitive stressors. Psychology and Health, 14(5), 859-868.

Department of Defense (2011). Yellow Ribbon Program. Retrieved from http://www.yellowribbon.mil, March 7, 2019.

DeShriver, M.M. \& Riddick, C.C. (1990). Effects of watching acquariums on elders' stress. Anthrozoos, 4(1), 44.

Dilley, S. (2011). Admit my guide dog, says blind journalist Sean Dilley. BBC News.

Disability Discrimination Act 1992 (Cth) s 9 (Austl.).

Dog Control Amendment Act 2006 s 2 (N.Z.).

Duncan, S.L. (2000). APIC State-of-the-Art Report: The implications of service animals in health care settings. American Journal of Infection Control, 28(2), 170-80. 
El-Nokaly, Magda, Michael Lee Hilton, Kevin Lee Doyle, Daniel Raymond Schaiper, Abel Saud, and Diane Lynn Prickel. (2007). Method and apparatus for measuring acute stress. U.S. Patent 7,213,600, issued May 8, 2007.

Ensminger, J.J. (2010). Service and therapy dogs in american society: Science, law and the evolution of canine caregivers. Springfield, IL: Charles C. Thomas.

Esnayra, J., \& Love, C. (2008). A survey of mental health patients utilizing psychiatric service dogs. Retrieved November, 15, 2009 from http://www.psychdog.org/

Evans, G. W., \& Johnson, D. (2000). Stress and open-office noise. Journal of Applied Psychology, 85(5), 779.

Ewing, S. A., Lay, D. C., \& Von Borell, E. (1999). Farm animal well-being: stress physiology, animal behavior, and environmental design. Prentice Hall.

Federal Emergency Management Agency. Disaster Search Canine Readiness Evaluation Process. Retrieved September 11, 2012 from http://leerburg.com/pdf/crep_bdy.pdf: Federal Emergency Management Agency; 1999.

Feldman, P. J., Cohen, S., Lepore, S. J., Matthews, K. A., Kamarck, T. W., \& Marsland, A. L. (1999). Negative emotions and acute physiological responses to stress. Annals of Behavioral Medicine, 21(3), 216-222.

Fine, A.H. (ed.) (2010). Handbook on Animal-Assisted Therapy: Theoretical Foundations and Guidelines for Practice. ( ${ }^{\text {rd }}$ ed.). San Diego, CA: Elsevier.

Flournoy, M. (2014) We aren’t doing enough to help veterans transition to civilian life. Retrieved from: http://www.washingtonpost.com/opinions/we-arent-doing-enough-tohelp-veterans-transition-to-civilian-life/2014/04/02/d43189e2-b52a-11e3-b89920667de76985_story.html. Accessed 2 Aug 2016. 
Foa, E. B., Davidson, J. R., Frances, A. E., Culpepper, L. E., Ross, R. E., \& Ross, D. E. (1999). The expert consensus guideline series: treatment of posttraumatic stress disorder. The Journal of Clinical Psychiatry, 66 (Supplement 16), 1-76.

Foreman, A., Parenti, L., Wilson, M., Wirth, O., \& Meade, B.J. (2015). Selecting Quality Service Dogs (Part 2): Temperament Characteristics. Association of Professional Dog Trainers: The Chronicle of the Dog. Winter.

Fredrickson, B. L., Mancuso, R. A., Branigan, C., \& Tugade, M. M. (2000). The undoing effect of positive emotions. Motivation and Emotion, 24(4), 237-258.

Frey, R., Decker, K., Reinfried, L., Klösch, G., Saletu, B., Anderer, P., ... \& Laggner, A. N. (2002). Effect of rest on physicians’ performance in an emergency department, objectified by electroencephalographic analyses and psychometric tests. Critical care medicine, 30(10), 2322-2329.

Friedmann, E., Thomas, S. A., Cook, L. K., Tsai, C. C., \& Picot, S. J. (2007). A friendly dog as potential moderator of cardiovascular response to speech in older hypertensives. Anthrozoös, 20(1), 51-63.

Friedman, E., Katcher, A., Lynch, J., \& Thomas, S. (1980). Animal companions and one-year survival of patients after discharge from a coronary care unit. Public Health Reports, 95(4), 307-312.

Friedmann, E., Locker, B. Z., \& Lockwood, R. (1993). Perception of animals and cardiovascular responses during verbalization with an animal present. Anthrozoös, 6(2), 115-134.

Fritz, C., Farver, T., Kass, P., \& Hart, L. (1995). Association with companion animals and the expression of noncognitive symptoms in Alzheimer’s patients. The Journal of Nervous and Mental Disease, 183 (7). 
Garde, A., Laursen, B., Jørgensen, A., \& Jensen, B. (2002). Effects of mental and physical demands on heart rate variability during computer work. European Journal of Applied Physiology, 87(4-5), 456-461.

Gaydos, L. S., \& Farnham, R. (1988). Human-animal relationships within the context of Rogers' principle of integrality. Advances in Nursing Science, 10(4), 72-80.

Gee, N. R., Friedmann, E., Stendahl, M., Fisk, A., \& Coglitore, V. (2014). Heart rate variability during a working memory task: Does touching a dog or person affect the response?. Anthrozoös, 27(4), 513-528.

Geist, T. S. (2011). Conceptual framework for animal assisted therapy. Child and Adolescent Social Work Journal, 28(3), 243.

Giles, D., N. Draper, and W. Neil (2016). Validity of the Polar V800 heart rate monitor to measure RR intervals at rest. European Journal of Applied Physiology, 116, 563-571.

González-Muñoz, E. L., \& Gutiérrez-Martínez, R. E. (2007). Contribution of mental workload to job stress in industrial workers. Work (Reading, Mass.), 28(4), 355-361.

Greb J. (2012). Scientific working group on dog and orthogonal detector guidelines. [September 12, 2012]; Available from: http://www.swgdog.org/.

Grossberg, J.M. \& Alf, E.F. (1985). Interaction with pet dogs: Effects on human cardiovascular response. Journal of the Delta Society, 20.

Guide Animal Act, R.S.B.C. 1996, C 177 (Can.)

Hamama, L., Hamama-Raz, Y., Dagan, K., Greenfeld, H., Rubinstein, C. \& Ben-Ezra, M. (2011). A preliminary study of group intervention along with basic canine training among traumatized teenagers: A 3-month longitudinal study. Children and Youth Services Review, 33, 1975-1980. 
Handlin, L., Nilsson, A., Ejdebäck, M., Hydbring-Sandberg, E., \& Uvnäs-Moberg, K. (2012). Associations between the psychological characteristics of the human-dog relationship and oxytocin and cortisol levels. Anthrozoös, 25(2), 215-228.

Hansen, K.M., Messinger, C.J., Baun, M.M. \& Megel, M. (1999). Companion animals alleviating distress in children. Anthrozoos, 12(3), 142.

Harris, J. I., Strom, T. Q., Ferrier-Auerbach, A. G., Kaler, M. E., Hansen, L. P., \& Erbes, C. R. (2017). Workplace social support in job satisfaction among veterans with posttraumatic stress symptoms: A preliminary correlational study. PloS one, 12(8), e0181344.

Hart, S. G. (2006). NASA-Task Load Index (NASA-TLX): 20 Years Llater. Paper presented at the Human Factors and Ergonomics Society.

Hart, S. G., \& Staveland, L. E. (1988). Development of NASA-TLX (Task Load Index): Results of Empirical and Theoretical Research. In P. A. H. N. Meshkati (Ed.), Human Mental Workload. Amsterdam, The Netherlands: Elsevier North Holland.

Hearing Ear Dogs, Guide Dogs, Service Dogs, and Search and Rescue Dogs, Stat. N. H. Rev. Stat. Ann. § 167-D:3 (1996).

Hennessy, M. B., Williams, M. T., Miller, D. D., Douglas, C. W., \& Voith, V. L. (1998). Influence of male and female petters on plasma cortisol and behaviour: can human interaction reduce the stress of dogs in a public animal shelter? Applied Animal Behaviour Science, 61(1), 63-77.

Hjortskov, N., Rissén, D., Blangsted, A. K., Fallentin, N., Lundberg, U., \& Søgaard, K. (2004). The effect of mental stress on heart rate variability and blood pressure during computer work. European Journal of Applied Physiology, 92(1-2), 84-89. 
Hofmann, S. G., \& Smits, J. A. J. (2008). Cognitive-behavioral therapy for adult anxiety disorders: A meta-analysis of randomized placebo-controlled trials. Journal of Clinical Psychiatry, 69, 621-632.

Hoge, C. W., Terhakopian, A., Castro, C. A., Messer, S. C., \& Engel, C. C. (2007). Association of posttraumatic stress disorder with somatic symptoms, health care visits, and absenteeism among Iraq war veterans. American Journal of Psychiatry, 164(1), 150-153.

Horn, L., Range, F., \& Huber, L. (2013). Dogs' attention towards humans depends on their relationship, not only on social familiarity. Animal Cognition, 16(3), 435-443.

Hoshikawa, Y., \& Yamamoto, Y. O. S. H. I. H. A. R. U. (1997). Effects of Stroop color-word conflict test on the autonomic nervous system responses. American Journal of Physiology-Heart and Circulatory Physiology, 272(3), H1113-H1121.

Hoummady, S., Péron, F., Grandjean, D., Cléro, D., Bernard, B., Titeux, E., ... \& Gilbert, C. (2016). Relationships between personality of human-dog dyads and performances in working tasks. Applied Animal Behaviour Science, 177, 42-51.

Hunt, M. G., \& Chizkov, R. R. (2014). Are therapy dogs like Xanax? Does animal-assisted therapy impact processes relevant to cognitive behavioral psychotherapy?. Anthrozoös, 27(3), 457-469.

Hyde, J. N. (2015). Service Dogs: An exploratory pilot study of a complementary approach to evidence-based treatment of PTSD in Combat Veterans of the Iraq and Afghanistan Wars (Doctoral dissertation, Adler School of Professional Psychology).

International Association of Human-Animal Interaction Organizations (IAHAIO). (2013). The IAHAIO definitions for animal-assisted intervention and animal-assisted activity and guidelines for wellness of animals involved. Retrieved October 18, 2016, from 
http://www.iahaio.org/new/fileuploads/

8000IAHAIO\%20WHITE\%20PAPER\%20TASK\%20FORCE \%20-

\%20FINAL\%20REPORT\%20-\%20070714.pdf.

Jovanovic, T., Norrholm, S. D., Fennell, J. E., Keyes, M., Fiallos, A. M., Myers, K. M., ... \&

Duncan, E. J. (2009). Posttraumatic stress disorder may be associated with impaired fear inhibition: relation to symptom severity. Psychiatry Research, 167(1-2), 151-160.

Joye, Y. (2011). Biophilia in Animal-Assisted Interventions—Fad or Fact?. Anthrozoös, 24(1), $5-15$.

Kaminski, J., \& Marshall-Pescini, S. (2014). The social dog: behavior and cognition. Elsevier.

Kausar, R. (2010). Perceived Stress, Academic Workloads and Use of Coping Strategies by University Students. Journal of Behavioural Sciences, 20(1).

Keane, T. M., Fairbank, J. A., Caddell, J. M., Zimering, R. T., Taylor, K. L., \& Mora, C. A. (1989). Clinical evaluation of a measure to assess combat exposure. Psychological Assessment: A Journal of Consulting and Clinical Psychology, 1(1), 53-55. doi: 10.1037/1040-3590.1.1.53

Kegel, A. (2016). Service dogs for the mind: Psychiatric service dogs for the treatment of posttraumatic stress disorder and alcohol use in veterans: A quantitative study (Doctoral dissertation, The Wright Institute).

Kemp, J., \& Bossarte, R. (2013). Suicide data report: 2012. Washington, DC: Department of Veterans Affairs, Mental Health Services, Suicide Prevention Program.

Kidd, T., Carvalho, L. A., \& Steptoe, A. (2014). The relationship between cortisol responses to laboratory stress and cortisol profiles in daily life. Biological Psychology, 99, 34-40. 
King, T., Marston, L. C., \& Bennett, P. C. (2012). Breeding dogs for beauty and behaviour: Why scientists need to do more to develop valid and reliable behaviour assessments for dogs kept as companions. Applied Animal Behaviour Science, 137(1-2), 1-12.

Kirton, A., Winter, A., Wirrell, E., Snead, O.C. (2008). Seizure response dogs: Evaluation of a formal training program. Epilepsy \& Behavior;13(3):499-504.

Kis, A., Turcsán, B., Miklósi, Á., \& Gácsi, M. (2012). The effect of the owner’s personality on the behaviour of owner-dog dyads. Interaction Studies, 13(3), 373-385.

Kleiger, R. E., Stein, P. K., \& Bigger Jr, J. T. (2005). Heart rate variability: measurement and clinical utility. Annals of Noninvasive Electrocardiology, 10(1), 88-101.

Kleykamp, M. (2013). Unemployment, earnings and enrollment among post 9/11 veterans. Social Science Research,42(3), 836-851. doi:10.1016/j.ssresearch.2012.12.017.

Kloep M.L.: The Effect of Psychiatric Service Dogs for PTSD Symptom Amelioration in Military Veterans [dissertation]. Southern Illinois University Carbondale, 2016.

Kloep, M. L., Hunter, R. H., \& Kertz, S. J. (2017). Examining the effects of a novel training program and use of psychiatric service dogs for military-related PTSD and associated symptoms. American Journal of Orthopsychiatry, 87(4), 425.

Koda, N., Shimoju, S. (2008). Public knowledge of and attitudes toward accessibility of assistance dogs for physically impaired people in Japan. Asian Journal of Disable Sociology, 7:74-85.

Kotrschal, K., Schöberl, I., Bauer, B., Thibeaut, A. M., \& Wedl, M. (2009). Dyadic relationships and operational performance of male and female owners and their male dogs. Behavioural Processes, 81(3), 383-391. 
Krause-Parello, C. A., Sarni, S., \& Padden, E. (2016). Military veterans and canine assistance for post-traumatic stress disorder: A narrative review of the literature. Nurse Education Today, 47, 43-50.

Kristal-Boneh, E., Melamed, S., Harari, G., \& Green, M. S. (1995). Acute and chronic effects of noise exposure on blood pressure and heart rate among industrial employees: the Cordis Study. Archives of Environmental Health: An International Journal, 50(4), 298-304.

Kruger, K. A., \& Serpell, J. A. (2010). Animal-assisted interventions in mental health: Definitions and theoretical foundations. In Handbook on animal-assisted therapy (pp. 3348). Academic Press.

Lago, D. (1994). Conceptual frameworks for human-animal bond research-a commentary. Anthrozoos, 7(1), 14-18.

Lang, U., Jansen, J., Wertenauer, F., Gallinat, J., \& Rapp, M. (2010). Reduced anxiety during dog assisted interviews in acute schizophrenic patients. European Journal of Integrative Medicine, 2, 123-127.

LaJoie, K. R. (2003). An evaluation of the effectiveness of using animals in therapy. Dissertation. UMI No. 3077675

LaRocco, J. M., House, J. S., \& French Jr, J. R. (1980). Social support, occupational stress, and health. Journal of Health and Social Behavior, 202-218.

Lass-Hennemann, J., Peyk, P., Streb, M., Holz, E., \& Michael, T. (2014). Presence of a dog reduces subjective but not physiological stress responses to an analog trauma. Frontiers in Psychology, 5, 1010. 
Lefebvre, S. L., \& Ellis, R. V. (2018). Reigning Cats and Dogs: Perks and Perils of Our Courtship with Companion Animals. Beyond One Health: From Recognition to Results, $197-244$.

Leveck, M. L., \& Jones, C. B. (1996). The nursing practice environment, staff retention, and quality of care. Research in Nursing \& Health, 19(4), 331-343.

Levinson, B. M. (1962). The dog as a "co-therapist." Mental Hygiene. New York.

Levinson, Borris M. (1972). Pets and Human Development, Springfield, IL: Charles C Thomas.

Ley, J. M., McGreevy, P., \& Bennett, P. C. (2009). Inter-rater and test-retest reliability of the Monash Canine Personality Questionnaire-Revised (MCPQ-R). Applied Animal Behaviour Science, 119(1-2), 85-90.

Liao, W., Zhang, W., Zhu, Z., \& Ji, Q. (2005, June). A real-time human stress monitoring system using dynamic Bayesian network. In 2005 IEEE Computer Society Conference on Computer Vision and Pattern Recognition (CVPR'05)-Workshops (pp. 70-70). IEEE.

Livestock Disease Control (2002). Stat. Mass. Stat. § 129-39F.

Lloyd, J. K. F. (2004). Exploring the match between people and their guide dogs: a thesis presented in fulfilment of the requirements for the degree of Doctor of Philosophy in Veterinary Science at Massey University, Turitea, Aotearoa/New Zealand (Doctoral dissertation, Massey University).

Lykourentzou, I., Antoniou, A., Naudet, Y., \& Dow, S. P. (2016, February). Personality matters: Balancing for personality types leads to better outcomes for crowd teams. In Proceedings of the 19th ACM Conference on Computer-Supported Cooperative Work \& Social Computing (pp. 260-273). ACM. 
Malliani, A., Pagani, M., Montano, N., \& Mela, G. S. (1998). Sympathovagal balance: a reappraisal. Circulation.

Manuck, S. B. (1994). Cardiovascular reactivity in cardiovascular disease:“Once more unto the breach”. International Journal of Behavioral Medicine, 1(1), 4-31.

Marston, L. C., \& Bennett, P. C. (2003). Reforging the bond-towards successful canine adoption. Applied Animal Behaviour Science, 83(3), 227-245.

Mason, M.S., Hagan, C.B. (1999). Pet-assisted psychotherapy. Psychological Reports, 84(3):1235-45.

Mass. Gen. Laws, Stat. $129 \S 39 F(2002)$.

McCune, S., Esposito, L., \& Griffin, J. A. (2017). Introduction to a thematic series on animal assisted interventions in special populations. Appl. Dev. Sci., 21 (2), 136-138.

Miele, S. (2016). Animal-Assisted Therapy for Military Veterans with Posttraumatic Stress Disorder: An Investigation on the Positive Effects of Attachment and Affiliation Behaviors. Poster Presentation, Dominican University of California.

Mills, J.T. $3^{\text {rd }} \&$ Yeager, A.F. (2012). Definitions of animals used in healthcare settings. US Army Med Dep J., 12-17.

Montano, N., Ruscone, T. G., Porta, A., Lombardi, F., Pagani, M., \& Malliani, A. (1994). Power spectrum analysis of heart rate variability to assess the changes in sympathovagal balance during graded orthostatic tilt. Circulation, 90(4), 1826-1831.

Mowry, R. L., Carnahan, S., \& Watson, D. (1994). Contributions of hearing assistance dogs to improving the independent living and rehabilitation of persons who are hearing impaired. In Project Final Technical Report No. H133B10001 (p. 77). National Institute for Disability and Rehabilitation Research. 
Mueller, M. K. (2014). The relationship between types of human-animal interaction and attitudes about animals: an exploratory study. Anthrozoös, 27(2), 295-308.

Myrtek, M., Aschenbrenner, E., \& Brügner, G. (2005). Emotions in everyday life: an ambulatory monitoring study with female students. Biological Psychology, 68(3), 237-255.

Naderi, S., Miklosi, A., Doka, A. \& Csanyi, V. (2001). Cooperative interactions between blind persons and their dogs. Applied Animal Behavior Science, 74 (1), pg. 59-80

Naderi, S., Miklósi, Á., Dóka, A., \& et al. (2002). Does dog-human attachment affect their interspecific cooperation. Acta Biologica Hungarica, 53(4), 537-550.

Nagengast, S. L., Baun, M. M., Megel, M., \& Leibowitz, J. M. (1997). The effects of the presence of a companion animal on physiological arousal and behavioral distress in children during a physical examination. Journal of Pediatric Nursing, 12(6), 323-330.

Nicholson, J., Kemp-Wheeler, S., \& Griffiths, D. (1995). Distress arising from the end of a guide dog partnership. Anthrozoös, 8(2), 100-110.

Nierenberg, A. A., Ostacher, M. J., Huffman, J. C., Ametrano, R. M., Fava, M., \& Perlis, R. H. (2008). A brief review of antidepressant efficacy, effectiveness, indications and usage for major depressive disorder. Journal of Occupational and Environmental Medicine, 50, 428-436.

Nisbett, R. E., \& Wilson, T. D. (1977). Telling more than we can know: Verbal reports on mental processes. Psychological Review, 84, 231-259.

Nondiscrimination on the Basis of Disability in State and Local Government Services (2011), Stat. 28 C.F.R Part 35, Appendix A.

Nondiscrimination on the Basis of Disability in Air Travel, Stat. 14 C.F.R. pt. 382 (2003). 
O'Farrell, V. (1997). Owner attitudes and dog behaviour problems. Applied Animal Behaviour Science, 52(3-4), 205-213.

O'Haire, M. E., Guérin, N. A., \& Kirkham, A. C. (2015). Animal-assisted intervention for trauma: A systematic literature review. Frontiers in Psychology, 6, 1121.

O'Haire, M. E., \& Rodriguez, K. E. (2018). Preliminary efficacy of service dogs as a complementary treatment for posttraumatic stress disorder in military members and veterans. Journal of Consulting and Clinical Psychology, 86(2), 179.

Orr, S. P., Lasko, N. B., Shalev, A. Y., \& Pitman, R. K. (1995). Physiologic responses to loud tones in Vietnam veterans with posttraumatic stress disorder. Journal of Abnormal Psychology, 104(1), 75.

Owen, R. P., Finton, B. J., Gibbons, S. W., \& DeLeon, P. H. (2016). Canine-assisted adjunct therapy in the military: An intriguing alternative modality. The Journal for Nurse Practitioners, 12(2), 95-101.

Parenti, L., Foreman, A., Meade, B. J., \& Wirth, O. (2013). A revised taxonomy of assistance animals. Journal of rehabilitation research and development, 50(6), 745.

Parenti, L., Foreman, A., Meade, B.J., Wirth, O., Wilson, M. (2015). Selecting

Quality Service Dogs (Part 1): Morphological and Health Considerations. Association of Professional Dog Trainers: The Chronicle of the Dog.

Parenti, L., Foreman, A., Wilson, M., Wirth, O., \& Meade, B.J. (2016). Selecting Quality Service Dogs (Part 3): Recommendations. Association of Professional Dog Trainers: The Chronicle of the Dog. Spring, 2016.

Payne, E., Bennett, P. C., \& McGreevy, P. D. (2015). Current perspectives on attachment and bonding in the dog-human dyad. Psychology Research and Behavior Management, 8, 71. 
Peer, J. E., \& Tenhula, W. (2016). Return to work in depression and anxiety. Handbook of Return to Work (pp. 633-652). Springer US.

Perry, C. M., Sheik-Nainar, M. A., Segall, N., Ma, R., \& Kaber, D. B. (2008). Effects of physical workload on cognitive task performance and situation awareness. Theoretical Issues in Ergonomics Science, 9(2), 95-113.

Pet Ownership for the Elderly and Persons With Disabilities. Fed Regist 2008;70:63834.

Pet Partners. 2012 [cited 2012 June 10]; Available from:

http://www.deltasociety.org/page.aspx?pid=183.

Physically Disabled Persons, Stat. Kan. Ann. Stat. § 39-1110 (2003).

Podberscek, A. L., \& Serpell, J. A. (1997). Aggressive behaviour in English cocker spaniels and the personality of their owners. Veterinary Record, 141(3), 73-76.

Pomeranz, B., Macaulay, R. J., Caudill, M. A., Kutz, I., Adam, D., Gordon, D. A. V. I. D., ... \& Cohen, R. J. (1985). Assessment of autonomic function in humans by heart rate spectral analysis. American Journal of Physiology-Heart and Circulatory Physiology, 248(1), H151-H153.

Prato-Previde, E., Fallani, G., \& Valsecchi, P. (2006). Gender differences in owners interacting with pet dogs: an observational study. Ethology, 112(1), 64-73.

Prigerson, H. G., Maciejewski, P. K., \& Rosenheck, R. A. (2002). Population attributable fractions of psychiatric disorders and behavioral outcomes associated with combat exposure among US men. American Journal of Public Health, 92(1), 59-63.

Radloff, L. S. (1977). The CES-D scale: A self-report depression scale for research in the general population. Applied Psychological Measurement, 1(3), 385-401

Rapaport, M.H., Clary, C., Fayyad, R., et al. (2005). Quality-of-life impairment in depressive 
and anxiety disorders. American Journal of Psychiatry, 162:1171-1178.

Rights of Blind and Physically Disabled Persons (2012). Stat. D.C. Code Ann. § 7-1009.

Ritchie, E. C., Chumley, P. R., Olmert, M. D., Yount, R. A., Laurent, M. S., \& Rumayor, C. (2016). Canines as assistive therapy for treatment of PTSD. Complementary and Alternative Medicine for PTSD, 165.

Robazza, C., Bortoli, L., \& Nougier, V. (1998). Physiological arousal and performance in elite archers: A field study. European Psychologist, 3(4), 263.

Robison-Andrew, E. J., Duval, E. R., Nelson, C. B., Echiverri-Cohen, A., Giardino, N., Defever, A., ... \& Rauch, S. A. (2014). Changes in trauma-potentiated startle with treatment of posttraumatic stress disorder in combat Veterans. Journal of Anxiety Disorders, 28(4), 358-362.

Rosenheck, R. A. (2008). Posttraumatic stress disorder and employment in veterans participating in Veterans Health Administration Compensated Work Therapy. Journal of rehabilitation research and development, 45(3), 427.

Rudstam, H., Gower, W. S., \& Cook, L. (2012). Beyond yellow ribbons: Are employers prepared to hire, accomodate and retain returning veterans with disabilities? Journal of Vocational Rehabilitation, 36, 87-95.

Sak v. City of Aurelia. W.D. Iowa 20112011.

Saunders, G. H., Biswas, K., Serpi, T., McGovern, S., Groer, S., Stock, E. M., ... \& McCranie, M. (2017). Design and challenges for a randomized, multi-site clinical trial comparing the use of service dogs and emotional support dogs in Veterans with post-traumatic stress disorder (PTSD). Contemporary Clinical Trials, 62, 105-113. 
Savych B., Klerman J.A., Loughran D.S. (2008) Recent trends in veteran unemployment as measured in the current population survey and the American community survey. Retrieved from: http://www.rand.org/pubs/technical_reports/TR485.html.

Sayer, N. A., Noorbaloochi, S., Frazier, P., Carlson, K., Gravely, A., \& Murdoch, M. (2010). Reintegration problems and treatment interests among Iraq and Afghanistan combat veterans receiving VA medical care. Psychiatric Services, 61(6), 589-597.

Schottenbauer, M. A., Glass, C. R., Arnkoff, D. B., Tendick, V., \& Gray, S. H. (2008). Nonresponse and dropout rates in outcome studies on PTSD: Review and methodological considerations. Psychiatry: Interpersonal and Biological Processes, 71(2), 134-168.

Sellers, D.M. (2005). The evaluation of an animal assisted therapy intervention for elders with dementia in long-term care. Activ. Adapt. Aging, 30, 61-77.

Selye, H. (2013). Stress in health and disease. Butterworth-Heinemann.

Selye, H. (1974). Stress sans détresse. Montreal: Édition La Presse.

Serpell, J. (1991). Beneficial effects of pet ownership on some aspects of human health and behaviour. Journal of the Royal Society of Medicine, 84(12), 717-720.

Serpell, J. A. (1996). Evidence for an association between pet behavior and owner attachment levels. Applied Animal Behaviour Science, 47(1), 49-60.

Serpell, J.A. (2010). Animal-assisted interventions in historical perspective. In: Fine AH, editor. Handbook on Animal-Assisted Therapy, 3rd ed., 17-32, New York: Elsevier.

Service Dog Central. 2012 [cited 2012 August 30]; Available from: http://servicedogcentral.org/content/node/35 
Shaffer, F. \& Ginsberg, J.P. (2017). An overview of heart rate variability metrics and norms. Front. Public Health, 5: 258. https://doi.org/10.3389/fpubh.2017.00258. Accessed 3/8/2018.

Shapiro, F. (2001). Eye Movement Desensitization and Reprocessing: Basic Principles, Protocols, and Procedures (2nd ed.). New York: Guilford.

Siegel, J.M. (1990). Stressful life events and use of physician services among the elderly: The moderating role of pet ownership. Journal of Personality and Social Psychology, 58(6):1081-6.

Singh, I. L., Sharma, H. O., \& Singh, A. L. (2005). Effect of training on workload in flight simulation task performance. Journal of the Indian Academy of Applied Psychology, 31(1-2), 81-90.

Siniscalchi, M., Stipo, C., \& Quaranta, A. (2013). " Like Owner, Like Dog": Correlation between the Owner's Attachment Profile and the Owner-Dog Bond. PloS one, 8(10), e78455.

Skevington, S. M., Lotfy, M., \& O'Connell, K. 2. (2004). The World Health Organization's WHOQOL-BREF quality of life assessment: psychometric properties and results of the international field trial. A report from the WHOQOL group. Quality of life Research, 13(2), 299-310.

Skinner, H. A. (1982). The drug abuse screening test. Addictive Behaviors, 7(4), 363-371.

Sloan, R. P., Shapiro, P. A., Bagiella, E., Boni, S. M., Paik, M., Bigger Jr, J. T., ... \& Gorman, J. M. (1994). Effect of mental stress throughout the day on cardiac autonomic control. Biological Psychology, 37(2), 89-99.

Smart, J. F. (2001). Disability, society and the individual. Austin, TX: Pro-Ed. 
Smith, M. J., Esnayra, J., \& Love, C. (2003). Use of a psychiatric service dog. Psychiatric Services, 54(1), 110-111.

Stern, L. (2017). Post 9/11 Veterans With Service-Connected Disabilities and their Transition to the Civilian Workforce: A Review of the Literature. Advances in Developing Human Resources, 19(1), 66-77.

Steptoe, A., Cropley, M., \& Joekes, K. (2000). Task demands and the pressures of everyday life: Associations between cardiovascular reactivity and work blood pressure and heart rate. Health Psychology, 19(1), 46.

Steptoe, A., \& Vogele, C. (1991). Methodology of mental stress testing in cardiovascular research. Circulation, 83(4 Suppl), II14-II24.

Stern, C., \& Chur-Hansen, A. (2013). Methodological considerations in designing and evaluating animal-assisted interventions. Animals, 3(1), 127-141.

Storms v. Fred Meyer Stores, Inc. Wash. Ct. App. 20052005

Stubbins, J. (1988). The politics of disability. In Yuker, H. (Ed.), Attitudes Toward Persons With Disabilities, 22-32. New York: Springer.

Sweaney, C. (N.D). A man's best friend or a Soldier's best medicine? How rehabilitation dogs can be utilized to treat veterans with post-traumatic stress disorder. Retrieved from https://www.csustan.edu/sites/default/files/honors/documents/CamilaSweaney.pdf. 14-19.

Sztajzel, J. (2004). Heart rate variability: a noninvasive electrocardiographic method to measure the autonomic nervous system. Swiss Medical Weekly, 134(35-36), 514-522.

Taelman, J., Vandeput, S., Spaepen, A., \& Van Huffel, S. (2009). Influence of mental stress on heart rate and heart rate variability. Paper presented at the 4th European conference of the international federation for medical and biological engineering. 
Tanielian, T., \& Jaycox, L. H. (2017). Invisible wounds of war. Santa Monica, CA: RAND Corporation.

Task Force of the European Society of Cardiology and the North American Society of Pacing and Electrophysiology (1996). Heart rate variability: Standards of measurement, physiological interpretation, and clinical use. European Heart Journal, 17, 354-381.

Taylor, M. F., Edwards, M. E., \& Pooley, J. A. (2013). “Nudging them back to reality”: toward a growing public acceptance of the role dogs fulfill in ameliorating contemporary veterans' PTSD symptoms. Anthrozoös, 26(4), 593-611.

Tedeschi, P., Fine, A.H., Helgeson, J.I. (2010). Assistance animals: Their evolving role in psychiatric service applications. In: A.H. Fine (ed.). Handbook on animal-assisted therapy: Theoretical foundations and guidelines for practice. (3rd ed.). San Diego, CA: Elsevier; p. 421-38.

Templer, D. I., Salter, C. A., Dickey, S., Baldwin, R., \& Veleber, D. M. (1981). The construction of a pet attitude scale. The Psychological Record, 31(3), 343-348.

Templer, D., Arikawa, H., Canfield, M., Munsell, K., \& Tangan, K. (2004). Modification of the pet attitude scale. Society \& Animals, 12(2), 137-142.

Therapy (1997). In F.C. Misch (Ed.), Merriam-Webster’s Collegiate Dictionary (10th ed.). Springfield, MA: Merriam- Webster.

Therapy (1994). In M. Spraycar (Ed.), Stedman’s Medical Dictionary (26th ed.). Baltimore: Williams and Wilkins.

Thorne, K. L., Devlin, E., \& Dingess, K. M. (2017). Service dogs for veterans with PTSD: Implications for Workplace Success. Career Planning \& Adult Development Journal, 33(2). 
The Delta Society (1997). Animal-Assisted Therapy: Therapeutic Interventions. Bellevue, WA: The Delta Society.

The United States Army Medical Journal (2012). Canine-assisted therapy in military medicine, April - June 2012. accessed at http://www.cs.amedd.army.mil/amedd_journal.aspx, on August 21 2015.

Todd-Schuelke, S., Trask, B., Wallace, C., Baun, M. M., Bergstrom. N. \& McCabe, B. (1992). Physiological effects of the use of a companion animal dog as a cue to relaxation in diagnosed hypertensives. http://www.deltasociety.org/AnimalsHealthAdultsPhysiological.htm.

Topál, J., Miklósi, Á., \& Csányi, V. (1997). Dog-human relationship affects problem solving behavior in the dog. Anthrozoös, 10(4), 214-224.

Turcsán, B., Range, F., Virányi, Z., Miklósi, Á., \& Kubinyi, E. (2012). Birds of a feather flock together? Perceived personality matching in owner-dog dyads. Applied Animal Behaviour Science, 140(3-4), 154-160.

United States Police Canine Association. PDI and EDD Certification Package. 2012 [September 12, 2012]; Available from: http://www.uspcak9.com/certification/pd1_certification_2012.pdf.

U.S. Dep't of Army, Stat. Reg. 190-12, Military Working Dog Program (2007).

U.S. Dep't of Army, Stat. Technical Bulletin Med. No. 4, DOD Human-Animal Bond Principles and Guidelines (2003).

Van Houtert, E. A., Endenburg, N., Wijnker, J. J., Rodenburg, B., \& Vermetten, E. (2018). The study of service dogs for veterans with Post-Traumatic Stress Disorder: a scoping literature review. European Journal of Psychotraumatology, 9(sup3), 1503523. 
Veltman, J. A., \& Gaillard, A. W. K. (1998). Physiological workload reactions to increasing levels of task difficulty. Ergonomics, 41(5), 656-669.

Veterans Affairs Department. (2012). Service dogs: A rule by the veteran affairs department on 5th October, 2012. Federal Register. Retrieved October 18, 2016, from https://www.federal register.gov/articles/2012/09/05/2012-21784/service-dogs\#h-9

Vincent, C., Belleville, G., Gagnon, D. H., Dumont, F., Auger, E., Lavoie, V., ... \& Lessart, G. (2017, September). Effectiveness of Service Dogs for Veterans with PTSD: Preliminary Outcomes. In AAATE Conf. (pp. 130-136).

Volhard J, Volhard W. (1997). The Canine Good Citizen: Every Dog Can be One. (2nd ed.). New York: Wiley Publishing.

Waghorn, G., Chant, D., White, P., \& Whiteford, H. (2005). Disability, employment and work performance among people with ICD-10 anxiety disorders. Australian and New Zealand Journal of Psychiatry, 39, 55-66.

Wahlström, J., Hagberg, M., Johnson, P., Svensson, J., \& Rempel, D. (2002). Influence of time pressure and verbal provocation on physiological and psychological reactions during work with a computer mouse. European Journal of Applied Physiology, 87(3), 257-263.

Watson, D., Clark, L. A., \& Tellegen, A. (1988). Development and validation of brief measures of positive and negative affect: The PANAS scales. Journal of Personality and Social Psychology, 54(6), 1063-1070. doi: 10.1037/0022-3514.54.6.1063.

Weathers, F. W., Litz, B. T., Herman, D. S., Huska, J. A., \& Keane, T. M. (1993, October). The PTSD Checklist (PCL): Reliability, validity, and diagnostic utility. In annual convention of the international society for traumatic stress studies, San Antonio, TX (Vol. 462). 
Wedl, M., Schöberl, I., Bauer, B., Day, J., \& Kotrschal, K. (2010). Relational factors affecting dog social attraction to human partners. Interaction Studies, 11(3), 482-503.

Westman, M., \& Eden, D. (1996). The inverted-U relationship between stress and performance: A field study. Work \& Stress, 10(2), 165-173.

White, M. (2011). The human-animal bond and combat-related posttraumatic stress symptoms (Doctoral dissertation). Retrieved from: https://scholarworks.waldenu.edu/dissertations/1093/.

White Cane Law (2003). Stat. Ill. Stat. § 775-3.

Wilson Learning (2004). The social styles handbook: Find your comfort zone and make people feel comfortable with you. Canada: Nova Vista Publishing.

Winkle, M., Crowe, T. K., \& Hendrix, I. (2012). Service dogs and people with physical disabilities partnerships: A systematic review. Occupational Therapy International, 19(1), 54-66.

White Cane Law (2003). Stat. Ill. Stat. § 775-3.

WHOQoL Group. (1998). Development of the World Health Organization WHOQOLBREF quality of life assessment. Psychological Medicine, 28(3), 551-558.

Woodward, S. H., Jamison, A. L., Gala, S., \& Holmes, T. H. (2017). Canine companionship is associated with modification of attentional bias in posttraumatic stress disorder. PloS one, 12(10), e0179912.

Yarborough, B. J. H., Owen-Smith, A. A., Stumbo, S. P., Yarborough, M. T., Perrin, N. A., \& Green, C. A. (2017). An observational study of service dogs for veterans with posttraumatic stress disorder. Psychiatric Services, 68(7), 730-734. 
Yeager, A. F., \& Irwin, J. (2012). Rehabilitative canine interactions at the Walter Reed national military medical center. US Army Medical Department Journal, 57-61.

Yount, R. A., Olmert, M. D., \& Lee, M. R. (2012). Service dog training program for treatment of posttraumatic stress in service members. US Army Medical Department Journal, 63-70.

Yount, R., Ritchie, E. C., Laurent, M. S., Chumley, P., \& Olmert, M. D. (2013). The role of service dog training in the treatment of combat-related PTSD. Psychiatric Annals, 43(6), 292-295.

Zapf, S. A., \& Rough, R. B. (2002). The development of an instrument to match individuals with disabilities and service animals. Disability and Rehabilitation, 24(1-3), 47-58.

Zautra, A. J., Affleck, G. G., Tennen, H., Reich, J. W., \& Davis, M. C. (2005). Dynamic approaches to emotions and stress in everyday life: Bolger and Zuckerman reloaded with positive as well as negative affects. Journal of Personality, 73(6), 1511-1538.

Zatzick DF, Marmar CR, Weiss DS, et al. (1997). Posttraumatic stress disorder and functioning and quality of life outcomes in a nationally representative sample of male Vietnam veterans. American Journal of Psychiatry, 154:1690-1695. 


\section{Chapter 8: Appendices}

Descriptive Data - Cardiac Function

\begin{tabular}{|l|r|r|r|r|}
\hline Variable & Mean & Std Error & Minimum & Maximum \\
\hline HR_BL & 73.8434615 & 2.4091851 & 60.11 & 96.24 \\
\hline HR_REC & 72.7046429 & 2.2432643 & 60.21 & 96.12 \\
\hline HR_T & 73.7478571 & 2.4164536 & 57.7 & 96.73 \\
\hline T_HRminusBL_HR & 1.0038462 & 0.6129676 & -4.31 & 10.95 \\
\hline T_HRminus_Rec_HR & 1.0432143 & 0.4732023 & -4.52 & 5.26 \\
\hline Rec_HRminus_BL_HR & -0.2776923 & 0.6144284 & -5.62 & 9.7 \\
\hline RatioT_HR_to_BL_HR & 1.0141559 & 0.0095243 & 0.934934 & 1.182166 \\
\hline RatioT_HR_to_Rec_HR & 1.0131177 & 0.0070112 & 0.930279 & 1.067126 \\
\hline RatioRec_HR_to_BL_HR & 0.9980638 & 0.0092367 & 0.921999 & 1.161371 \\
\hline
\end{tabular}

Descriptive Data - Work Load

\begin{tabular}{|l|r|r|r|r|}
\hline Variable & Mean & Std Error & Minimum & Maximum \\
\hline TLX_Overall_Workload & 25.5833333 & 2.6945827 & 5 & 54.16667 \\
\hline TLX_Mental & 20.5 & 3.4353638 & 5 & 65 \\
\hline TLX_Physical & 10.6666667 & 1.6906323 & 5 & 40 \\
\hline TLX_Temporal & 39.1666667 & 6.0032718 & 5 & 100 \\
\hline TLX_Performance & 15.6666667 & 2.2197304 & 5 & 60 \\
\hline TLX_Effort & 38.5 & 6.4467313 & 5 & 100 \\
\hline TLX_Frustration & 29 & 5.3627065 & 5 & 90 \\
\hline
\end{tabular}

Descriptive Data - Task Performance

\begin{tabular}{|l|l|r|r|r|}
\hline Variable & Mean & \multicolumn{1}{|l|}{ Std Error } & Minimum & Maximum \\
\hline Answered_per_minute & 26.8087801 & 1.7920382 & 13.45455 & 47.6 \\
\hline
\end{tabular}

Descriptive Data - Affect

\begin{tabular}{|l|r|r|r|r|}
\hline Variable & \multicolumn{1}{|l|}{ Mean } & \multicolumn{1}{|l|}{ Std Error } & Minimum & Maximum \\
\hline PANAS_Positive_BL & 30.7 & 2.1405499 & 10 & 48 \\
\hline PANAS_Positive_Task & 30.0333333 & 2.106085 & 11 & 48 \\
\hline PANAS_Positive_Rec & 30.6551724 & 2.0993055 & 11 & 47 \\
\hline PANAAS_Negative_BL & 12.0333333 & 0.4660505 & 10 & 19 \\
\hline PANAS_Negative_Task & 12.9666667 & 0.8755732 & 10 & 30 \\
\hline PANAS_Negative_Rec & 12.3793103 & 0.5859895 & 10 & 23 \\
\hline $\begin{array}{l}\text { PANAS_Pos_BL minus } \\
\text { Task }\end{array}$ & 0.6666667 & 0.5494686 & -5 & 10 \\
\hline $\begin{array}{l}\text { PANAS_Pos_Task minus } \\
\text { Rec }\end{array}$ & 0.0344828 & 1.0079521 & -13 & 15 \\
\hline $\begin{array}{l}\text { PANAS_Neg_BL minus } \\
\text { Task }\end{array}$ & -0.9333333 & 0.781883 & -12 & 8 \\
\hline
\end{tabular}




\begin{tabular}{|l|l|l|l|l|}
\hline $\begin{array}{l}\text { PANAS_Neg_Task minus } \\
\text { Rec }\end{array}$ & 0.6551724 & 0.8143961 & -11 & 13 \\
\hline
\end{tabular}

Descriptive Data - Personality Characteristics \& Outcome Measures

\begin{tabular}{|l|r|r|r|r|}
\hline Variable & Mean & Std Error & Minimum & Maximum \\
\hline CESD & 27.33 & 1.92 & 7 & 41 \\
\hline PALS & 172.83 & 2.18 & 149 & 184 \\
\hline WHQOL & 56.67 & 4.07 & 36 & 86 \\
\hline Human Assertiveness & 41.5 & 2.05 & 22 & 55 \\
\hline Human Responsiveness & 25.17 & 1.18 & 15 & 32 \\
\hline Human Versatility & 22.33 & 0.81 & 14 & 28 \\
\hline Dog Assertiveness & 33.67 & 2.65 & 17 & 55 \\
\hline Dog Responsiveness & 29.67 & 1.83 & 8 & 35 \\
\hline Dog Versatility & 22.83 & 4.07 & 4 & 28 \\
\hline Human-Dog Assertiveness & 7.83 & 3.28 & -28 & 24 \\
\hline
\end{tabular}

Descriptive Data - Correlational

\begin{tabular}{|l|l|r|r|}
\hline Variable & by Variable & Spearman $\boldsymbol{\rho}$ & \multicolumn{1}{|c|}{ Prob $>|\boldsymbol{\rho}|$} \\
\hline HF_REC 2 & A Human Assertiv - Dog Assertiv & 0.0001 \\
\hline HF_REC 2 & A Human Versat-Dog Versat & -0.9428571 & 0.004805 \\
\hline HF_REC 2 & A Human Versatil/Dog Versatil & -0.9428571 & 0.004805 \\
\hline HF_REC 2 & A Human Assert/Dog Assert & 0.9428571 & 0.004805 \\
\hline LF_HFRatio_REC 2 & A Human Assertiv - Dog Assertiv & -0.8857143 & 0.018845 \\
\hline LF_HFRatio_BL 2 & A Human Respons - Dog Respons & -0.840668 & 0.036058 \\
\hline LF_HFRatio_BL 2 & A Human Respons/Dog Respons & -0.840668 & 0.036058 \\
\hline TLX_+7:334Temporal 2 & A Human Versat-Dog Versat & -0.840668 & 0.036058 \\
\hline TLX_Temporal 2 & A Human Versatil/Dog Versatil & -0.840668 & 0.036058 \\
\hline TLX_Temporal 2 & A Human Assert/Dog Assert & 0.840668 & 0.036058 \\
\hline LF_BL 2 & A Human Assertiv - Dog Assertiv & 0.8285714 & 0.041563 \\
\hline LF_REC 2 & A Human Assertiv - Dog Assertiv & 0.8285714 & 0.041563 \\
\hline PALS & B CESD & 0.8285714 & 0.041563 \\
\hline SDNN_REC 2 & A Human Assertiv - Dog Assertiv & 0.8285714 & 0.041563 \\
\hline
\end{tabular}

